\title{
Time series transcriptomics reveals a $B B X 32-$ directed control of dynamic acclimation to high light in mature Arabidopsis leaves
}

Running Title: The regulation of dynamic acclimation in Arabidopsis

Ruben Alvarez-Fernandez ${ }^{1,5}$, Christopher A. Penfold ${ }^{3,5}$, Gregorio Galvez-

Valdivieso $^{1,10}$, Marino Exposito-Rodriguez ${ }^{1}$, Ellie J. Stallard ${ }^{1}$, Laura Bowden ${ }^{2,7}$, Jonathan D. Moore ${ }^{2,8}$, Andrew Mead ${ }^{2,9}$, Phillip A. Davey ${ }^{1}$, Jack S.A. Matthews ${ }^{1}$, Jim Beynon $^{2}$, Vicky Buchanan-Wollaston ${ }^{2}$, David L. Wild ${ }^{3}$, Tracy Lawson ${ }^{1}$, Ulrike Bechtold ${ }^{1}$, Katherine Denby ${ }^{4}$ and Philip M. Mullineaux ${ }^{1 *}$

${ }^{1}$ School of Life Sciences, University of Essex, Wivenhoe Park, Colchester, Essex, CO4 3SQ, UK.

${ }^{2}$ School of Life Sciences, Warwick University, Coventry, CV4 7AL, UK.

${ }^{3}$ Department of Statistics, Warwick University, Coventry, CV4 7AL, UK.

${ }^{4}$ Department of Biology, University of York, Heslington, York, YO10 5DD, UK.

${ }^{5}$ present address: Phoremost Ltd, Building 250, Babraham Research Campus. Cambridgeshire, CB22 3AT, UK

${ }^{6}$ present address: Department of Physiology, Development and Neuroscience, University of Cambridge, Downing Site, Cambridge CB2 3EG, UK

${ }^{7}$ present address: Science and Advice for Scottish Agriculture, Roddinglaw Road, Edinburgh EH12 9FJ, UK.

${ }^{8}$ present address: John Innes Centre, Norwich Research Park, Colney, Norwich, NR4 7UH, UK.

${ }^{9}$ present address: Computational and Analytical Sciences, Rothamsted Research, Harpenden, Hertfordshire, AL5 2JQ, UK.

${ }^{10}$ present address: Departamento de Botánica, Ecología y Fisiología Vegetal, Instituto Andaluz de Biotecnología and Campus Agroalimentario de Excelencia Internacional ceiA3, Campus de Rabanales, Edif. C-6, 1a Planta, Universidad de Córdoba, 14071 Córdoba, Spain.

\section{*corresponding author: mullin@essex.ac.uk}

The author responsible for distribution of materials integral to the findings presented in this article in accordance with the policy described in the Instructions for Authors (www.plantcell.org) is: Philip M. Mullineaux (mullin@essex.ac.uk). 


\section{SUMMARY}

35 The photosynthetic capacity of mature leaves increases after several days' exposure to constant or intermittent episodes of high light (HL) and is manifested primarily as changes in chloroplast physiology. This is termed dynamic acclimation but how it is initiated and controlled is unknown. From fully expanded Arabidopsis leaves, we determined HL-dependent changes in transcript abundance of 3844 genes in a 0-6h time-series transcriptomics experiment. It was hypothesised that among such genes were those that contribute to the initiation of dynamic acclimation. By focussing on HL differentially expressed transcription (co-)factor (TF) genes and applying dynamic statistical modelling to the temporal transcriptomics data, a gene regulatory network (GRN) of 47 predominantly photoreceptor-regulated (co)-TF genes was inferred. The most connected gene in this network was B-BOX DOMAIN CONTAINING PROTEIN32 (BBX32). Plants over-expressing BBX32 were strongly impaired in dynamic acclimation and displayed perturbed expression of genes involved in its initiation. These observations led to demonstrating that as well as regulation of dynamic acclimation by BBX32, CRYPTOCHROME1, LONG HYPOCOTYL5, CONSTITUTIVELY PHOTOMORPHOGENIC1 and SUPPRESSOR OF PHYA-105 are also important regulators of this process. Additionally, the $B B X 32$-centric GRN provides a view of the transcriptional control of dynamic acclimation distinct from other photoreceptor-regulated processes, such as seedling photomorphogenesis.

Keywords: Photosynthesis, B-Box proteins, acclimation, high light, hydrogen peroxide, Arabidopsis, Bayesian dynamic statistical modelling, gene regulatory networks, transcriptomics. 
The exposure of plants to increased light intensities can lead to the development of enhanced photosynthetic capacity in mature leaves and is termed dynamic acclimation. Dynamic acclimation, an important determinant of plant fitness or crop yield, is under genetic as well as environmental control and includes changes in the expression of many genes (Murchie and Horton, 1997; Walters et al., 1999; Oguchi et al., 2003; Murchie et al., 2005; Eberhard et al., 2008; Athanasiou et al., 2010; Schottler and Toth, 2014; van Rooijen et al 2015; Vialet-Chabrand et al., 2017). In young expanding leaves, acclimation to increased light intensity (hereafter termed high light; HL) brings about increased photosynthetic capacity by eliciting changes in both leaf morphology, such as altered leaf and vascular diameter in minor veins (Oguchi et al., 2003; Terashima et al., 2011; Adams III et al., 2014; Vialet-Chabrand et al., 2017) and changes to chloroplast physiology such as adjustments to the composition of reaction centers and light harvesting antennae (Walters et al., 1999, Murchie and Horton, 1997; Murchie et al., 2005; Drozak and Romanowska, 2006; Vialet-Chabrand et al., 2017). In contrast, in mature leaves exposure to sustained or episodic HL brings about changes primarily in chloroplast physiology that raise the light use efficiency of photosynthesis, which can reflect increased rates of photosynthesis and/or a decreased number of photosystem II (PSII) reaction centers (Walters et al., 1999; Murchie et al., 2005; Athanasiou et al., 2010; van Rooijen et al., 2015; Vialet-Chabrand et al., 2017).

It is not known how HL exposure initiates chloroplast-level dynamic acclimation. However, an important lead is provided from an early study (Walters et al., 1999). This was a comparison of Arabidopsis photoreceptor signalling mutants' photosynthetic capacity and PSII efficiency grown under two different light intensities (PPFDs) of 100 and $400 \mu \mathrm{mol} \mathrm{m} \mathrm{m}^{-2} \mathrm{~s}^{-1}$ (PPFD stands for photosynthetically active photon flux density). From this study, it was proposed that a PHYTOCHROMEA (PHYA), PHYB and CRYPTOCHROME1 (CRY1) photoreceptor driven CONSTITUTIVELY PHOTOMORPHOGENIC/DE-ETIOLATED1/FUSCA (COP/DET/FUS) regulatory module could transmit signals from the nucleus to chloroplasts to participate in establishing increased photosynthetic capacity (Walters et al.,1999). In support of this, photosynthesis-associated nuclear genes (PhANGs) are among the most enriched gene classes subject to control from photoreceptors in de-etiolating seedlings (Chory and Peto, 1990; Holtan et al., 2011; Shikata et al., 
2014; Li et al., 2015; Ganguly et al., 2015; Pham et al., 2018). Various combinations of the 11 COP/DET/FUS loci (Lau and Deng, 2012), in conjunction with other regulatory genes, control the integration of signals from photoreceptors and are central to many plant-light environment interactions including seedling photomorphogenesis, the shade avoidance response, stomatal opening and development, the timing of flowering and cross-talk between phytohormone and light signalling (Dong et al., 2014; Huang et al., 2014; Lau and Deng, 2012; Pham et al., 2018).

The establishment of dynamic acclimation takes up to 6 days (Athanasiou et al., 2010) and prior to this, plants must deal with HL by dissipating excitation energy to minimise irreversible photoinhibition. Photoinhibition is caused by oxidative damage to the photosynthetic apparatus brought about by increased production of singlet oxygen ( ${ }^{1} \mathrm{O}_{2}$; Triantaphyllides et al., 2008; Ramel et al., 2013; Mullineaux et al., 2018). This is achieved by a combination of non-photochemical and photochemical quenching (NPQ and PQ respectively; Baker, 2008; Eberhard et al., 2008; Ruban and Belgio, 2014). All leaves have an extant capability to dissipate excitation energy, which is augmented under HL by localised and systemic induction of further photoprotective NPQ and/or PQ (Long et al., 1994; Karpinski et al., 1999; Eberhard et al., 2008; Li et al., 2009; Galvez-Valdivieso et al., 2009; Suorsa et al., 2012; Ruban and Belgio, 2014). NPQ is the resonance transfer of excitation energy to xanthophyll carotenoids from excited chlorophylls and its subsequent thermal dissipation ( $\mathrm{Li}$ et al., 2000; Baker, 2008). PQ is the dissipation of excitation energy by consumption of reducing equivalents by a range of metabolic processes including enhanced photosynthetic capacity, but is also associated with increased foliar levels of hydrogen peroxide $\left(\mathrm{H}_{2} \mathrm{O}_{2}\right)$ and the superoxide anion (Long et al., 1994; Wingler et al., 2000; Badger et al., 2000; Schiebe, 2004; Schieble et al., 2004; Streb et al., 2005; Diaz et al., 2007; Eberhard et al., 2008; Driever and Baker, 2010; Kangasjarvi et al., 2012; Schiebe and Dietz, 2012; Lawson et al., 2013; Heyno et al., 2014; Mullineaux et al., 2018).

In this study, we hypothesised that the first hours of exposure of mature leaves to $\mathrm{HL}$ initiates dynamic acclimation although an increase in photosynthetic capacity takes several days to develop. This hypothesis is an extension of an earlier proposal regarding the temporal order of events leading to protection against oxidative stress- 
125 induced photoinhibition, the re-structuring of light harvesting antennae and PSI and

126 PSII reaction centers (Eberhard et al., 2008). We tested this hypothesis by first

127 developing HL and low light (LL) time series transcriptomics datasets from a defined

128 fully expanded leaf of LL-grown Arabidopsis plants. Analysis of these data revealed

129 that processes interpreted as the first steps in establishing dynamic acclimation

130 could be identified and were largely complete within 4h of HL exposure. From

131 comparison with other published transcriptomics datasets, we noted an over-

132 representation of differentially expressed transcription (co)factor genes involved in

133 light- and photoreceptor-regulated photomorphogenesis of seedlings. This led us via

134 dynamic statistical modelling to identify B-BOX DOMAIN CONTAINING PROTEIN32

135 (BBX32) as a negative regulator of dynamic acclimation. BBX32 encodes a Zn-finger

136 transcription co-factor which forms associations with diverse transcription regulators,

137 such as LONG HYPOCOTYL5 (HY5) and BBX4 to alter their function and is most

138 studied in the context of seedling photomorphogenesis and the control of flowering

139 time (Holtan et al., 2011; Park et al., 2011; Gangappa and Botto, 2014; Tripathy et

140 al., 2017). In turn, the involvement of $B B X 32$ led us to identify $H Y 5, C R Y 1$,

141 PHYTOCHROME INTERACTING FACTOR (PIF) genes and COP1/SUPPRESSOR

142 OF phytochromeA-105 (SPA) genes as further regulators of dynamic acclimation. It

143 was concluded that many signalling aspects of photoreceptor-driven seedling

144 photomorphogenesis are also active in mature fully expanded leaves to control

145 dynamic acclimation.

\section{Results}

147 GO analysis of time series transcriptomics of HL-exposed leaves provides

148 insights into the initiation of dynamic acclimation

149 The starting point for this study was the development of a HL time series

150 transcriptomics experiment. Our plan was to subject groups of time-resolved

151 differentially expressed genes (DEGs) to Variational Bayesian State Space

152 Modelling (VBSSM; see Methods), which requires highly resolved time series data

153 (Beal et al., 2005; Penfold and Wild, 2011; Penfold and Buchanan-Wollaston, 2014;

154 Bechtold et al., 2016). Therefore, we opted for 30 min sampling over a $6 \mathrm{~h} \mathrm{HL}$ period

155 beginning $1 \mathrm{~h}$ after subjective dawn (see Methods). We chose this time period

156 because it spans the initiation of both the short term and long-term acclimation to $\mathrm{HL}$

157 proposed by Eberhard et al. (2008; see Introduction). 
158 Full transcriptome profiles using CATMA microarrays (Sclep et al., 2007) were 159 obtained from leaf 7 of HL-exposed plants along with parallel LL controls (see 160 Methods). Microarray analysis of variance (MAANOVA; Wu et al., 2003; see

161 Methods) was used to extract expression values from each probe for every treatment

162 for each technical and biological replicate. To determine DEGs that showed a

163 significant difference between HL-exposed leaves and the LL controls over all or part

164 of the time period, a Gaussian process two-sample test (GP2S; Stegle et al., 2010)

165 was applied and 4069 probes were selected with a Bayes factor score >10 which corresponded to 3844 DEGs (Supplemental Data Set 1). The full data set is deposited with Gene Expression Omnibus (GEO; GSE78251).

168 To obtain further insight into the overall response to $\mathrm{HL}$ at the molecular level, 169 hierarchical co-cluster analysis of the 3844 DEGs was carried out using 170 SplineCluster (Heard et al., 2005). We reasoned that groups of DEGs that display 171 similar temporal patterns of expression could be co-regulated and clustering would

172 be useful in identifying groups of genes for dynamic modelling. On the basis of 173 comparing temporal gene expression patterns in both the HL-exposed and control LL 174 leaves (see Methods), the 3844 DEGs were divided into 43 temporal clusters (Fig.

$1751 \mathrm{~A}$; Supplemental Data Set 1). The outcome of this co-clustering was differential 176 transcript abundance between LL and HL conditions superimposed on a range of 177 temporal expression trends across $6 \mathrm{~h}$ of the diel. Plotted examples showing a range 178 of temporal and differential expression in 6 clusters can be viewed in Supplemental 179 Figure 1.

180 The clusters are ordered such that 1-13 show general transcript abundance to be lower in HL vs LL samples and/or displayed a downward pattern over the diel

182 (Fig.1A; e.g. clusters 3 and 13 in Supplemental Fig. 1). This pattern changes 183 progressively with increasing degree of expression being higher in HL than LL but 184 against a descending diel pattern in clusters 14-20 (Fig. 1A, e.g. cluster 18 in 185 Supplemental Fig. 1), followed by transient but progressively increasingly greater 186 differential transcript levels in HL samples compared with LL in clusters 21-26 (Fig. 187 1A, e.g. cluster 23 in Supplemental Fig. 1) to progressively sustained periods of 188 higher expression in HL compared with LL from cluster 27-43 against a 189 background of level or increasing transcript levels across the diel (Fig. 1A; e.g. 190 clusters 33 and 43 in Supplemental Figure 1). 
bioRxiv preprint doi: https://doi.org/10.1101/2020.12.23.424212; this version posted December 26, 2020. The copyright holder for this preprint (which was not certified by peer review) is the author/funder, who has granted bioRxiv a license to display the preprint in perpetuity. It is made available under aCC-BY 4.0 International license.

191 To gain a better view of the timings of differential expression in response to $\mathrm{HL}$, the

192 DEGs from the time-local GP2S (Supplemental Dataset 1) were used to identify

193 intervals of differential expression as described by Windram et al. (2012). A

194 histogram of the time of first differential expression (HL compared to LL) is shown in

195 Figure $1 \mathrm{~B}$ and indicates that response to $\mathrm{HL}$ is rapid with $>700$ genes becoming

196 differentially expressed by 1 hour into the HL time course. Nevertheless, it was also

197 clear that changes in transcript abundance were being initiated for significant

198 numbers of genes up to $4 \mathrm{~h} \mathrm{HL}$. In summary, the response of the leaf 7 transcriptome

199 to $\mathrm{HL}$ entails changed expression in response to the stimulus, with changes

200 occurring across the time of the experiment against a backdrop of complex changes

201 in transcript abundance across 6 h out of an 8h photoperiod.

202 Gene Ontology (GO) analysis showed that clusters 22, 23, 25 were highly enriched

203 for generic abiotic stress-defensive genes ( $P$ value $\leq 0.1$, Bonferroni corrected;

204 Supplemental Data Set 2). In contrast, some of the other clusters displayed a

205 different set of GO function enrichments (Supplemental Data Set 2). These multiple

206 enriched sets were consistent with a re-adjustment to cellular metabolism. For

207 example, in clusters 39 and 41 - 43 with generally higher expression in $\mathrm{HL}$

208 compared with LL, there was over-representation of genes associated with amino

209 acid and protein synthesis respectively. Among the clusters showing a lowered

210 expression in HL compared with LL, there was enrichment for genes associated with

211 cell wall metabolism (callose deposition, cell wall thickening Cluster 1),

212 phenylpropanoid and glucosinolate metabolism (Clusters 1 and 10 respectively),

213 basal resistance to infection (Cluster 3) and chromatin re-modelling (cluster 10).

\section{Induction of dynamic acclimation}

215 To test our interpretation of the HL time series data, we determined if dynamic

216 acclimation could be induced by exposing a plant every day to 4h HL (see Methods).

217 This period of HL exposure was chosen since most differential expression had been

218 initiated by this time (Fig. 1B). Other than being shortened to $4 \mathrm{~h}$, the environmental

219 conditions were the same as for the time series transcriptomics experiment (see

220 Methods). The daily HL regime brought about a stepwise increase in the operating

221 efficiency of PSII (Fq'/Fm') (Baker, 2008) of fully expanded leaves (Fig. 2A;

222 Supplemental Data Set 3). By day 5, PSII operating efficiency had increased 
223 substantially (e.g. 78\% at $800 \mu \mathrm{mol} \mathrm{m} \mathrm{m}^{-2}$ actinic PPFD; Fig. 2B; see also Fig.4B).

224 This pattern was followed by equivalent changes in Fv'/Fm' and Fq'/Fv'

225 (Supplemental Fig. 2A; Supplemental Data Set 3). Fv'/Fm' indicates the maximum

226 operating efficiency of PSII at a given PPFD and a rise in this parameter indicates a

227 decline in NPQ (Baker, 2008). Fq'/Fv' is the PSIl efficiency factor and is

228 mathematically identical to the coefficient for PQ $\left(q_{p}\right)$ and indicates increased

229 capacity to drive electron transport (Baker, 2008). Control LL-grown plants of the

230 same age as the plants subjected to 5 daily HL treatments did not show these

231 changes in chlorophyll fluorescence (CF) parameters (Supplemental Fig. 2B;

232 Supplemental Data Set 3).

233 The first exposure to HL (day 1 ) did not result in irreversible photoinhibition

234 (Supplemental Fig. 3A) or significant tissue damage (Supplemental Fig. 3B). This

235 was confirmed in the HL time series data, which used the same PPFDs, in which

236 steady levels of transcripts for genes considered to be markers for $\mathrm{H}_{2} \mathrm{O}_{2}(A P X 2$ and

237 FER1, Ball et al., 2004; Gadjev et al., 2006) rose but those associated with ${ }^{1} \mathrm{O}_{2}-$

238 induced signalling (AAA-ATPase and BAP1, Ramel et al., 2013) remained

239 unchanged or declined (Supplemental Fig. 3C). The changes in the expression of

240 these marker genes indicated the HL treatment used in the time series

241 transcriptomics experiments, also did not elicit photodamage and provided

242 conditions that could promote dynamic acclimation.

243 The increased operating efficiency of PSII (Fq'/Fm' and also Fq'/Fv') after the 5-day

$244 \mathrm{HL}$ treatment (Fig. 2A; Supplemental Fig. 2A; Supplemental Data Set 3) could have

245 reflected enhanced photosynthetic capacity. To test this possibility, gas-exchange

246 measurements for photosynthesis were carried out (see Methods). The same

247 experiment was repeated and, in the photoperiod following the last HL treatment,

248 measurements of $\mathrm{CO}_{2}$ assimilation rates $(A)$ over a range of light intensities in fully

249 expanded leaf 7 of these plants (Boyes et al., 1998) were taken. This showed that

250 the light-saturated photosynthetic rate $\left(A_{\text {sat }}\right)$ was significantly greater $(\mathrm{P}<0.001)$ by

$25164 \%$ compared with LL control plants (Fig. 2C). In contrast, after a single 4h HL

252 exposure, followed by photosynthesis measurements in the next photoperiod, no

253 increase in $A_{\text {sat }}$ was observed (Fig. 2C). In a separate series of experiments, the

254 measurement of $A$ over a range of internal leaf $\mathrm{CO}_{2}$ concentrations $(C l)$ also showed

255 that the maximal $\mathrm{CO}_{2}$-saturated rate of photosynthesis $\left(A_{\max }\right)$ increased by $31 \%(\mathrm{P}<$ 
0.002) after 5 daily HL exposures (Fig. 2D). This confirmed that repeated HL exposures did not solely affect stomatal behaviour but brought about an increase in treatments observed in the previous experiments (Fig. 2A) occurred also in larger older leaves that were required for gas exchange measurements (Supplemental

\section{Figure 2C; see Methods).}

262 In summary, increased $A_{\text {sat }}$ and $A_{\max }$ after 5 days of repeated HL exposure (Fig. 2C,

263 D) was accompanied by a highly significant increase in Fq'/Fm' (Fig. 2A,

264 Supplemental Figure 2C; P > 0.0001, ANOVA and Tukey HSD; Supplemental Data Set 3) reflecting an increased photochemical efficiency to support dynamic acclimation. Therefore, a substantial (>40\%; typically using the median $800 \mu \mathrm{mol} \mathrm{m}$ $\mathrm{s}^{-1}$ actinic PPFD value) change in Fq'/Fm' between days 1 and 5 of repeated HL was subsequently used as a more convenient image-based measurement of the establishment of dynamic acclimation and consequent increased photosynthetic 270 capacity.

Dynamic statistical modelling infers a BBX32-centric network of HL-regulated transcription factor genes.

273 The HL time series data were used to infer gene regulatory networks (GRNs) using 274 VBSSM (Beal et al., 2005; Penfold and Wild 2011). We chose VBSSM because it 275 has been demonstrated to infer known GRNs from temporal gene expression data 276 and to infer novel GRNs whose highly connected genes (nodes) have subsequently 277 been shown experimentally to have a novel and important function (Beal et al., 2005; 278 Penfold and Wild, 2011; Breeze et al., 2011; Penfold and Buchanan-Wollaston, 279 2014; Windram and Denby 2015; Bechtold et al., 2016). However, due to the limited 280 number of time points, we opted to infer networks for around 100 genes or probes in 281 order to avoid overfitting by constraining the network size (Beal et al., 2005;

282 Allahverdeyeva et al., 2015; Windram and Denby, 2015; Bechtold et al., 2016). To 283 accommodate this limitation, we focussed on DEGs coding for transcription (co-) 284 factors (TFs). We reasoned that TF GRNs would control the expression of a wide 285 network of genes and by inferring GRNs this would allow us to identify and focus on the most connected TF genes, often termed hub genes (Windram and Denby, 2015;

287 Albihlal et al., 2018). Consequently, we reasoned that upstream hub TF genes 288 would directly and indirectly regulate the expression of a sufficiently large number of 
bioRxiv preprint doi: https://doi.org/10.1101/2020.12.23.424212; this version posted December 26, 2020. The copyright holder for this preprint (which was not certified by peer review) is the author/funder, who has granted bioRxiv a license to display the preprint in perpetuity. It is made available under aCC-BY 4.0 International license.

genes to influence whole leaf HL responses and acclimation phenotypes. Therefore, the intention was to screen highly connected candidate regulatory hub TF genes directly for their impact upon whole plant dynamic acclimation.

292 It was estimated that there were 371 HL DEGs coding for TFs or transcription co293 factors (Supplemental Data Set 4). To narrow our selection further, comparisons 294 were made between the $43 \mathrm{HL}$ temporal clusters (Fig. 1A; Supplemental Data Set 1) 295 and 14 publicly available transcriptomics data sets or meta-analyses of such data for 296 treatments or mutants perturbed in chloroplast-to-nucleus and ROS-mediated signalling (Supplemental Data Set 5). On a cluster-by-cluster basis, the highest number of significant $(P<0.00001)$ overlaps in clusters $1,2,3,5,6,9,10,14,16,17$ and 27 were encountered with phyA/phyB DEGs (Supplemental Data Set 5) among which genes involved in chloroplast-to-nucleus (retrograde) signalling had been identified (Shikata et al., 2014). This observation suggested that photoreceptormediated regulation of $\mathrm{HL}$-responsive genes was highly represented in the time series transcriptomics dataset. Therefore, we examined whether photoreceptorregulated TF and co-transcription factor genes (Shikata et al., 2014; Dong et al., 2014) were also over-represented in the HL dataset. This was the case. Ninety-one (91) photoreceptor- and light-regulated TF DEGs were over-represented in the time series transcriptomics data, irrespective of which temporal cluster they were drawn from ( $P=1.4 \mathrm{E}-06$; Hypergeometric Distribution Test, Supplemental Data Set 4). The $\mathrm{HL}$ time series expression data from these 91 genes were used to infer networks with VBSSM.

311 The first inferred network for HL revealed LATE ELONGATED HYPOCOTYL (LHY) as the most highly connected gene (Supplemental Fig. 4A). However, mutant lhy-21

313 plants were not perturbed in dynamic acclimation (Supplemental Fig. 4B). Therefore,

314 the VBSSM modelling was re-iterated but omitting LHY expression data. This inferred a 47 node-HL network centred on BBX32 (Fig. 3). The transcript levels of

316 the 12 most connected nodes ( $\geq 3$ edges) across the time series, under LL and HL 317 conditions, is shown in Supplemental Figure 5 and shows the diversity of expression 318 patterns derived from the temporal clusters (Supplemental Data Set 1; Fig. 1A; B).

\section{BBX32 is a negative regulator of dynamic acclimation}

320 Dynamic acclimation was tested in two independent BBX32 over-expressing 321 (BBX32-OE) genotypes (BBX32-10 and BBX32-12) and a T-DNA insertion mutant 
bioRxiv preprint doi: https://doi.org/10.1101/2020.12.23.424212; this version posted December 26, 2020. The copyright holder for this preprint (which was not certified by peer review) is the author/funder, who has granted bioRxiv a license to display the preprint in perpetuity. It is made available under aCC-BY 4.0 International license.

322 (bbx32-1; see Methods and Holtan et al., 2011). BBX32-OE plants showed a highly

323 significant impairment of dynamic acclimation (Fig. 4A; Supplemental Data Set 6). In

324 contrast, bbx32-1 plants showed a weak but significant accelerated dynamic

325 acclimation phenotype (Fig. 4B; Supplemental Data Set 6). We define an

326 accelerated acclimation phenotype as a significant enhancement of PSII operating

327 efficiency over one or more days in the $5 \mathrm{~d}$ serial $\mathrm{HL}$ treatment. The strong negative

328 impact of $B B X 32$ over-expression on dynamic acclimation was confirmed

329 subsequently by showing a significant inhibition of photosynthetic capacity $\left(A_{\text {sat }}\right)$ after

3305 days of daily $4 \mathrm{~h} \mathrm{HL}$ exposure (Fig. 4C). Consequently, it was concluded that

$331 B B X 32$ is a negative regulator of dynamic acclimation.

332 Transcriptomics provides a partial verification of the BBX32 HL TF network

333 In order to explore further the connections depicted in the network model (Fig. 3),

334 massively parallel RNA sequencing (RNAseq; Supplemental Data Set 7) was carried

335 out (see Methods; GEO; GSE158898) to profile the foliar transcriptome of fully

336 expanded leaves of Col-0 and BBX32-OE plants exposed to 3.5h HL in comparison

337 with LL controls. From the RNAseq data, the transcript levels of 25 of 47 constituent

338 genes in the inferred network were significantly altered by constitutive BBX32 over-

339 expression compared with Col-0 plants in LL and/or HL (Fig. 5). Therefore, these

340 data partly validated this (co)TF GRN and suggested that $B B X 32$ engages in both

341 positive and negative regulation of the other TF genes in this network (Fig. 3; Fig. 5).

342 The transcriptome of BBX32OE plants links initial responses to $H L$ with

343 dynamic acclimation.

344 The greatly impaired ability of $B B X 32-O E$ plants to undergo dynamic acclimation

345 (Fig. 4A, C), prompted an analysis of the RNAseq data on the impact of BBX32 over-

346 expression on the transcript levels of photosynthesis-associated genes (PhAGs;

347 https://www.kegg.jp/dbget-bin/www_bget?pathway+ath00195). There was a clear

348 influence of $B B X 32$ over-expression under $L L$ and $H L$ on the transcript levels of a

349 range of transcripts coding for LH Antenna proteins, Calvin-Benson cycle enzymes

350 and components of photosynthetic electron transport, PSI and PSII (Fig. 6;

351 Supplemental Data Set 8). We concluded that these and other transcripts affected in

$352 B B X 32-O E$ plants may reflect their perturbed photosynthetic physiology. 
353 This widespread disruption of PhAG transcript levels led us to examine the impact of

$354 B B X 32$ over-expression on other cellular processes. In the RNAseq experiment, of

355 the 2903 genes whose transcript levels were HL responsive (Padj. < 0.05; $\geq 2$-fold

356 differentially expressed; Supplemental Data Set 7), BBX32 over-expression

357 perturbed the transcript levels of $32 \%$ and $15 \%$ of them in LL and HL conditions

358 respectively (Fig. 7A; Supplemental Data Set 7). The HL/LL Col-0 DEGs were

359 enriched for 35 GO BP terms (Supplemental Data Set 9) and 26 of them were also

360 significantly over-represented in the BBX32-OE / Col-0 LL and BBX32-OE / Col-0 HL

361 DEGs (Supplemental Data Set 9). These shared GO groups all describe responses

362 to various abiotic and biotic stresses or response to endogenous stimuli such as

363 salicylic acid or $\mathrm{H}_{2} \mathrm{O}_{2}$. This analysis indicates that $B B X 32$ influences a wide range of

364 cellular responses to stress, which includes regulation of genes associated with

365 basal immunity to infection.

366 The DEGs from BBX32-OE HL and LL treated plants were also compared with the 3673844 time-series HL DEGs (Fig. 7B; Supplemental Data Set 2; Supplemental Data

368 Set 10). Although the number of overlapping genes was lower (Fig. 7B), BBX32-OE

$369 \mathrm{HL}$ DEGs again confirmed enrichment for a range of GO terms that describe generic

370 responses to environmental stress (Supplemental Data Set 10). However, the 408

371 BBX32-OE LL DEGs also differentially expressed in the HL time series dataset, also

372 revealed significant enrichment $(F D R<0.05)$ of a range of additional functions

373 (Supplemental Data Set 10) including glucosinolate and glycosinolate metabolism

374 (GO:0019760, GO:0050896, GO:006143, GO:0019757, GO:0016144, GO:0019761,

375 GO:0019758), cell wall thickening (GO:0052543, GO:0052386) and callose

376 deposition (GO:0052543, GO:0052545). Down-regulation of these groups of genes

377 in the HL time series data (Supplemental Data Sets 1 and 2) may reflect a re-

378 distribution of resources towards dynamic acclimation and away from basal immunity

379 (see above and Discussion). The observations here suggest $B B X 32$ may play a

380 regulatory role in these processes (see Discussion) but also reinforces that $B B X 32$

381 influences immediate responses before or during a single exposure to HL.

\section{CRY1- and HY5- regulated control of dynamic acclimation}

$383 B B X 32$ has been proposed to be a negative regulator of the integration of light

384 signals from phytochromes (PHYs) and cryptochromes (CRYs) during

385 photomorphogenesis (Holtan et al., 2011; Gangappa and Botto, 2014). BBX32-OE 
bioRxiv preprint doi: https://doi.org/10.1101/2020.12.23.424212; this version posted December 26, 2020. The copyright holder for this preprint (which was not certified by peer review) is the author/funder, who has granted bioRxiv a license to display the preprint in perpetuity. It is made available under aCC-BY 4.0 International license.

386

seedlings display a long hypocotyl phenotype in the light like photoreceptor mutants and mutations in LONG HYPOCOTYL5 (HY5; Holtan et al., 2011). Notably, HY5 is a member of the BBX32-centric GRN (Fig. 3; Fig. 5) and along with $C R Y 1$, has also been implicated in influencing the expression of $\mathrm{HL}$-inducible gene expression (Kleine et al., 2007; Shaikali et al., 2012; Chen et al., 2013). Furthermore, PHYA-, $P H Y B$ - and $C R Y 1$-mediated signaling was proposed to regulate maximum photosynthetic capacity in plants grown in a range of PPFDs (Walters et al 1999; see Introduction). These considerations prompted us to test dynamic acclimation in photoreceptor-defective and hy5 mutants.

No significant impact of $P H Y A$ or $P H Y B$ on acclimation was observed (Supplemental Fig. 6A, B). In contrast, cry1 mutants almost completely failed to undergo any dynamic acclimation (Fig. 8A, B), whereas cry2-1 was not impaired (Supplemental Fig. 6C). One of the cry1 mutants shown (cry1M32; Fig. 8B) arose serendipitously from a screening of T-DNA insertion mutants in genes coding for 7-transmembrane proteins that had been postulated to be implicated in HL-mediated G protein signaling (Galvez-Valdivieso et al., 2009; Gorecka et al., 2014). However, the one mutant recovered from this screening, was shown subsequently to be deficient in dynamic acclimation due to a disabling second site mutation in CRY1 (see Methods). Since the defective acclimation phenotype was identified prior to knowing the identity of the causal mutation we took this to be forward genetic evidence of the importance of $C R Y 1$ in dynamic acclimation in mature leaves.

The light environment used to grow plants for this study and subject to HL was enriched for blue wavelengths (Supplemental Figure 7; see Discussion). Therefore, we considered the possibility that a role for phytochromes in dynamic acclimation could be obscured, favouring a predominance of CRY1 under our growth conditions. To test this notion, a mutant harbouring a constitutively active form of PHYB, phyBY276H (YHB) in a Col-0 background (Jones et al., 2015) was tested for dynamic acclimation (Fig. 8C). This mutant exhibited a higher PSIl operating efficiency than Col-0 after 1 day of $\mathrm{HL}$ exposure. This accelerated acclimation phenotype is in keeping with being a constitutively active positive regulator of dynamic acclimation. 
417 Mutants defective in HY5 function were strongly impaired in dynamic acclimation

418 (Fig. 8D, E) consistent with being a member both of a BBX32-centric GRN and being 419 a positive regulator of CRY1-mediated dynamic acclimation (Fig 8A, B).

420 COP1, PIF and SPA genes regulate dynamic acclimation

421 In both photomorphogenesis and shade avoidance responses, the transduction of 422 signals from photoreceptors is mediated via one or more DET/COP/FUS regulatory 423 complexes (Lau and Deng, 2012), which act as platforms for the post-translational 424 control of the levels of HY5 and the integration into the signaling of the TFs 425 PHYTOCHROME INTERACTING FACTORS (PIFs) and regulatory proteins 426 SUPPRESSOR OF PHYA-105 (SPA) (Hardtke et al 2000; Toledo-Ortiz et al 2003; 427 Lian et al 2011; Dong et al 2014; Huang et al 2014; Lau and Deng 2012; Gangappa 428 and Botto, 2016; Hoecker 2017; Pham et al 2018; Lau et al., 2019). CRY1 and PIFs 429 have been shown also to physically interact independent of COP/DET/FUS 430 (Pedmale et al., 2016; Ma et al., 2016). In the VBSSM-inferred GRN, PIF4 and 431 SPA1 were predicted to have a regulatory connection to BBX32 (Fig. 3; Fig.5). 432 Significantly, $187 \mathrm{HL}$ time series DEGs overlapped $(P=0.0018$; Hypergeometric 433 Distribution Test) with a set of 1120 genes identified as commonly regulated by 434 SPA1, 2, 3, 4, PIF1, 3, 4, 5 and COP1 in de-etiolating and light-exposed seedlings 435 (Pham et al., 2018). Interestingly, the most significant GO Biological Process 436 function coded by these overlapping genes was Photosynthesis (GO: 0015979; FDR $437=2.7$ E-17; Supplemental Data Set 11).

438 Cop1-4 plants, despite a severely dwarfed shoot morphology (Fig. 9A; Deng and 439 Quail, 1992; Gangappa and Kumar, 2018), displayed a highly elevated PSII 440 operating efficiency (Fq'/Fm') by day 1 of the $\mathrm{HL}$ acclimation regime compared with 441 Col-0 (Fig. 9B) like the HL response of YHB plants (Fig. 8C). In contrast, despite a 442 similar dwarf shoot morphology (Fig. 9A), det1-1 displayed no defect in dynamic 443 acclimation (Fig. 9D). This strongly suggests that the dynamic acclimation response 444 of chloroplasts is independent of shoot size and that these two traits are not coupled. 445 Furthermore, spa1/spa2/spa3 (spa1,2,3) plants also displayed an accelerated 446 acclimation phenotype (Fig. 9C). Therefore, it was concluded that one or more type 447 of COP1/SPA complex (Huang et al., 2014; Hoecker, 2017) are negative regulators 448 of dynamic acclimation and that DET1 plays no role in dynamic acclimation. 
bioRxiv preprint doi: https://doi.org/10.1101/2020.12.23.424212; this version posted December 26, 2020. The copyright holder for this preprint (which was not certified by peer review) is the author/funder, who has granted bioRxiv a license to display the preprint in perpetuity. It is made available under aCC-BY 4.0 International license.

There is a high degree of redundancy among the PIF TF family and therefore a quadruple null mutant of PIF1,3, 4 and 5 (hereafter called pifq; Leivar et al., 2008) was tested for its capacity for dynamic acclimation. These plants displayed a severe dwarf phenotype as previously described (Leivar et al., 2008), but also a significant inhibition of dynamic acclimation (Fig. 9E). In contrast, the dynamic acclimation of a single mutant allele of PIF4 (pif4-2) was normal (Supplemental Fig. 6D).

\section{DISCUSSION}

\section{The time series HL transcriptomics data indicates the initiation of dynamic}

\section{acclimation processes}

458 The exposure to a 7.5-fold increase in PPFD (HL; see Methods) presents both a threat and an opportunity to the plants in this study. The threat comes from the possibility that the PPFD will continue to increase and render the plant susceptible to irreversible photoinhibition. The opportunity comes from enhancing photosynthesis by initiating dynamic acclimation (Fig. 2A-D). Accompanying enhanced photosynthesis was also a lowering of reliance on the dissipation of excitation energy using NPQ (Supplemental Fig. 2A), which can limit plant productivity (Kromdiijk et al., 2016).

The adaptation to a potential increase in photooxidative stress and photoinhibition (see Introduction) is the early $(\leq 1 \mathrm{~h})$ strong but transient change in transcript abundance of 257 genes in clusters 21-26, upon exposure to HL. Clusters 22, 23, 25 and 26 include among them 64 known genes that promote abiotic stress tolerance (Fig. 1A, B; cluster 23 in Supplemental Fig. 1; Supplemental Fig. 2C; Supplemental Data Set 1; Supplemental Data Set 2). The transiently enhanced expression of these genes presumably allows the plant to overcome any potential initial detrimental effects of the $\mathrm{HL}$ exposure, as many other studies have reported (e.g. Ball et al., 2004; Gadjev et al., 2006; Ramel et al., 2012; 2013; Willems et al., 2016; Crisp et al., 2017; Huang et al., 2019).

476 Coordinated alteration in specific biological processes was evident in some clusters.

477 Down-regulated clusters include those collectively associated with aspects of basal 478 or innate resistance to pathogens (Underwood, 2012; Piasecka et al., 2015).

479 Examples include genes coding for cell wall modifications and callose deposition 480 (cluster 1), defense response to bacteria (cluster 3 ) and glucosinolate / glycosinolate 
bioRxiv preprint doi: https://doi.org/10.1101/2020.12.23.424212; this version posted December 26, 2020. The copyright holder for this preprint (which was not certified by peer review) is the author/funder, who has granted bioRxiv a license to display the preprint in perpetuity. It is made available under aCC-BY 4.0 International license.

481

482

483

484

485

486

487

488

489

490

491

492

493

494

495

496

497

498

499

500

501

502

503

504

505

506

507

508

509

510

511

512

513

biosynthesis (cluster 10). In this study, plants were grown at a PPFD below their light saturated rate of photosynthesis (Asat; Fig. 2C; see Methods). Plants grown under such light-limiting conditions may initially have to re-allocate resources away from some cellular processes in order to begin acclimation and take advantage of a sustained increase in PPFD. Photosynthetically active expanded but not senescing leaves, such as leaf 7 used here (see Methods), have been suggested to maintain a higher degree of poising of immunity to respond to biotic stress compared with abiotic stress (Berens et al., 2019). Therefore, in a converse situation where a potential abiotic stress threat emerges, the diversion of resources from defense against pathogens may be an appropriate response. Meanwhile, among the DEG time series clusters whose transcript levels increased at various points in the experiment, are those that could be preparing the leaf to increase its photosynthetic and metabolic capacity in order to begin acclimation (Eberhard et al., 2008; Dietz, 2015). Genes in over-represented GO BP terms included those involved in macromolecule synthesis and especially translation (clusters 41-43) and related metabolic processes such as enhanced amino acid and organic acid biosynthesis (cluster 39).

A single exposure to $4 \mathrm{~h} \mathrm{HL}$ is not sufficient to induce dynamic acclimation at the physiological level, requiring, under our conditions, a further 3 daily episodes of $4 \mathrm{~h}$ HL for this to begin to occur (Fig. 2A-D). Our experience is consistent with a previous study where dynamic acclimation took around 5 days to be fully manifested and 2-3 days to discern any change in photosynthesis rates after a permanent shift from a photoperiod PPFD of $100 \mu \mathrm{mol} \mathrm{m} \mathrm{m}^{-2}$ to $400 \mu \mathrm{mol} \mathrm{m} \mathrm{m}^{-2} \mathrm{~s}^{-1}$ (Athanasiou et al., 2010). However, it should be noted that the $\mathrm{HL}$ regime used did not produce dynamic acclimation for the Col-0 accession but did for others such as Ws-2 and Ler-0 (Athanasiou et al., 2010). In contrast, the shorter more intense PPFDs used in this study induced dynamic acclimation in Col-0 and also Ws-0 (Fig. 2A-D; Fig. 4A-D;

Fig. 8A-E; Supplemental Fig. 4B).

\section{$B B X 32$ connects a range of cellular processes to dynamic acclimation}

Of all the comparisons carried out with relevant transcriptomics data sets, the most extensive overlap with time series HL DEGs was with those from dark-germinated phyA/phyB seedlings exposed to red light (Supplemental Data Set 5; Shikata et al., 2014). While this was initially surprising because of the very different experimental 
514

515

516

517

518

519

520

521

522

523

524

525

526

527

528

529

530

531

532

533

534

535

536

537

538

539

540

\section{1}

542

543

544

545

546

conditions, earlier studies had shown a strong influence of photoreceptor genes ( $C R Y$ s and $P H Y s$ ) on photosynthetic capacity in Arabidopsis grown at a range of PPFDs (Walters et al., 1999) and an impact on the induction of some HL-responsive genes (Kleine et al., 2007; Shaikali et al., 2012; Guo et al., 2017). Our own and the published data above, prompted a selection of 91 light- and PHYA/B-regulated (co)TF genes (Supplemental Data Set 5). The HL time series expression data from these genes was subjected to VBSSM, which after two iterations, inferred a highly interconnected BBX32-centric (co)TF GRN (Fig. 3 and see Results). In the GRN, $>50 \%$ of the nodes (genes) were subsequently confirmed by RNAseq to be influenced significantly in their expression by BBX32 (Fig.3; Fig. 5).

Over-expression of $B B X 32$ clearly demonstrated that this gene is a negative regulator of dynamic acclimation (Fig. 4A-D) and has an extensive influence on immediate responses to $\mathrm{HL}$ that include processes associated with photosynthesis (Fig. 6; Supplemental Data Set 8). Notably, depressed levels of LHCB4.3 transcript in $B B X 32-\mathrm{OE} \mathrm{HL}$ and LL plants (Fig. 6) could be important since levels of this antenna protein are closely linked to the degree of long-term acclimation to $\mathrm{HL}$ (Albanese et al., 2016).

$B B X 32$ overexpression also impacts on a range of cellular processes that can be associated with basal immunity, including multiple GO designations for glucosinolate/glycosinolate metabolism, callose deposition, responses to chitin and to pathogens (Supplemental Data Sets 7, 9 and 10). This observation is consistent with the enrichment of the same processes noted in down-regulated temporal clusters (see above; Supplemental Data Set 2) and supports our suggestion that in wild type plants, down-regulation of basal immunity may be a necessary prerequisite for successful dynamic acclimation (see above). We propose that $B B X 32$ control of aspects of basal immunity is part of its regulation of the initiation of dynamic acclimation.

$B B X 32$ showed a greater transcript abundance over LL controls at any point onwards from the $2 \mathrm{~h}$ HL timepoint. Nevertheless, its transcript abundance was on a downward trend through the diel, paralleling its LL pattern of expression (Supplemental Fig. 5). Interestingly, while BBX32-OE plants displayed a 66-fold elevated $B B X 32$ transcript level in $\mathrm{LL}$, this value reduced to 33-fold after $3.5 \mathrm{~h} \mathrm{HL}$ (Supplemental Data Set 7). The enhanced $B B X 32$ expression in these plants is 
547 driven by the CaMV 35S promoter (Holtan et al., 2011), therefore the decline in

548 transcript abundance over a diel could indicate that a temporal post-transcriptional

549 control operates to determine BBX32 transcript levels.

550 The strong negative impact of $B B X 32$ over-expression upon dynamic acclimation

551 suggested that a defective gene ought to confer a converse elevated phenotype. The

552 mutant bbx32-1 (see Results; Holtan et al., 2011), displayed a weakly significant

553 trend of enhanced PSII operating efficiency compared with Col-0 between days 2

554 and 4 of the 5 days of $4 \mathrm{~h} \mathrm{HL}$ exposure (Fig. 4B). This genotype, however, is unlikely

555 to be a null mutant. The mutagenic T-DNA is inserted such that the first 172 amino

556 acid residues of BBX32 would still be produced and a truncated transcript spanning

557 this region has been detected in bbx32-1 seedlings (Holtan et al., 2011). The

558 retained $\mathrm{N}$-terminal region coded by this allele harbors the single B-Box zinc finger

559 domain of BBX32 (Gangappa and Botto, 2014) and downstream sequences to

560 residue 88 , capable of binding at least one target protein, the transcription regulator

561 EMBRYONIC FLOWER1 (EMF1; Park et al., 2011). The possibility of a partially

562 functional truncated $B B X 32$ may explain the weak phenotype of bbx32-1 with respect

563 to this acclimation phenotype (Fig. 4B) and also its mild constitutive

564 photomorphogenic phenotype in seedlings (Holtan et al., 2011).

\section{Two levels of control of dynamic acclimation}

566 The time series data and the VBSSM modelling led us to identify BBX32 and $H Y 5$ as

567 strong negative and positive regulators respectively of dynamic acclimation in mature

568 leaves (Fig. 4A-D; Fig. 8D, E) and places the start of the process right at the first

569 hours of exposure to HL. This represents new functions for these two important

570 genes and extends their role to cover a further dimension in the interaction of the

571 mature plant with its light environment. In seedlings, HY5 controls the positive

572 regulation of chlorophyll content, transcript levels of PhaGs in cool temperatures

573 (Toledo-Ortiz et al., 2014) and the control of chloroplast development during

574 photomorphogenesis (Ruckle et al., 2007), which suggests, along with data shown

575 here (Fig. 6; Supplemental Data Set 8), that control of these photosynthesis-

576 associated processes by a $B B X 32 / H Y 5$-regulatory module is retained throughout the

577 life of the plant. Furthermore, we have established that $B B X 32$ fulfills the criterion of

578 regulating both immediate responses to $\mathrm{HL}$ and the resulting dynamic acclimation,

579 thus providing a link between these temporally distinct processes and experimental 
580

581

582

583

584

585

586

587

588

589

590

591

592

593

594

595

596

597

598

599

600

601

602

603

604

605

606

607

608

609

610

611

612

support for the hypothesis proposed here and by Eberhard et al. (2008; see Introduction).

The comparison drawn between the control of photomorphogenesis and dynamic acclimation was extended by establishing that $C R Y 1$ (and possibly $P H Y B$ ) and one or more members of the PIF family are positive regulators of dynamic acclimation (Fig. 8A, C; Fig. 9E), while COP1 and one or more of SPA1, SPA2 and SPA3, are negative regulators (Fig. 9B, C). Again, by analogy with seedling photomorphogenesis, we suggest that these genes act together to suppress dynamic acclimation under LL conditions by enabling the ubiquitin-mediated degradation of HY5 and other TFs. In HL, this suppression would be reversed by CRY1 physically interacting with and inhibiting the action of COP1/SPA protein. (Laubinger et al., 2004; Lian et al., 2011, Lau and Deng 2012; Huang et al., 2014; Gangappa and Botto, 2016; Hoecker, 2017; Pham et al., 2018; Lau et al., 2019). Consequently, CRY1 would cause the re-direction of HY5 to the activation of dynamic acclimation. However, a further adaptation may be required to slow or accelerate dynamic acclimation. For example, to fine tune the establishment of dynamic acclimation in a fluctuating light environment. We suggest under $\mathrm{HL}$, when $H Y 5$ is free of negative regulation by $C O P 1 / S P A$, that $B B X 32$ is the important additional moderator of the establishment of dynamic acclimation. We speculate in the scheme in Figure 10 how this system may work and provides a basis for further studies. The transcriptional control of $H Y 5$ and by extension, other members of the BBX32-centric GRN (Fig. 3; Fig. 10), could be subject to regulation by additional intracellular signals in $\mathrm{HL}$, such as those from chloroplasts and hormones, serving to coordinate a range of cellular processes for dynamic acclimation (Hardkte et al, 2000; Galvez-Valdivieso et al 2009; Estavillo et al., 2011; Ramel et al., 2012; 2013; Dietz, 2015; Gangappa and Botto, 2016; Guo et al., 2016; Exposito-Rodriguez et al., 2017).

The opposing regulation of dynamic acclimation by BBX32 and HY5 could mean that some form of genetic interaction between these genes drives its establishment in a manner similar to their negative and positive regulation respectively of photomorphogenesis (Datta et al., 2007; Holtan et al., 2011; Xu et al., 2014; Gangappa and Botto, 2016). However, BBX32 does not bind DNA and has been proposed to act as transcription co-factor in complexes with several TFs (Park et al., 
613 2011; Holtan et al., 2011; Ganagappa and Botto, 2016; Tripathi et al., 2017). Of

614 relevance here, in a tripartite complex with BBX21, BBX32 has been suggested to

615 diminish the binding of HY5 to its target promoters (Datta et al., 2007; Holtan et al.,

616 2011; Xu et al., 2014; Gangappa and Botto, 2016). Therefore, alongside

617 transcriptional control of $H Y 5$ by $B B X 32$, there may also be this post-translational

618 control of HY5 action by BBX32 during dynamic acclimation.

619 The proposed need for both a CRY1/COP1/SPA- and a BBX32-mediated control of 620 dynamic acclimation (Fig.10) comes also from considerations about light quality and 621 intensity. First, the fluence of blue light in the $\mathrm{HL}$ exposure used in this study would 622 exceed the saturation of CRY1 activation, which is ca. $32-40 \mu \mathrm{mol} \mathrm{m} \mathrm{m}^{-1}$ blue light 623 (Hoang et al., 2008; Liu et al., 2020). Therefore, while CRY1 signaling would need to 624 be activated (i.e. on) for dynamic acclimation to happen, further signaling input may 625 be required from other sources via $B B X 32$ and its GRN to modulate the degree of 626 response. A second factor is that at high fluence, CRY1 may produce $\mathrm{H}_{2} \mathrm{O}_{2}$ in the 627 nucleus (Consentino et al., 2015). $\mathrm{H}_{2} \mathrm{O}_{2}$ for $\mathrm{HL}$ signaling is primarily synthesized and 628 exported from chloroplasts and is dependent upon an active photosynthetic electron 629 transport chain (Exposito-Rodriguez et al., 2017; Mullineaux et al., 2018). However, 630 this does not exclude the possibility that the $\mathrm{HL}$-dependent accumulation of $\mathrm{H}_{2} \mathrm{O}_{2}$ in 631 nuclei may be augmented from other sources such as photo-saturated CRY1, 632 signals from which could be fed into the BBX32-centric GRN.

633 In contrast to Arabidopsis grown at differing PPFDs but using similar fluorescent 634 lighting to this study (Walters et al., 1999; see Methods), no influence of PHYA or 635 PHYB was observed on dynamic acclimation (Supplemental Fig. 6A, B). This could 636 have been a consequence of the degree of blue light used in both the growth 637 conditions and in applying a HL exposure (9\% and 58\% of total PPFD respectively; 638 Supplemental Fig. 7; see Methods). This range of wavelengths in artificial lighting is 639 typical of many controlled environment conditions (Naznin et al., 2019) and may 640 have favored a response mediated by $C R Y 1$. The observation that plants harboring 641 a constitutively active PHYB (YHB) allele displayed a partially accelerated 642 acclimation phenotype (Fig. 8C) means that phytochromes could also control 643 dynamic acclimation under some light environments and modify or interact with a 644 CRY1-dependent signaling pathway (Ahmad et al., 2002; Yu et al., 2010). 
645 A further explanation could be that the PHY mutants were altered in leaf

646 development such that this impacted on their photosynthetic properties. Equally, we

647 cannot rule out effects of a similar nature on BBX32-OE, hy5, cry1, cop1 and spa1,2

6483 plants, but the clear lack of influence of a more severe dwarf shoot morphology on

649 chloroplast level acclimation in det1-1 plants argues against this (Fig. 9A, D).

650 BBX32 over-expressed in Arabidopsis and soybean - control of a balance

651 between photosynthetic capacity and leaf longevity?

652 Arabidopsis (At)BBX32 has been over-expressed in transgenic soybean (Glycine

653 max. Merr., here called BBX32OE-soya) and year-on-year at different field sites

654 produced up to an $18.5 \%$ increase in yield (Preuss et al., 2012). BBX32-OE

655 Arabidopsis plants showed impaired dynamic acclimation and a consequent strong 656 depression in Asat (Fig. 4C). This would appear to be at odds with the likelihood of

657 an increased seed yield in the field. However, at the whole plant level, this effect may 658 not be negative when considered as follows: BBX32-OE Arabidopsis plants show 659 delayed flowering caused by the interaction of BBX32 with BBX4 (COL3), EMF1 and 660 possibly other regulators of flowering time (Park et al., 2011; Tripathi et al., 2017).

661 One consequence of delayed flowering is often the retardation of leaf senescence 662 (Gan and Amasino, 1995; Wingler et al., 2010). Similarly, the BBX32OE-soya 663 displayed an extended period of reproductive development associated with delayed 664 leaf senescence thus contributing to the increased yield phenotype, similar to some 665 "stay green" crop genotypes (Preuss et al., 2012; Kamal et al., 2019). While leaf 666 senescence has not been measured in the BBX32-OE plants, nodes on the BBX32667 centric GRN include GOLDEN-LIKE2 (GLK2) and ACTIVATING FACTOR1 (ATAF1; 668 also called NO APICAL MERISTEM ATAF1/2 CUP SHAPED COTYLEDON (CUC)2 669 (NAC2); Fig. 3; Fig. 5; Supplemental Dataset 8). These genes are implicated in the 670 maintenance of chloroplast integrity and are determinants of the entry of Arabidopsis 671 leaves into senescence (Waters et al., 2009; Garapati et al., 2015; Song et al., 672 2018).

673 The potential negative effect of AtBBX32 over-expression in soybean depressing 674 maximal photosynthetic capacity may not have proved detrimental because of the 675 way the crop is grown commercially. Modern soybean varieties are grown as a row 676 crop to achieve a high canopy coverage that maximises the absorption of light 677 (Shepherd et al., 2018; Koester et al., 2014). Within the canopy, the photosynthetic 
678

679

680

681

682

683

684

685

686

687

688

689

690

691

692

693

694

695

696

697

698

699

700

701

702

703

704

705

706

707

708

709

rate of leaves below Asat may not have been significantly affected by AtBBX32 overexpression in soya, as observed in Arabidopsis BBX32-OE plants (Fig. 4D). Furthermore, we speculate that the photosynthetic capability of leaves exposed to full sun in $B B X 320 E$-soya plants, while perhaps being unable to achieve a maximal Asat, benefitted from an enhanced leaf longevity and chloroplast integrity. A further effect could also have been that like their Arabidopsis counterparts, the BBX32OEsoya plants had higher NPQ (Supplemental Data Set 6) perhaps linked to enhanced PsbS transcript levels (Fig. 6), PsbS being a key determinant of the qE component of NPQ (Li et al., 2000). Consequently, the BBX32OE-soya plants may have been less susceptible to photooxidative stress (see Introduction). Thus, while raised NPQ could have lowered photosynthetic efficiency and diverted excitation energy away from photosynthesis, this may have had a protective effect under certain field and agronomic conditions and consequently improving overall crop performance.

In summary, that a network of TF genes could control dynamic acclimation, encompassing a wide range of cellular processes, implies a complex and extensive regulation that would provide resilience and flexibility in being able to accommodate input from further intracellular and extracellular signaling. At the whole plant level, this would allow for the degree of photosynthetic capacity and acclimation in individual leaves to be adjusted according to their specific micro-environments making this acclimation a truly dynamic process.

\section{METHODS}

\section{Growth conditions}

Plants were grown in an $8 \mathrm{~h}$ photoperiod (short day) at a PPFD of $150( \pm 10) \mu \mathrm{mol}$ $\mathrm{m}^{-2} \mathrm{~s}^{-1}$ under fluorescent tubes (Phillips TLD 58W, 830 (warm whites); the spectrum of the light source is shown in Supplemental Figure 7), $22 \pm 1{ }^{\circ} \mathrm{C}, 1 \mathrm{KPa}$ vapour pressure deficit (VPD) and cultivation conditions as described previously (Bechtold et al., 2016; Windram et al., 2012). Unless stated otherwise, all plants were used from 35 to 40 days post-germination (dpg).

\section{Arabidopsis genotypes}

The following Arabidopsis mutants and transgenic lines, all in a Col-0 background, have been described previously: BBX32-10, BBX32-12, bbx32-1 (Holtan et al., 2011), hy5-215 (Oyama et al., 1997), hy5-2 (Ruckle et al., 2007), pifq (Leivar et al., 
2008), cop1-4 (Deng and Quail, 1992), det1-1 (Chory et al., 1989), spa1/spa2/spa3 phyBY276H (YHB; Jones et al., 2015).

\section{Identification of the cry1M32 mutant.}

715 Based upon earlier research in our laboratory (Galvez-Valdivieso et al., 2009;

716 Gorecka et al., 2014) in which we studied a possible role for heterotrimeric G proteinmediated high light $(\mathrm{HL})$ signaling, we set out to identify candidate genes coding for

7187 transmembrane proteins that may have a role as $\mathrm{G}$ protein coupled receptors. A collection of 59 T-DNA insertion mutants in genes coding for putative 7transmembrane proteins (Moriyama et al., 2006; a kind gift from Professor Alan Jones, University of North Carolina) was screened for perturbed chlorophyll

722 fluorescence in response to $\mathrm{HL}$ exposure (see below). The screening revealed that

723 the insertion line Sail_1238_E12 (hereafter termed M32) was deficient in dynamic

724 acclimation (Fig. 8B). The information available on T-DNA flanking sequences

725 indicated that this was a T-DNA insertion in the first exon of At4g21570, a gene

726 encoding a transmembrane protein of unknown function. However, complementation

727 of M32 by transformation with the wild type At4g21570 gene did not restore a wild-

728 type phenotype (data not shown).

729 Besides being defective in dynamic acclimation, M32 was impaired in blue light

730 inhibition of hypocotyl elongation under both low and high blue light fluence,

731 accumulated less chlorophylls and anthocyanins than Col-0 under blue light, and

732 presented delayed flowering time when grown in short day photoperiod.

733 (Supplemental Fig. 8 B-E). Later and in the light of our subsequent hypothesis that

734 CRY1-mediated signaling controls dynamic acclimation in Arabidopsis (see Results 735 and Discussion), we realized that M32 resembled the phenotype of known cry1

736 mutants. Therefore, we tested if $C R Y 1$ was altered in this mutant. $C R Y 1$ was

737 amplified from its genomic DNA and the PCR product was Sanger sequenced on

738 both strands. Col-0 CRY1 amplicon was also sequenced. The analysis of the 739 sequence showed that in $M 32, C R Y 1$ contains a single point mutation $(G \rightarrow A)$, which 740 caused a substitution of Gly ${ }_{347}$ Arg mutation in CRY1 (Supplemental Fig. 8F). This 741 mutation was previously identified in a screening of EMS-mutagenized Arabidopsis 742 seedlings (Ahmad et al., 1995) and designated as hy4-15, and affects the domain 
bioRxiv preprint doi: https://doi.org/10.1101/2020.12.23.424212; this version posted December 26, 2020. The copyright holder for this preprint (which was not certified by peer review) is the author/funder, who has granted bioRxiv a license to display the preprint in perpetuity. It is made available under aCC-BY 4.0 International license.

743 comprising the photolyase signature sequence. As a consequence, hy4-15 plants

744 produce a wild type amount of full length CRY1, but the protein is not functional.

745 Therefore, we concluded that M32 mutant is in fact a cry1 mutant that we named

746 cry1M32.

\section{$747 \quad H L$ exposures}

748 The HL exposure was a PPFD of $1100( \pm 100) \mu \mathrm{mol} \mathrm{m} \mathrm{m}^{-2} \mathrm{~s}^{-1}$ from a white light 749 emitting diode (LED) array (Isolight 4000; Technologica Ltd, Colchester UK) as 750 described previously (Gorecka et al., 2014) and which permitted the simultaneous 751 exposure of 9 plants. The spectrum of the LED array is shown in Supplemental 752 Figure 7. The HL exposure raised leaf temperature by $5^{\circ} \mathrm{C}$ within 5 min of exposure 753 which remained at this level for the remainder of the experiment (Gorecka et al., 754 2014). To determine the effect of this raised temperature (and the accompanying 755 change in VPD) on the wider leaf transcriptome, we carried out a microarray analysis 756 on plants exposed to $\mathrm{HL}$ for 30 mins, or $27^{\circ} \mathrm{C}$ under $\mathrm{LL}$ for $30 \mathrm{mins}\left(\mathrm{LL} / 27^{\circ} \mathrm{C}\right)$ 757 compared with LL/22 ${ }^{\circ} \mathrm{C}$ control plants. There were 609 DEGs (1.5-fold change; FDR $758<0.05$ ) that responded to $\mathrm{HL}$ and/or LL/27 ${ }^{\circ} \mathrm{C}$ (Supplemental Data Set 12; see also 759 GSE87755 and GSE87756). Of these DEGs, 73 responded to the temperature 760 increase alone (Supplemental Data Set 12). Given the small number, these were not 761 eliminated from the time series data but none of the (co)TF DEGs (Supplemental 762 Data Set 4) fell into this group.

For the HL time series transcriptomics, two consecutive sowings, 24h apart, 764 were grown to $35 \mathrm{dpg}$ on the same growth room shelf and randomized across the 765 shelf every day. Leaf 7 (Boyes et al., 2001) was tagged at $30 \mathrm{dpg}$. We used this staging of plant growth and 3 LED Isolight arrays to treat 27 plants each day. The HL exposure began $1 \mathrm{~h}$ after subjective dawn and was completed $1 \mathrm{~h}$ before subjective dusk. Each set of tagged leaves (4) at each HL time point and their LL controls (4) were sampled within $5 \mathrm{~min}$ at time $0.5 \mathrm{~h}$ and each $0.5 \mathrm{~h}$ interval for the $6 \mathrm{~h}$ exposure. Two HL experiments were conducted with duplicate samplings of a full range of time 771 points on each day. In addition, 4 time zero samples were processed for the $0 \mathrm{~h}$ time 772 point. Both HL experiments provided a total of 100 samples for RNA extraction.

773 These were 4 biological replicates (i.e. 4 sampled leaves) per timepoint per HL 774 treatment (48 samples) and LL control (48 samples) plus 4 zero time point samples. 
bioRxiv preprint doi: https://doi.org/10.1101/2020.12.23.424212; this version posted December 26, 2020. The copyright holder for this preprint (which was not certified by peer review) is the author/funder, who has granted bioRxiv a license to display the preprint in perpetuity. It is made available under aCC-BY 4.0 International license.

To elicit dynamic acclimation, plants were subjected to $4 \mathrm{~h} \mathrm{HL}$, followed by a $0.5 \mathrm{~h}$ dark adaptation and then exposed to a range of actinic PPFDs (over $50 \mathrm{~min}$ ) to collect CF data (see below). This HL treatment was repeated daily and CF data collected from the same plants for 5 consecutive days or on Days 1 and 5 only as stated.

\section{CF measurements and imaging}

781 During the time series HL experiments, CF measurements were taken from leaf 7 of 782 one plant in situ under each isolight using PAM-2000 portable modulated 783 fluorimeters (PAM-2000, Walz GmbH, Effeltrich, Germany). At the end of each experiment the dark-adapted CF parameter Fv/Fm was determined for the same plants and LL controls and then again $24 \mathrm{~h}$ after being returned to growth conditions.

For dynamic acclimation experiments, photosynthetic efficiency was estimated with a CF imaging system (Fluorimager, Technologica Ltd, Colchester, UK), exposing the plants to increasing actinic PPFD from 200-to-1400 $\mu \mathrm{mol} \mathrm{m} \mathrm{m}^{-2} \mathrm{~s}^{-1}$ in $200 \mu \mathrm{mol} \mathrm{m} \mathrm{m}^{-2} \mathrm{~s}^{-1}$ steps every 5 min as described previously (Barbagallo et al., 2003; Gorecka et al., 2014). Whole rosette CF images were collected at each PPFD and processed using software (Technologica Ltd) to collect numerical data typically from fully expanded leaves ( $\geq 4$ per plant) for Fq'/Fm', Fv'/Fm' and Fq'/Fv' (Barbagallo et al., 2003; Baker, 2008, Gorecka et al., 2014). In some experiments, the diminished size of mutant plants rendered image processing problematic and in such stated cases, whole rosette data were collected. The raw data were fed via Excel into a program in $\mathrm{R}$ to calculate, plot and statistically analyse the CF parameters (Gorecka et al., 2014).

797 The fluorimager software produces average data of all leaf pixel values. CF 798 parameters were represented as mean \pm SE from a minimum of 4 plants, and 799 statistical significance was estimated with ANOVA followed by a post-hoc TukeyHSD 800 test.

\section{Measurement of photosynthesis}

$802 A$ was measured on leaf 7 of plants at $49 \mathrm{dpg}$ using an infrared gas exchange 803 system (CIRAS-1, PP Systems, Amesbury, MA, USA). The response of $A$ to 804 changes in the intercellular $\mathrm{CO}_{2}$ concentration $\left(C_{i}\right)$ was measured under a saturating 805 PPFD, provided by a combination of red and white LEDs (PP Systems, Amesbury, MA, USA). In addition, the response of $A$ to changes in PPFD from saturating to sub- 
807

808

809

810

811

812

813

814

815

816

817

818

819

820

821

822

823

824

825

826

827

828

829

830

831

832

833

834

835

836

837

838

saturating levels was measured using the same light source at the current

atmospheric $\mathrm{CO}_{2}$ concentration $\left(390 \mu \mathrm{mol} \mathrm{mol}{ }^{-1}\right)$. All gas analysis was made at a leaf temperature of $20( \pm 1)^{\circ} \mathrm{C}$ and a VPD of $1( \pm 0.2) \mathrm{KPa}$. Plants were sampled between 1 and 4 hours after the beginning of the photoperiod. For each leaf, steady state rates of $A$ at current atmospheric $\left[\mathrm{CO}_{2}\right]$ were recorded at the beginning of each measurement.

\section{Relative ion leakage}

The method described by Overmyer et al. (2008) was followed. Briefly, leaves were collected from plants and placed in $5 \mathrm{ml}$ de-ionized water, incubated with rotary shaking (100 rpm) for $4 \mathrm{~h}$ and the conductivity of the solution determined with a conductivity meter (Mettler Toledo, Leicester, UK) calibrated according to the manufacturer's instructions. Leaves were frozen overnight, thawed and conductivity measured again. Relative ion leakage was expressed as 'conductivity after 4 h' / 'conductivity after freeze-thawing'.

\section{RNA extraction, labelling and hybridisation to microarrays}

For the time series $\mathrm{HL}$ experiment, RNA was extracted from leaf 7 samples, labelled

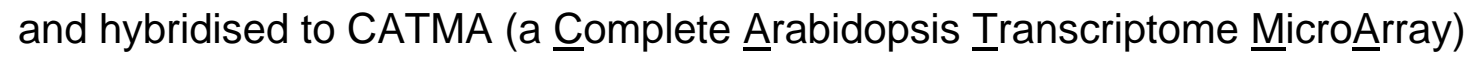
microarrays (v3; Sclep et al., 2007) as described by Breeze et al. (2011). Two technical replicates were used per biological replicate. Four biological replicates with a total of 13 time points per treatment (HL and $L L)$ were analysed in this way, resulting in a highly replicated high-resolution time series of expression profiles. The hybridisation of labelled cDNA samples' experimental design for the HL and LL time series followed a statistically randomised loop design (Supplemental Fig. 9), which enabled expression to be determined at different time points both within and between treatments. After hybridization and washing, microarrays were scanned for Cy3 and Cy5 fluorescence and analysed as below. The raw and processed data are deposited with NCBI GEO (GSE78251).

\section{Analysis of Microarray Data}

This has been described in detail previously (Breeze et al., 2011; Windram et al., 2012). Briefly, a mixed model analysis using MAANOVA (Wu et al., 2003; Breeze et al., 2011) was used with the same random (dye, array slides) and fixed variables (time point, treatments and biological replicate) to test the interaction between these 
839 factors as for the analysis of time series microarray data for senescing, Botrytis

840 cinerea-infected, Pseudomonas syringae-infected and drought-stressed leaves

841 (Breeze et al., 2011; Windram et al., 2012; Lewis et al., 2015; Bechtold et al., 2016).

842 Predicted means were calculated for each gene probe for each of the combinations

843 of treatment, biological replicate and time point and for each of the combinations of

844 treatment and time point from averages of the biological replicates.

845 A GP2S Bayes' factor (Stegle et al., 2010) was used to rank probes and genes in

846 order of likelihood of differential expression over the whole of the time series.

847 Inspection of selected probes from the rank order of likelihood of differential

848 expression was used to identify significant changes in expression with a Bayes'

849 factor cut-off >10 giving 4069 probes corresponding to 3844 DEGs (Supplemental

850 Data Set 1).

\section{Clustering of Gene Expression Profiles}

852 The expression patterns of the identified DEGs in $\mathrm{HL}$ and $\mathrm{LL}$ were co-clustered with

853 SplineCluster (Heard et al., 2005), using the mean expression profiles of the

854 biological replicates generated from MAANOVA and a prior precision value of 0.001

855 as described previously (Windram et al., 2012; Bechtold et al., 2016).

\section{GO analysis}

857 GO annotation analysis was performed using DAVID (Huang et al., 2008) or

858 AGRIGO (Du et al., 2010) with the GO Biological Process (BP) category (Ashburner

859 et al., 2000). Overrepresented GO_BP categories were identified using a

860 hypergeometric test with an FDR threshold of 0.05 compared against the whole

861 annotated genome as the reference set.

\section{Comparisons with published transcriptomics data}

863 The 3844 HL DEGs were compared on a cluster-by-cluster basis with publicly

864 available transcriptomics data. The references for each dataset are in the main

865 reference section of the paper. Each DEG list from published data was mapped to

866 AGI codes when necessary, cleaned to obtain single AGI codes since in some

867 microarray data, probes mapped to several genes or were listed as "no_match" and

868 were eliminated from the list. Overlaps within each cluster and their statistical

869 significance were determined using a Hypergeometric Distribution Test (phyper

870 function in $\mathrm{R}(\mathrm{v} 3.2 .1)$ ) in a custom $\mathrm{R}$ script, available upon request. When required, 
871 Venn diagrams of overlaps between Data Sets were plotted with Venny

872 (http://bioinfogp.cnb.csic.es/tools/venny/index.html) and the significance of the

873 overlaps calculated using the R phyper function.

\section{VBSSM}

875 A full description of VBSSM applied to this type of time series transcriptomics data is

876 provided in Bechtold et al. (2016). The individual expression data for each biological

877 replicate $(n=4)$ for selected DEGs in $\mathrm{HL}$ was run through the VBSSM algorithm (Beal

878 et al., 2005) on a local server at the University of Essex (Bechtold et al., 2016) to

879 generate the GRNs as described in Results. The VBSSM output files were imported,

880 mapped and plotted with Cytoscape (Shannon et al., 2003;

881 http://www.cytoscape.org/).

882

\section{Expression profiling by RNAseq}

883 Mature (non-senescent) leaves were excised from 4 biological replicate plants per 884 treatment, their total RNA extracted, and quality controlled as previously described 885 (Albihlal et al., 2018). Library construction after mRNA enrichment and double 886 stranded cDNA synthesis carried out using Illumina protocols by Novogene (UK) Ltd 887 (Cambridge, UK; en.novogene.com/). Library sequencing was carried out on an 888 Illumina HiSeq 4000 with a 150 base paired end reads to a depth of 20 million. 889 Extraction and quality control of data from raw fastq files was carried out using the 890 program CASAVA (Hosseini et al.,2010). The mapping of reads to the TAIR10

891 Arabidopsis genome sequence, followed by sorting and indexing of BAM output files 892 was carried out using default settings in the program HISAT2 (v2.0.5; Kim et al., 893 2015). Across all samples, > 92.5\% of bases read attained the Q30 score threshold. 894 Transcript assembly and quantification was as fragments per kilobase of transcript 895 sequence per million base pairs sequenced (FPKM) using HTseq (in union mode; 896 Anders et al., 2015). Determination of differential expression between different 897 genotypes and treatments was done using the program DEseq2 (Love et al., 2014) 898 after read count normalisation and an adjusted $p$ value threshold of $<0.05$ (negative 899 binomial distribution $p$ value model and FDR correction). Raw and processed data 900 files were deposited in NCBI Gene Expression Omnibus (GSE158898).

901 Locus codes of genes mentioned in the paper 
AT1G01720, ATAF1; AT1G04400, CRY2; AT1G06180, MYB13; AT1G09100, AAA-

903

904

905

906

907

908

909

910

911

912

913

914

915

916

917

918

919

920

921

922

923

924

925

926

927

928

929

930

931

932

933

ATPase; AT1G09570, PHYA; AT1G14150, PnsL2; AT1G14920, GAl; AT1G16300,

GAPCP-2; AT1G22190, RAP2.4; AT1G22640, MYB3; AT1G25540, PFT1;

AT1G25550, MYB-like; AT1G29910, Lhcb1/CAB3; AT1G29920, CAB2/LHCIl;

AT1G29930, CAB1/LHCII; AT1G43670, FBPASE; AT1G44575, PsbS; AT1G49720, ABF1; AT1G50420, SCL3; AT1G50640, ERF3; AT1G68520, BBX14; AT1G69010, BIM2; AT1G69490, NAP; AT1G70000, MYBD; AT1G75540, BBX21; AT1G76100, PETE1; AT1G76570, LHCB7; AT1G77450, NAC032; AT1G79550, PGK; AT2G01290, RPI2; AT2G05070, LHCB2; AT2G18790, PHYB; AT2G21330, FBA1; AT2G24540, AFR; AT2G24790, BBX4; AT2G27510, FD3; AT2G28350, ARF10; AT2G30790, PSBP-2; AT2G32950, COP1; AT2G34430, LHB1B1; AT2G34720, NFYA4; AT2G35940, BLH1; AT2G40100, LHCB4.3; AT2G40970, MYBC1; AT2G43010, PIF4; AT2G46270, GBF3; AT2G46340, SPA1; AT3G08940, LHCB4.2; AT3G09640, APX2; AT3G21150, BBX32; AT3G27690, LHCB2.3; AT3G60750, TK; AT3G61190, BAP1; AT4G05180, PSBQ-2; AT4G05390, RFNR1; AT4G08920, CRY1; AT4G10180, DET1; AT4G10340, LHCB5; AT4G15090, FAR1; AT4G17460, HAT1; AT4G29190, OZF2; AT4G32730, PC-MYB1; AT4G38960, BBX19; AT5G01600, FER1; AT5G07580, ERF106; AT5G08520, MYBS2; AT5G11260, HY5; AT5G11530, EMF1; AT5G12840, NF-YA1; AT5G15210, HB30; AT5G28450, LHC1; AT5G38420, RBCS2B; AT5G38430, RBCS1B; AT5G42520, BPC6; AT5G43270, SPL2; AT5G44190, GLK2; AT5G51190, ERF105; AT5G61270, PIF7; AT5G61590, ERF107; AT5G62000, ARF2; AT5G65310, HB5; AT5G67300, MYBR1; AT5G67420, LBD37; ATCG00020, PSBA; ATCG00270, PSBD; ATCG00300, PSBZ; ATCG00350, PSAA.

\section{SUPPLEMENTAL DATA SETS, TABLES AND FIGURES}

Supplemental Figure 1. Examples of temporal differentially expressed clusters.

Supplemental Figure 2. A comparison of plants exposed to daily HL for 5 days with their equivalent age LL controls and induction of dynamic acclimation in older plants.

Supplemental Figure 3. The HL exposure used does not produce extensive photodamage to leaves.

Supplemental Figure 4. The first draft inferred HL gene regulatory network and dynamic acclimation in Ihy-21 plants. 
bioRxiv preprint doi: https://doi.org/10.1101/2020.12.23.424212; this version posted December 26, 2020. The copyright holder for this preprint (which was not certified by peer review) is the author/funder, who has granted bioRxiv a license to display the preprint in perpetuity. It is made available under aCC-BY 4.0 International license.

934 Supplemental Figure 5. Temporal patterns of transcript abundance of the 12 most connected genes in the BBX32-centric GRN under LL and HL conditions

936 Supplemental Figure 6. Dynamic acclimation of phyB-9, phyA-211, cry2-1 and pif49372 plants compared with Col-0.

938 Supplemental Figure 7. Spectral properties of the growth lights and isolight used for 939 HL exposure.

940 Supplemental Figure 8. Identification and characterisation of cry1-M32.

941 Supplemental Figure 9. A randomized loop design employed for loading samples 942 onto the two-channel CATMA arrays.

943 Supplemental Data Set 1. The 3844 HL DEGs on a cluster-by-cluster basis.

944 Supplemental Data Set 2. Significantly enriched Biological Process GO Terms for 945 the HL DEGs in each temporal cluster.

946 Supplemental Data Set 3. Statistical data for CF measurements of 24 - 28 dpg Col0 947 plants and 44-48 dpg Col-0 plants undergoing dynamic acclimation.

948 Supplemental Data Set 4. Annotated transcription (co-)factor genes differentially 949 expressed in HL vs. LL leaves.

950 Supplemental Data Set 5. Significant overlaps, on a cluster-by-cluster basis, 951 between publicly available gene expression datasets and transcriptomic meta952 analyses for mutants and treatments that perturb chloroplast-nucleus signalling,

953 ROS-metabolism or are undergoing dynamic acclimation.

954 Supplemental Data Set 6. Photosynthetic efficiency of BBX32-OE, bbx32-1, hy5-2 955 and hy5-215 plants during induction of dynamic acclimation.

956 Supplemental Data Set 7. Transcripts that show a significant change in response to 957 3.5h HL in Col-0 and/or in BBX32-OE LL and HL plants.

958 Supplemental Data Set 8. FKPM values for transcripts coding for (A)

959 photosynthesis-associated nuclear and plastid-encoded genes and (B) (co-)TFs in 960 the inferred gene regulatory network in Figure 3.

961 Supplemental Data Set 9. Significantly enriched GO BP Terms common between 962 BBX32-OE LL / Col-0 LL, BBX32-OE HL / Col-0 HL and HL/LL Col-0 DEGs. 
963 Supplemental Data Set 10. DEGs in the GO BP terms common between BBX32-

964 OE / Col-0 LL, BBX32-OE HL / Col-0 HL and from the HL time series clusters.

965 Supplemental Data Set 11. Significantly enriched GO BP terms for HL DEGs that 966 overlap with seedling-expressed genes commonly regulated by COP1, SPA and PIF 967 gene families.

968 Supplemental Data Set 12. Differentially expressed genes from leaf 7 of

969 Arabidopsis subjected to a 30 min temperature rise from $22^{\circ} \mathrm{C}$ to $27^{\circ} \mathrm{C}$ under $\mathrm{LL}$ and 970 HL conditions.

\section{AUTHOR CONTRIBUTIONS}

972 PMM, UB, GGV and RAF carried out the HL time series experiments and RNA 973 extractions. PMM, RAF and EJS conducted the CF measurements for HL responses 974 and dynamic acclimation. MER carried out the RNA extractions and with EJS and 975 PMM, conducted the RNAseq data analysis. TL designed the gas exchange 976 measurements, which were performed by JSAM and PAD. CAP, LB, JDM, AM, RAF 977 and PMM were responsible for microarray data generation and analysis. RAF and 978 PMM conducted the VBSSM modelling under the guidance of CAP. PMM, KJD, 979 DLW, JB, VB-W and UB developed the HL time series project. PMM conceived and 980 wrote the manuscript with contributions from all authors.

\section{ACKNOWLEDGEMENTS}

We thank Silvere Vialet-Chabrand and Steven Driever for discussions and advice on statistical and physiological aspects of the study. Laura Flanders and Rahjish Khanna for the BBX32 OE lines and bbx32-1. We acknowledge European (Nottingham) Arabidopsis Stock Centre for providing cry1-304, cry2-1, phyA-219, phyB-9, pifq, pif4-1, Ihy-21, and det1-1. Matthew Jones and Ute Hoecker respectively are gratefully acknowledged for providing seed of cop1-4, Col-0 YHB and spa1/spa2/spa3. This work was supported by the UK Biotechnology and Biological Sciences Research Council (grants BB/F005822/1 and BB/F005806/1).

990 CAP and DLW were supported by the UK Engineering and Physical Science 991 Research Council (grant EP/I036575/1). JSAM was supported by NERC-CASE 992 award (ENV-EATR-DTP: NE/L002582/1). 


\section{REFERENCES}

995 Adamiec, M., Drath, M. and Jackowski, G. (2008) Redox state of plastoquinone pool

996 regulates expression of Arabidopsis thaliana genes in response to elevated

997 irradiance. Acta Biochimica Polonica 55: 161-173.

998 Adams III, W.W., Cohu, C.M., Amiard, V. and Demming-Adams, B (2014)

999 Associations between the acclimation of phloem-cell wall ingrowths in minor veins 1000 and maximal photosynthesis rate. Frontiers Plant Sci. 5: article 24.

1001 Ahmad, M. and Cashmore, A.R. (1993) HY4 gene of $A$. thaliana encodes a protein 1002 with characteristics of a blue-light photoreceptor. Nature 366: 162-166.

1003 Ahmad, M., Lin, C. and Cashmore, A.R. (1995) Mutations throughout an Arabidopsis 1004 blue-light photoreceptor impair blue-light-responsive anthocyanin accumulation and 1005 inhibition of hypocotyl elongation. Plant J. 8: 653-658.

1006 Ahmad, M., Grancher, N., Heil, M., Black, R.M., Giovani, B., Galland, P. and 1007 Lardemer, D. (2002) Action spectrum for cryptochrome-dependent hypocotyl growth 1008 inhibition in Arabidopsis. Plant Physiol. 129: 774-785.

1009 Albanese, P., Manfedi, M., Meneghesso, A., Marengo, E., Saracco, G., Barber, J., 1010 Morosinotto, T. and Pagliano, C. (2016) Dynamic reorganization of photosystem II 1011 supercomplexes in response to variations in light intensities. Biochim. Biophys. Acta 1012 1857: 1651-1660.

1013 Albihlal, W.S., Obomighie, I., Blein, T., Persad, R., Chernukhin, I., Crespi, M., 1014 Bechtold, U. and Mullineaux, P.M. (2018) Arabidopsis HEAT SHOCK

1015 TRANSCRIPTION FACTORA1b regulates multiple developmental genes under 1016 benign and stress conditions. J. Exp. Bot. 69: 2847-2862.

1017 Allahverdiyeva, Y., Battchikova, N., Brosché, M., Fujii, H., Kangasjärvi, S., Mulo, P., 1018 Mähönen, A.P., Nieminen, K., Overmyer, K., Salojärvi, J. and Wrzaczek, M. (2015) 1019 Integration of photosynthesis, development and stress as an opportunity for plant 1020 biology. New Phytol. 208: 647-655. 
1021 Ashburner, M., Ball, C.A., Blake, J.A., Botstein, D., Butler, H., Cherry, J.M., Davis, A.P., Dolinski, K., Dwight, S.S., Eppig, J.T., Harris, M.A., Hill, D.P., Issel-Tarver, L.,

1023 Kasarskis, A., Lewis, S., Matese, J.C., Richardson, J.E., Ringwald, M., Rubin, G.M.

1024 and Sherlock, G. (2000) Gene Ontology: tool for the unification of biology. Nat.

1025 Genet. 25: 25-29.

1026 Athanasiou, K., Dyson, E.C., Webster, R.E. and Johnson, G.N. (2010) Dynamic 1027 acclimation of photosynthesis increases plant fitness in changing environments.

1028 Plant Physiol. 152: 366-373.

1029 Badger, M.R., von Caemmerer, S., Ruuska, S. and Nakano, H. (2000) Electron flow 1030 to oxygen in higher plants and algae: rates and control of direct photoreduction 1031 (Mehler reaction) and rubisco oxygenase. Phil. Trans. R. Soc. Lond. B 355: 143310321446.

1033 Baker, N. R. (2008) Chlorophyll fluorescence: A probe of photosynthesis in vivo. 1034 Annu. Rev. Plant Biol. 59: 89-113.

1035 Ball, L., Accotto, G.P., Bechtold, U., Creissen, G., Funck, D., Jimenez, A., Kular, B., 1036 Leyland, N., Mejia-Carranza, J., Reynolds, H., Karpinski, S. and Mullineaux, P.M. 1037 (2004) Evidence for a direct link between glutathione biosynthesis and stress 1038 defense gene expression in Arabidopsis. Plant Cell 16: 2448-2462.

1039 Barbagallo, R.P., Oxborough, K., Pallett, K.E. and Baker, N.R. (2003) Rapid, non1040 invasive screening for perturbations of metabolism and plant growth using 1041 chlorophyll fluorescence imaging. Plant Physiol. 132: 485-493.

1042 Beal, M.J., Falciani, F., Ghahramani, Z., Rangel, C. and Wild, D. L. (2005) A 1043 Bayesian approach to reconstructing genetic regulatory networks with hidden 1044 factors. Bioinformatics 21: 349-356.

1045 Bechtold, U., Richard, O., Zamboni, A., Gapper, C., Geisler, M., Pogson, B., 1046 Karpinski, S. and Mullineaux, P.M. (2008) Impact of chloroplastic- and extracellular1047 sourced ROS on high light-responsive gene expression in Arabidopsis. J. Exp. Bot. 1048 59: 121-133

1049 Bechtold, U., Lawson, T., Meyer, R.C., Mejia-Carranza, J., Brown, I.R., Altmann, T., 1050 Ton, J. and Mullineaux, P.M. (2010) Constitutive salicylic acid defences do not 
1051

1052

1053

1054

1055

1056

1057

1058

1059

1060

1061

1062

1063

1064

1065

1066

1067

1068

1069

1070

1071

1072

1073

1074

1075

1076

1077

1078

1079

1080

1081

compromise seed yield, drought tolerance and water productivity in the Arabidopsis accession C24. Plant Cell Environ. 33: 1959-1973.

Bechtold, U., Penfold, C.A., Jenkins, D.J., Legaie, R., Moore' J.D., Lawson, T., Matthews, J.S.A., Vialet-Chabrand, S.R.M., Baxter, L., Subramaniam, S., Hickman, R., Florance, H., Sambles, C., Salmon, D.L., Feil, R., Bowden, L., Hill, C., Baker' N.R., Lunn, J.E., Finkenstädt’B., Mead, A., Buchanan-Wollaston, V.,Beynon, J., Rand' D.A., Wild, D.L., Denby, K.J., Ott, S., Smirnoff, N. and Mullineaux, P.M. (2016) Time-series transcriptomics reveals that AGAMOUS-LIKE22 affects primary metabolism and developmental processes in drought-stressed Arabidopsis. Plant Cell 28: in press doi/10.1105/tpc.15.00910.

Benjamini, Y. and Hochberg, Y. (1995) Controlling the false discovery rate: a practical and powerful approach to multiple testing. J.R. Statist. Soc. B. 57: 289-300.

Berens, M.L., Wolinska, K.W., Spaepen, S., Ziegler, J., Nobori,T., Nair, A., Krüler, V., Winkelmüller, T.M., Wang, Y., Mine, A., Becker, D., Garrido-Oter, R., SchulzeLefert, P. and Tsuda, K. (2019) Balancing trade-offs between biotic and abiotic stress responses through leaf age-dependent variation in stress hormone cross-talk Proc. Natl. Acad. Sci. USA 116: 2364-2373.

Boyes, D.C., Zayed, A.M., Ascenzi, R., McCaskill, A.J., Hoffman, N.E., Davis, K.R. and Görlach, J. (2001) Growth stage -based phenotypic analysis of Arabidopsis. A model for high throughput functional genomics in plants. Plant Cell 13: 1499-1510.

Breeze, E., Harrison, E., McHattie, S., Hughes, L., Hickman, R., Hill, C., Kiddle, S., Kim, Y-S., Penfold, C.A., Jenkins, D., Zhang, C., Morris, K., Jenner, C., Jackson, s., Thomas, B., Tabrett, A., Legaie, R., Moore, J.D., Wild, D.L., Ott, S., Rand, D., Beynon, J., Denby, K., Mead, A. and Buchanan-Wollaston, V. (2011) High-resolution temporal profiling of transcripts during Arabidopsis leaf senescence reveals a distinct chronology of processes and regulation. Plant Cell 23: 873-894.

Chory, J. and Peto, C.A. (1990) Mutations in the DET1 gene affect cell-type-specific expression of light-regulated genes and chloroplast development in Arabidopsis. Proc. Natl. Acad. Sci. USA 87: 8776-8780.

Chen, D., Xu, G., Tang, W., Jing, Y., Ji, Q., Fei, Z. and Lin, R. (2013) Antagonistic basic helix-loop-helix/bZIP transcription factors for transcriptional modules that 
1082

1083

1084

1085

1086

1087

1088

1089

1090

1091

1092

1093

1094

1095

1096

1097

1098

1099

1100

1101

1102

1103

1104

1105

1106

1107

1108

1109

1110

1111

integrate light and reactive oxygen species signalling in Arabidopsis. Plant Cell 25: 1657-1673.

Chory, J., Peto, C., Feinbaum, R., Pratt, L. and Ausubel, F. (1989) Arabidopsis thaliana mutant that develops as a light-grown plant in the absence of light. Cell 58: 991-999.

Consentino, L., Lambert, S., Martino, C., Jourdan, N., Bouchet, P.-E., Witczak, J., Castello, P., El-Esawi, M., Corbineau, F., d'Harlingue, A. and Ahmad, M. (2015) Blue-light dependent reactive oxygen species formation by Arabidopsis cryptochrome may define a novel evolutionary conserved signaling mechanism. New Phytol. 206: 1450-1462.

Crisp, P.A., Ganguly, D.R., Smith, A.B., Murray, K.D., Estavillo, G.Z., Searle, I., Ford, E., Bogdanovic, O., Lister, R., Borevitz, J.O., Eichten, S.R. and Pogson, B.J. (2017). Rapid recovery gene downregulation during excess light stress and recovery in Arabidopsis. Plant Cell 29: 1836-1863.

Datta, S., Hettiarachchi, C., Johansson, H. and Holm, M. (2007) SALT TOLERANCE HOMOLOG2, a B-Box protein in Arabidopsis that activates transcription and positively regulates light-mediated development. Plant Cell 19: 3242-3255.

Davletova, S., Rizhsky, L., Liang, H. J., Zhong, S. Q., Oliver, D. J., Coutu, J., Shulaev, V., Schlauch, K. and Mittler, R. (2005) Cytosolic ASCORBATE PEROXIDASE1 is a central component of the reactive oxygen gene network of Arabidopsis. Plant Cell 17: 268-281.

Deng, X.-W. and Quail, P.W. (1992) Genetic and phenotypic characterization of cop1 mutants of Arabidopsis thaliana. Plant J. 2: 83-95.

Díaz, M., De Haro, V., Muñoz, R. and Quiles, M.J. (2007) Chlororespiration is involved in the adaptation of Brassica plants to heat and high light intensity. Plant Cell Environ. 30: 1578-1585.

Dietz, K.J., Horling, F., König, J. and Baier, M. (2002) The function of the chloroplast 2-cysteine peroxiredoxin in peroxide detoxification and its regulation. J. Exp. Bot. 53: 1321-1329. 
1112 Dietz, K.-J. (2015) Efficient high light acclimation involves rapid processes at multiple 1113 mechanistic levels. J. Exp. Bot. 66: 2401-2414.

1114 Dong, J., Tang, D., Gao, Z., Yu, R., Li, K., He, H., Terzaghi, W., Deng, X.W. and 1115 Chen, H. (2014) Arabidopsis DE-ETIOLATED1 represses photomorphogenesis by 1116 positively regulating phytochrome-interacting factors in the dark. Plant Cell 26: 363011173645.

1118 Driever, S. and Baker, N.R. (2010) The water-water cycle in leaves is not a major 1119 alternative electron transport sink for dissipation of excess excitation energy when $1120 \mathrm{CO}_{2}$ assimilation is restricted. Plant Cell Environ. 34: 837-846.

1121 Drozak, A. and Romanowska, E. (2006) Acclimation of mesophyll and bundle sheath 1122 chloroplasts of maize to different irradiances during growth. Biochim. Biophys. Acta 1757: 1539-1546.

1124 Du, Z., Zhou, X., Ling, Y., Zhang, Z. and Su, Z. (2010) agriGO: a GO analysis toolkit 1125 for the agricultural community. Nucl. Acids Res. 38: W64-W70.

1126 Eberhard, S., Finazzi, G. and Wollman, F.-A. (2008). The dynamics of 1127 photosynthesis. Annu. Rev. Genet. 42: 463-515.

1128 Estavillo, G.M., Crisp, P.A., Pomsiriwong, W., Wirtz, M., Collinge, D., Carrie, C., 1129 Giraud, E., Whelan, J., David, P., Javot, H., Brearley, C., Hell, R., Marin, E. and 1130 Pogson, B.J. (2011) Evidence for a SAL1-PAP chloroplast retrograde pathway that 1131 functions in drought and high light signalling in Arabidopsis. Plant Cell 23: 399211324012.

1133 Exposito-Rodriguez, M., Laissue, P.P., Yvon-Durocher, G., Smirnoff, N. and 1134 Mullineaux, P.M. (2017). Photosynthesis-dependent $\mathrm{H}_{2} \mathrm{O}_{2}$ transfer from chloroplasts 1135 to nuclei provides a high-light signalling mechanism. Nature Comms. 8: art. 49.

1136 Gadjev, I., Vanderauwera, S., Gechev, T.S., Laloi, C., Minkov, I.N., Shulaev, V., 1137 Apel, K., Inzé, D., Mittler, R. and Van Breusegem, F. (2006) Transcriptomic footprints 1138 disclose specificity of reactive oxygen species signaling in Arabidopsis. Plant 1139 Physiol. 141: 436-455.

1140 Galvez-Valdivieso, G., Fryer, M.J., Lawson, T., Slattery, K., Truman, W., Smirnoff, 1141 N., Asami, T., Davies, W.J., Jones, A.M., Baker, N.R. and Mullineaux, P.M. (2009) 
bioRxiv preprint doi: https://doi.org/10.1101/2020.12.23.424212; this version posted December 26, 2020. The copyright holder for this preprint (which was not certified by peer review) is the author/funder, who has granted bioRxiv a license to display the preprint in perpetuity. It is made available under aCC-BY 4.0 International license.

1142 The high light response in Arabidopsis involves ABA signaling between vascular and 1143 bundle sheath cells. Plant Cell 21: 2143-2162.

1144 Gan, S. and Amasino, R.M. (1995) Inhibition of leaf senescence by autoregulated 1145 production of cytokinin. Science 270: 1986-1988.

1146 Gangappa, S.N. and Botto, J.F. (2014) The BBX family of plant transcription factors. 1147 Trends Plant Sci. 19: 460-470.

1148 Gangappa, S.N. and Botto, J.F. (2016) The multifaceted roles of HY5 in plant growth 1149 and development. Mol. Plant 9: 1353-1365.

1150 Gangappa, S.N. and Kumar, S.V. (2018) DET1 and COP1 modulate the coordination 1151 of growth and immunity in response to key seasonal signals in Arabidopsis. Cell 1152 Reports 25: 29-37.

1153 Ganguly, D., Crisp, P., Harter, K., Pogson, B.J. and Albrecht-Borth, V. (2015) 1154 Genetic suppression of plant development and chloroplast biogenesis via the Snowy 1155 Cotyledon 3 and Phytochrome B pathways. Func. Plant Biol. 42: 676-686.

1156 Garapati, P., Xue, G.-P., Munné-Bosch, S. and Balazadeh, S. Transcription factor 1157 ATAF1 in Arabidopsis promotes senescence by direct regulation of key chloroplast 1158 maintenance and senescence transcriptional cascades. (2015) Plant Physiol. 168: 1159 1122-1139.

1160 Gorecka, M., Alvarez-Fernandez, R., Slattery, K., McAusland, L., Davey, P.A., 1161 Karpinski, S., Lawson, T. and Mullineaux, P. M. (2014) Abscisic acid signalling 1162 determines susceptibility of bundle sheath cells to photoinhibition in high light1163 exposed Arabidopsis leaves. Phil. Trans. R. Soc. B 369: 20130234.

1164 Guo, H., Yang, H., Mockler, T.C. and Lin, C. Regulation of flowering time by 1165 Arabidopsis photoreceptors. Science 279: 1360-1363.

1166 Guo, Z., Wang, F., Xiang, X., Ahammed, G.J., Wang, M., Onac, E., Zhou, J., Xia, X., 1167 Shi, K., Yin, X., Chen, K., Yu, J., Foyer, C.H. and Zhou, Y. (2016) Systemic induction 1168 of photosynthesis via illumination of the shoot apex is mediated sequentially by 1169 phytochrome B, auxin and hydrogen peroxide in tomato. Plant Physiol. 172: 125911701272. 
1171 Hardtke, C.S., Gohda, K., Osterlund, M.T., Oyama, T., Okada, K. and Deng, X.W.

1172 (2000) HY5 stability and activity in Arabidopsis is regulated by phosphorylation in its 1173 COP1 binding domain. EMBO J. 19: 4997-5006.

1174 Heard, N.A., Holmes, C.C., Stephens, D.A., Hand, D.J., and Dimopoulos, G. (2005). 1175 Bayesian co-clustering of Anopheles gene expression time series: Study of immune 1176 defense response to multiple experimental challenges. Proc. Natl. Acad. Sci. USA 1177 102: 16939-16944.

1178 Heyno, E., Innocenti, G., Lemaire, S.D., Issakadis-Bourguet, E. and Krieger-Liszkay, 1179 A. (2014) Putative role of the malate valve enzyme NADP-malate dehydrogenase in $1180 \quad \mathrm{H}_{2} \mathrm{O}_{2}$ signalling in Arabidopsis. Phil. Trans. R. Soc. B 369: 20130228.

1181 Hoang, N., Schleicher, E., Kacprzak, S., Bouly, J.P., Picot, M., Wu, W., Berndt, A., 1182 Wolf, E., Bittl, R. and Ahmad, M (2008) Human and Drosophila cryptochromes are 1183 light activated by flavin photoreduction in living cells. PLoS Biol. 6: e160.

1184 Hoecker, U. (2017) The activities of the E3 ubiquitin ligase COP1/SPA, a key 1185 repressor in light signalling. Curr. Op. Plant Biol. 37: 63-69.

1186 Holtan, H.E., Bandong, S., Marion, C.M., Adam, L., Tiwari, S., Shen, Y., Mloof, J.N., 1187 Maszle, D.R., Ohto, M., Preuss, S., Meister, R., Petracek, M., Repetti, P.P., Reuber, 1188 L., Ratcliffe, O.J. and Khanna, R. (2011) BBX32, an Arabidopsis B-Box protein, 1189 functions in light signalling by suppressing HY5-regulated gene expression and 1190 interacting with STH2/BBX21. Plant Physiol. 156: 2109-2123.

1191 Huang, D.W., Sherman, B.T. and Lempicki, R.A. (2008) Systematic and integrative 1192 analysis of large gene lists using DAVID bioinformatics resources. Nature Protocols 1193 4: 44-57.

1194 Huang, J., Zhao, X. and Chory J. (2019) The Arabidopsis transcriptome responds 1195 specifically and dynamically to high light stress. Cell Reports 29: 4186-4199.

1196 Huang, X., Ouyang, X. and Deng, X.W. (2014) Beyond repression of 1197 photomorphogenesis: role switching of COP/DET/FUS in light signalling. Curr. Op. 1198 Plant Biol. 21: 96-103.

1199 Inzé, A., Vanderauwera, S., Hoeberichts, F.A., Vandorpe, M., Van Gaever, T. and 1200 Van Breusegem, F. (2012) A subcellular localization compendium of hydrogen 1201 peroxide-induced proteins. Plant Cell Environ. 35: 308-320. 
1202

1203

1204

1205

1206

1207

1208

1209

1210

1211

1212

1213

1214

1215

1216

1217

1218

1219

1220

1221

1222

1223

1224

1225

1226

1227

1228

1229

1230

1231

1232

1233

Jones M.A., Hu, W., Litthauer, S., Lagarias, J.C. and Harmer, S.L. (2015)

A constitutively active allele of phytochrome $B$ maintains circadian robustness in the absence of light. Plant Physiol. 169: 814-825.

Jung, H.-S., Crisp, P.A., Estavillo, G.M., Cole, B., Hong, F., Mocklere, T.C., Pogson, B.J. and Chory, J. (2013) Subset of heat-shock transcription factors required for the early response of Arabidopsis to excess light. Proc. Natl. Acad. Sci. USA 110: 14474-14479.

Kamal, N.M., Gorafi, Y.S.A., Abdelrahman, M., Abdellatef, E. and Tsujimoto, H. (2019) Stay green trait: A prospective approach for yield potential, and drought and heat stress adaptation in globally important cereals. Int. J. Mol. Sci. 20: art. 5837.

Kangasjärvi, S., Neukermans, J., Li, S., Aro, E.-M. and Noctor, G. (2012)

Photosynthesis, photorespiration, and light signalling in defence responses. J. Exp. Bot. 63: 1619-1636.

Karpinski, S., Escobar, C., Karpinska, B., Creissen, G. and Mullineaux, P.M. (1997) Photosynthetic electron transport regulates the expression of cytosolic ascorbate peroxidase gene in Arabidopsis during excess light stress. Plant Cell 9: 627-640.

Karpinski, S., Reynolds, H., Karpinska, B., Wingsle, G., Creissen, G. and Mullineaux, P.M. (1999) Systemic signalling and acclimation in response to excess excitation energy in Arabidopsis. Science 284: 654-657.

Kim, C., Meskauskiene, R., Zhang, S., Lee, K.P., Ashok, M.L., Blajecka, K., Herrfurth, C., Feussner,I. and Apel K. (2012) Chloroplasts of Arabidopsis are the source and a primary target of a plant-specific programmed cell death signaling pathway. Plant Cell 24: 3026-3039.

Kim, D., Langmead, B. and Salzberg, S.L. (2015) HISAT: a fast-spliced aligner with low memory requirements. Nature Methods 12: 357-360.

Kleine, T., Kindgren, P., Benedict, C., Hendrickson, L. and Strand Å. (2007)

Genome-wide gene expression analysis reveals a critical role for

CRYPTOCHROME1 in the response of Arabidopsis to high irradiance. Plant Physiol. 144: 1391-1406.

Koester, R.P., Skoneczka, J.A., Cary, T.R., Diers, B.W. and Ainsworth, E.A. (2014) Historical gains in soybean (Glycine max Merr.) seed yield are driven by linear 
1234 increases in light interception, energy conversion, and partitioning efficiencies. J. Exp. Bot. 65: 3311-3321.

1236 Kromdiijk, J., Glowacka, K., Leonelli, L., Gabilly, S.T., Iwai, M., Niyogi, K.K. and

1237 Long, S.P. (2016) Improving photosynthesis and crop productivity by accelerating 1238 recovery from photoprotection. Science 354: 857-861.

1239 Kumar, S.V. and Wigge, P.A. (2010) H2A.Z-containing nucleosomes mediate the 1240 thermosensory response in Arabidopsis. Cell 140: 136-147.

1241 Lau, K., Podolec, R., Chappuis, R., Ulm, R. and Hothorn, M. (2019) Plant

1242 photoreceptors and their signalling components compete for binding to the ubiquitin 1243 ligase COP1 using their VP-peptide motifs. EMBO J. 38: e102140.

1244 Lau, O.S. and Deng, X.W. (2012) The photomorphogenic repressors COP1 and 1245 DET1: 20 years later. Trends Plant Sci. 17: 584-593.

1246 Laubinger, S., Fittinghoff, K. and Hoecker, U. (2004) The SPA quartet: A family of 1247 WD-repeat proteins with a central role in suppression of photomorphogenesis in 1248 Arabidopsis. Plant Cell 16: 2293-2306

1249 Lawson, T., Davey, P.A., Yates, S.A., Bechtold, U., Baeshen, M., Baeshen, N., 1250 Mutwaktil, M.Z., Sabir, J., Baker, N.R., Mullineaux, P.M. (2014) C3 photosynthesis in 1251 the desert plant Rhazya stricta is fully functional at high temperatures and light 1252 intensities. New Phytol. 201: 862-873.

1253 Lee, J., He, K., Stolc, V., Lee, H., Figueroa, P., Gao, Y., Tongprasit, W., Zhao, H., 1254 Lee, I. and Deng, X.W. (2007) Analysis of transcription factor HY5 genomic binding 1255 sites revealed its hierarchical role in light regulation of development. Plant Cell 19: 1256 731-749.

1257 Leivar, P., Monte, E., Oka, Y., Liu, T., Carle, C., Castillon, A., Huq, E. and Quail, 1258 P.H. Multiple phytochrome-interacting bHLH transcription factors repress premature 1259 seedling photomorphogenesis in darkness. Curr. Biol. 18: 1815-1823.

1260 LePage, E., Zampini, É. and Brisson, N. (2013) Plastid genome instability leads to 1261 reactive oxygen species production and plastid-to-nucleus retrograde signalling in 1262 Arabidopsis. Plant Physiol. 163: 867-881.

1263 Lewis, L.L., Polanski, K., de Torres-Zabala, M., Jayaraman, S. Bowden, L., Moore, 1264 J., Penfold, C.A., Jenkins, D.J., Hill, C., Baxter, L., Kulasekaran, S., Truman, W., 
1265 Littlejohn G., Prusinska, J., Mead, A., Steinbrenner,J., Hickman, R., Rand, D., Wild, 1266 D.L., Ott, S., Buchanan-Wollaston, V., Smirnoff, N., Beynon, J., Denby, K. and Grant 1267 M. (2015) Transcriptional dynamics driving MAMP-triggered immunity and pathogen 1268 effector-mediated immunosuppression in Arabidopsis leaves following infection with 1269 Pseudomonas syringae pv tomato DC3000. Plant Cell 27: 3038-3064.

1270 Li, K., Gao, Z., He, H., Terzaghi, W., Fan, L.-M., Deng, X.W. and Chen, H. (2015). 1271 Arabidopsis DET1 represses photomorphogenesis in part by negatively regulating 1272 DELLA protein abundance in darkness. Mol. Plant 8: 622-630.

1273 Li, X., Björkman, O., Shih, C., Grossman, A.R., Rosenquist, M., Jansson, S. and 1274 Niyogi, K.K. (2000). A pigment-binding protein essential for regulation of 1275 photosynthetic light harvesting. Nature 403: 391-395.

1276 Li, Z., Wakao, S., Fischer, B.B. and Niyogi, K.K. (2009) Sensing and responding to 1277 excess light. Ann. Rev. Plant Biol. 60: 239-260.

1278 Lian, H.-L., He, S.-B., Zhang, Y.-C., Zhu, D.-M., Zhang, J.Y., Jia, K.-P., Sun, S.-X., 1279 Li, L. and Yang, H.-Q. (2011) Blue-light-dependent interaction of cryptochrome 1 with 1280 SPA1 defines a dynamic signaling mechanism. Genes Dev. 25:1023-1028.

1281 Liu Q., Su T., He W., Ren H., Liu S., Chen Y., Gao L., Hu X., Lu H., Cao S., Huang 1282 Y., Wang X., Wang, Q., and Lin, C. (2020) Photooligomerization determines 1283 photosensitivity and photoreactivity of plant cryptochromes. Mol. Plant. 13, 398-413.

1284 Long, S.P., Humphries, S. and Falkowski, P.G. (1994) Photoinhibition of 1285 photosynthesis in nature. Ann. Rev. Plant Biol .45: 633-662.

1286 Love, M.I., Huber, W. and Anders, S. (2014. Moderated estimation of fold change 1287 and dispersion for RNA-seq data with DESeq2. Genome Biol., 15: 550.

1288 Ma, D., Li, X., Guo, Y., Chu, J., Fang, S., Yan, C., Noel, J.P. and Liu, H. (2016) 1289 Cryptochrome 1 interacts with PIF4 to regulate high temperature-mediated hypocotyl 1290 elongation in response to blue light. Proc. Natl. Acad. Sci. USA 113: 224-229.

1291 Mittler, R., Vanderauwera, S., Gollery, M. and Van Breusegem, F. (2004) Reactive 1292 oxygen network of plants. Trends Plant Sci. 9: 490-498. 
1293 Moriyama, E.N., Strope, P.K., Opiyo, S.O., Chen, Z. and Jones, A.M. (2006). Mining

1294 the Arabidopsis thaliana genome for highly-divergent seven transmembrane 1295 receptors. Genome Biol. 7: R96.

1296 Mullineaux, P.M., Exposito-Rodriguez, M., Laissue, P.P. and Smirnoff, N. (2018)

1297 ROS-dependent signaling pathways in plants and algae exposed to high light:

1298 Comparisons with other eukaryotes. Free Rad. Biol. Med. 122: 52-64.

1299 Murchie, E.H. and Horton, P. (1997) Acclimation of photosynthesis to irradiance and 1300 spectral quality in British plant species: chlorophyll content, photosynthetic capacity 1301 and habitat preference. Plant Cell Environ. 20: 438-448.

1302 Murchie, E.H., Hubbert, S., Peng, S. and Horton, P. (2005). Acclimation of photosynthesis to high irradiance in rice: gene expression and interactions with leaf development. J. Exp. Bot. 56: 449-460.

Naznin, M.T., Lefsrud, M., Gravel, V. and Azad, M.O.K. (2019) Blue light added with red LEDS enhance growth characteristics, pigments content, and antioxidant capacity in lettuce, spinach, kael, Basil and sweet pepper in a controlled environment. Plants 8: art. 93.

1309 Oelze, M.-L., Vogel, M.O., Alsharafa, K., Kahmann, U., Viehhauser, A., Maurino, 1310 V.G. and Dietz, K.-J. (2012) Efficient acclimation of the chloroplast antioxidant defence of Arabidopsis thaliana leaves in response to a 10- or 100-fold light increment and the possible involvement of retrograde signals. J. Exp. Bot. 63: 129713131313.

1314 Oguchi, R., Hikosaki, K. and Hirose, T. (2003) Does the photosynthetic light1315 acclimation need change in leaf anatomy? Plant Cell Environ. 26: 505-512.

1316 Overmyer, K., Köllist, H., Tuominen, H., Betz, C., Langebartels, C., Wingsle, G., 1317 Kangasjärvi, S., Brader, G., Mullineaux, P. and Kangasjärvi, J. (2008) Complex 1318 phenotypic profiles leading to ozone sensitivity in Arabidopsis thaliana mutants. Plant 1319 Cell Environ. 31: 1237-1249.

1320 Oyama,T., Shimura, Y. and Okada, K. (1997) The Arabidopsis HY5 gene encodes a 1321 bZIP protein that regulates stimulus-induced development of root and hypocotyl. 1322 Genes Dev. 11: 2983-2995. 
1323 Park, H.-Y., Lee, S.-Y., Seok, H.-Y., Kim, S.-H., Sung, Z.R. and Moon, Y.-H. (2011)

1324 EMF1 interacts with EIP1, EIP6 or EIP9 involved in the regulation of flowering time in 1325 Arabidopsis. Plant Cell Physiol. 52: 1376-1388.

1326 Pedmale, U., Huang, S.C., Zander, M., Cole, B.J., Hetzel, J., Ljung, K., Reis, P.A.B., 1327 Sridevi, P., Nito, K., Nery, J.R., Ecker, J.R. and Chory, J. (2015) Cryptochromes 1328 interact directly with PIFs to control plant growth in limiting blue light. Cell, 163: 2331329245.

1330 Penfold, C.A. and Wild, D.L (2011) How to infer gene networks from expression 1331 profiles, revisited. Interface Focus 1: 857-870.

1332 Penfold, C.A. and Buchanan-Wollaston, V. (2014) Modelling transcriptional networks 1333 in leaf senescence. J. Exp. Bot. 65: 3859-3873.

1334 Pham, V.C., Xu, X. and Huq, E. (2018) Molecular bases for the constitutive 1335 photomorphogenic phenotypes in Arabidopsis. Development 145: dev169870.

1336 Piasecka, A., Jedrzejczak-Rey, N. and Bednarek, P. (2015) Secondary metabolites 1337 in plant innate immunity: conserved function of divergent chemicals. New Phytol. 1338 206: 948-964.

1339 Preuss, S.B., Meister, R., Xu, Q., Urwin, C.P., Tripodi, F.A., Screen, S.E., Anil, V.S., 1340 Zhu, S., Morrell, J.A., Liu, G., Ratcliffe, O.J., Reuber, L., Khanna, R., Goldman, B.S., 1341 Bell, E., Ziegler, T.E., McClerren, A.L., Ruff, T.G. and Petracek, M.E. (2012).

1342 Expression of the Arabidopsis thaliana BBX32 gene in soybean increases grain 1343 yield. PLoS ONE 7: e30717.

1344 Ramel, F., Birtic, S., Ginies, C., Soubigopu-Taconnat, L., Triantaphylidès, S. and 1345 Havaux, M. (2012) Carotenoid oxidation products are stress signals that mediate 1346 gene responses to singlet oxygen in plants. Proc. Natl. Acad. Sci. USA 109: 553513475540.

1348 Ramel, F., Ksas, B., Akkari, E., Mialoundama, A.S., Monnet, F., Krieger-Liszkay, A., 1349 Ravanat, J.-L., Mueller, M.J., Bouvier, F. and Havaux, M. (2013) Light-induced 1350 acclimation of the Arabidopsis chlorina1 mutant to singlet oxygen. Plant Cell, 25: 1351 1445-1462. 
bioRxiv preprint doi: https://doi.org/10.1101/2020.12.23.424212; this version posted December 26, 2020. The copyright holder for this preprint (which was not certified by peer review) is the author/funder, who has granted bioRxiv a license to display the preprint in perpetuity. It is made available under aCC-BY 4.0 International license.

1352 Reed, J., Nagatani, A., Elich, T., Fagan, M. and Chory, J. (1994) Phytochrome A and 1353 phytochrome B have overlapping but distinct functions in Arabidopsis development. 1354 Plant Physiol. 104: 1139-1149.

1355 Rossel, B., Wilson, P. B., Hussain, D., Woo, N.S., Gordon, M.J., Mewett, O.P., 1356 Howell, K.A., Whelan, J., Kazan, K. and Pogson, B.J. (2007) Systemic and 1357 intracellular responses to photooxidative stress in Arabidopsis. Plant Cell 19: 409113584110.

1359 Ruban, A.V. and Belgio, E. (2014) The relationship between maximum tolerated light 1360 intensity and photoprotective energy dissipation in the photosynthesis antenna: chloroplast gains and losses. Phil. Trans. R. Soc. B 369: 20130222. Ruckle, M.E., DeMarco, S.M. and Larkin, R.M. (2007) Plastid signals remodel light signalling networks and are essential for efficient chloroplast biogenesis in Arabidopsis. Plant Cell 19: 3944-3960.

1365 Schiebe, R. (2004) Malate valves to balance cellular energy supply. Physiol. Plant. 1366 120: 21-26.

1367 Schiebe, R. and Dietz, K.-J. (2012) Reduction-oxidation network for flexible 1368 adjustment of cellular metabolism in photoautotrophic cells. Plant Cell Environ. 35: 1369 202-216.

1370 Schottler, M.A. and Toth, S.Z. (2014) Photosynthetic complex stoichiometry 1371 dynamics in higher plants: environmental acclimation and photosynthetic flux control. 1372 Frontiers Plant Sci. 5: article 188.

1373 Sclep, G., Allemeersch, J., Liechti, R., De Meyer, B., Beynon, J., Bhalerao, R., 1374 Moreau, Y., Nietfeld, W., Renou, J-P., Reymond, P., Kuiper, M.T.R. and Hilson, P. 1375 (2007) CATMA, a comprehensive genome-scale resource for silencing and transcript 1376 profiling of Arabidopsis genes. BMC Bioinformatics 8: 400.

1377 Shaikhali, J., Barajas-Lopéz, J.D., Ötvös, K., Kremnev, D., Garcia, A.S., Srivastava, 1378 V., Wingsle, G., Bako, L. and Strand, A. (2012) The CRYPTOCHROME1-dependent 1379 response to excess light is mediated through the transcriptional activators ZINC 1380 FINGER PROTEIN EXPRESSED IN INFLORESCENCE MERISTEM LIKE1 and 1381 ZML2 in Arabidopsis. Plant Cell 24: 3009-3025. 
1382

1383

1384

1385

1386

1387

1388

1389

1390

1391

1392

1393

1394

1395

1396

1397

1398

1399

1400

1401

1402

1403

1404

1405

1406

1407

1408

1409

1410

1411

Shannon, P., Markiel, A., Ozier, O., Baliga, N.S., Wang, J.T., Ramage, D., Amin, N., Schwikowski, B. and Ideker ,T. (2003) Cytoscape: a software environment for integrated models of biomolecular interaction networks. Genome Res. 13: 24982504.

Shao, N., Duan, G.Y. and Bock, R. (2013) A mediator of singlet oxygen responses in Chlamydamonas reinhardtii and Arabidopsis identified by a luciferase-based genetic screen in algal cells. Plant Cell 25: 4209-4226.

Shepherd, M.J., Lindsey, L.E. and Lindsey, A.J. (2018). Soybean canopy cover measured with Canopeo compared with light interception. Agric. Environ. Lett. 3: 180031.

Shikata H., Hanada, K., Ushijima, T., Nakashima, M., Suzuki, Y. and Matsushita, T. (2014) Phytochrome controls alternative splicing to mediate light responses in Arabidopsis. Proc. Natl. Acad. Sci. USA 111: 18781-18786.

Song, Y., Jiang, Y., Kuai, B. and Li, L. (2018) CIRCADIAN CLOCK-ASSOCIATED 1 inhibits leaf senescence in Arabidopsis. Front. Plant Sci. 9: 280.

Stegle, O., Denby, K.J., Cooke, E.J., Wild, D.L., Ghahramani, Z., and Borgwardt, K.M. (2010). A robust Bayesian two-sample test for detecting intervals of differential gene expression in microarray time series. J. Comput. Biol. 17: 355-367.

Streb, P., Josse, E.-M., Gallouët, E., Baptist, F., Kuntz, M. and Cornic, G. (2005) Evidence for alternative electron sinks to photosynthetic carbon assimilation in the high mountain plant species Ranunculus glacialis. Plant Cell Environ. 28: 1123-1135.

Suorsa, M., Järvi, S., Grieco, M., Nurmi, M., Pietrzykowska, M., Rantala, M., Kangasjärvi, S., Paakkarinen, V., Tikkanen, M., Jansson, S. and Aro, E.-M. (2012) PROTON GRADIENT REGULATION5 is essential for proper acclimation of Arabidopsis photosystem I to naturally and artificially fluctuating light conditions. Plant Cell. 24: 2934-2948.

Terashima, I., Hanba, Y.T., Tholen, D. and Niinemets, Ü. (2011) Leaf functional anatomy in relation to photosynthesis. Plant Physiol. 155: 108-116.

Toledo-Ortiz, G., Huq, E. and Quail, P.H. (2003) The Arabidopsis Basic/Helix-LoopHelix transcription factor family. Plant Cell 15: 1749-1770. 
bioRxiv preprint doi: https://doi.org/10.1101/2020.12.23.424212; this version posted December 26, 2020. The copyright holder for this preprint (which was not certified by peer review) is the author/funder, who has granted bioRxiv a license to display the preprint in perpetuity. It is made available under aCC-BY 4.0 International license.

1412 Toledo-Ortiz, G., Johansson, H., Lee, K.P., Bou-Torrent, J., Stewart, K., Steel, G., 1413 Rodriguez-Concepción, M. and Halliday, K.J. (2014) The HY5-PIF regulatory module 1414 coordinates light and temperature control of photosynthetic gene transcription. PLOS 1415 Genetics 10: e1004416.

1416 Triantaphyllidès, C., Krischke, M., Hoeberichts, F.A., Ksas, B., Gresser, G., Havaux, 1417 M., Van Breusegem, F. and Mueller, M.J. (2008) Singlet oxygen is the major reactive 1418 oxygen species involved in photooxidative damage to plants. Plant Physiol. 148: 1419 960-968.

1420 Tripathi, P., Carvallo, M., Hamilton, E.E., Preuss, S. and Kay, S.A. (2017)

1421 Arabidopsis B-BOX32 interacts with CONSTANS-LIKE3 to regulate flowering. Proc.

$1422 \quad$ Natl. Acad. Sci. USA 114: 172-177.

1423 Underwood, W. (2012) The plant cell wall: a dynamic barrier against pathogen 1424 invasion. Frontiers Plant Sci. 3: Article 85.

1425 Van Acken, O. and Whelan, J. (2012) Comparison of transcriptional changes to 1426 chloroplast and mitochondrial perturbations reveals common and specific responses 1427 in Arabidopsis. Fronters Plant Sci. 3: article 291.

1428 Vandenabeele, S., Vanderauwera, S., Vuylsteke, M., Rombauts, S., Langebartels, 1429 C., Seidlitz, H.K., Zabeau, M., Van Montagu, M., Inzé, D. and Van Breusegem, F. 1430 (2004) Catalase deficiency drastically affects gene expression induced by high light 1431 in Arabidopsis thaliana. Plant J. 39: 45-58.

1432 van Rooijen, R., Aarts, M.G.M. and Harbinson, J. (2015) Natural genetic variation for 1433 acclimation of photosynthetic light use efficiency to growth irradiance in Arabidopsis.

1434 Plant Physiol. 167: 1412-1429.

1435 Vermeirssen, V., De Clercq, I., Van Parys, T., Van Breusegem, F. and Van de Peer, 1436 Y. (2014) Arabidopsis ensemble reverse-engineered gene regulatory network 1437 discloses interconnected transcription factors in oxidative stress. Plant Cell 26: 465614384679.

1439 Vialet-Chabrand, S., Matthews J.S.A., Simkin, A.J., Raines, C.A and Lawson, T. 1440 (2017). Importance of fluctuations in light on plant photosynthetic acclimation. Plant 1441 Physiol. 173: 2163-2179. 
1442 Walters, R. G., Rogers, J.J.M., Shephard, F. and Horton, P. (1999) Acclimation of

1443 Arabidopsis thaliana to the light environment: the role of photoreceptors. Planta 209:

1444 517-527.

1445 Waters, M.T., Wang, P., Korkaric, M., Capper, R.G., Saunders, N.J. and Langdale, 1446 J.A. (2009) GLK transcription factors coordinate expression of the photosynthetic 1447 apparatus in Arabidopsis. Plant Cell 21: 1109-1128.

1448 Willems, P., Mhamdi, A., Stael, S., Storme, V., Kerchev, P., Noctor, G., Gevaert, K. 1449 and Van Breusegem, F. (2016) The ROS wheel: Refining transcriptional footprints.

1450 Plant Physiol. 171: 1720-1733.

1451 Windram, O., Madhou, P., McHattie, S., Hill, C., Hickman, R., Cooke, E., Jenkins, D. 1452 J., Penfold, C. A., Baxter, L., Breeze, E., Kiddle, S. J., Rhodes, J., Atwell, S., 1453 Kliebenstein, D. J., Kim, Y., Stegle, S., Borgwardt, K., Zhang, C., Tabrett, A., 1454 Legaie, R., Moore, J., Finkenstadt, B., Wild, D. L., Mead, A., Rand, D., Beynon, J., 1455 Ott, S., Buchanan-Wollaston, V. and Denby, K. J. (2012) Arabidopsis defense 1456 against Botrytis cinerea: Chronology and regulation deciphered by high-resolution 1457 temporal transcriptomic analysis. Plant Cell 24: 3530-3557.

1458 Windram, O. and Denby, K.J. (2015) Modelling signalling networks underlying plant 1459 defence. Curr. Op. Plant Biol. 27: 165-171.

1460 Wingler, A., Lea, P.J., Quick, W.P. and Leegood, R.C. (2000) Photorespiration: 1461 metabolic pathways and their role in stress protection. Phil. Trans. R. Soc. Lond. B

1463 Wingler, A., Purdy, S.J., Edwards, S.-A., Chardon, F. and Masclaux-Daubresse, C. 1464 (2010) QTL analysis for sugar-regulated leaf senescence supports flowering1465 dependent and -independent senescence pathways. New Phytol. 185: 420-433.

1466 Wituszyńska, W., Ślesak, I., Vanderauwera, S., Szechyńska-Hebda, M., Kornaś, A., 1467 Van Der Kelen, K., Mühlenbock, P., Karpińska, B., Maćkowski, S., Van Breusegem, 1468 F. and Karpiński, Stanisław (2013) LESION SIMULATING DISEASE1, ENHANCED 1469 DISEASE SUSCEPTIBILITY1, and PHYTOALEXIN DEFICIENT4 conditionally 1470 regulate cellular signaling homeostasis, photosynthesis, water use efficiency, and 1471 seed yield in Arabidopsis. Plant Physiol. 161: 1795-1805. 
1472 Xu, D., Li, J., Gangappa, S.N., Hettiarachchi, C., Lin, F., Andersson, M.X., Jiang, Y.,

1473 Deng, X.W. and Holm, M. (2014) Convergence of light and ABA signalling on the

1474 ABI5 promoter. PLOS Genetics 10: e1004197.

1475 Yoshida, Y., Sarmiento-Manus, R., Yamori, W., Ponce, M.R., Micol, J.L. and

1476 Tsukaya, H. (2018) The Arabidopsis phyB-9 mutant has a second-site mutation in

1477 the VENOSA4 gene that alters chloroplast size, photosynthetic traits, and leaf

1478 growth. Plant Physiol. 178: 3-6.

1479 Yu, X., Liu, H., Klejnot, J. and Lin, C. (2010) The cryptochrome blue light receptors.

1480 The Arabidopsis Book e0135; doi: 10.1199/tab.0135.

1481

1482

1483

1484

1485

1486

1487

1488

1489

1490

1491

1492

1493

1494

1495

1496

1497

1498

1499

1500

1501

1502

\section{FIGURE LEGENDS}

\section{Figure 1. Temporal patterns of gene expression in LL- and HL-exposed leaf 7.}

(A) Visual output of co-clustered expression values by SplineCluster. This was done for the 3844 genes already identified as differentially expressed in HL vs LL over the time of the experiment (see Results and Supplemental Dataset 1). The values range from $\log _{2} 2.5$ (red) to $-\log _{2} 2.0$ (green). The 43 temporal clusters can be counted in the accompanying dendrogram. The timepoints are shown on the $y$-axes for the HL and LL gene expression.

(B) The number of HL/LL differentially expressed probes at each time point.

Figure 2. Induction of dynamic acclimation by repeated daily exposure to $\mathrm{HL}$.

(A) Plants were exposed daily to $4 \mathrm{~h} \mathrm{HL}$ and Fq'/Fm' determined for mature leaves. After the HL, plants were dark adapted and imaged under increasing actinic PPFD from $200-$ to- $1400 \mu \mathrm{mol} \mathrm{m} \mathrm{m}^{-2} \mathrm{~s}^{-1}$ in $200 \mu \mathrm{mol} \mathrm{m} \mathrm{m}^{-2} \mathrm{~s}^{-1}$ increments every $5 \mathrm{~min}$. The data were collected as CF images and processed digitally to collect values from mature leaves. The plants were treated in this way daily for 5 days: day 1 (blue), day 2 (red), day 3 (olive green), day 4 (purple) and day 5 (light blue). The data (mean \pm SE) correspond to 38 plants at $24-28$ dpg over 6 experiments and the asterisks show differences in CF parameters between days 1 and 5 were significant $(P \leq 0.001$; ANOVA and TukeyHSD). The full statistical data comparing all days of HL exposure are provided in Supplemental Data Set 5. 
bioRxiv preprint doi: https://doi.org/10.1101/2020.12.23.424212; this version posted December 26, 2020. The copyright holder for this preprint (which was not certified by peer review) is the author/funder, who has granted bioRxiv a license to display the preprint in perpetuity. It is made available under aCC-BY 4.0 International license.

1503 (B) Daily changes in Fq'/Fm' plotted from the data in A and Supplemental Data Set 5 1504 (right panel). Fq'/Fm' values are from the same plants over the daily $\mathrm{HL}$ exposures 1505 showing the the increase in PSIl operating efficiency at $800 \mu \mathrm{mol} \mathrm{m}^{-2} \mathrm{~s}^{-1} \mathrm{PPFD}$ 1506 actinic light over the 5 days of the experiments.

1507 (C) Photosynthesis plotted as $\mathrm{CO}_{2}$ assimilation rate $(A)$ as a function of actinic PPFD 1508 in mature leaf 7 (mean \pm SE; $n=8$ plants for each treatment; $49 \mathrm{dpg}$ ).

1509 Measurements were taken the day after 1 (dashed lines) and 5 days (solid lines) of 1510 daily $4 \mathrm{~h} \mathrm{HL}$ exposures (blue lines) along with the LL control plants (red lines) not 1511 subjected to this treatment.

1512 (D) Photosynthesis plotted as $\mathrm{CO}_{2}$ assimilation rate $(A)$ as function of leaf internal $1513 \mathrm{CO}_{2}$ concentration $(\mathrm{Ci}$ ) in mature leaf 7 (mean $\pm \mathrm{SE} ; \mathrm{n}=8$ plants for each treatment; $151449 \mathrm{dpg}$ ). Measurements were taken the day after 5 days of daily $4 \mathrm{~h} \mathrm{HL}$ exposures 1515 (blue line) along with the LL control (red line). A was determined by Infra-Red Gas 1516 Analysis (see Methods). Asterisks indicate significant differences $(P<0.02$;

1517 covariant T and two-tailed F tests) between LL and HL-exposed plants.

1518 Figure 3. Inferred HL gene regulatory network. The network shown was 1519 generated from the time series expression data for HL DEGs. The DEGs code for 1520 transcription (co)factors that are also light- and/or PHYA/PHYB regulated in de1521 etiolating seedlings. The network was generated using VBSSM (threshold z-score = 1522 2.33; see Methods) and initially visualised using Cytoscape (v3.3.2; Shannon et al., 1523 2003) but re-drawn manually to improve clarity. The network shown is from the 1524 second iteration of the modelling, which omitted expression data for LHY (First 1525 iteration; Supplemental Fig. 4A). The genes depicted in rectangular nodes were 1526 responsive to $B B X 32$ over-expression in $\mathrm{HL}$ and / or LL exposed leaves and showed 1527 significantly $(\mathrm{P}<0.05$; Tukey HSD) by showing higher $(+)$ or lower $(+)$ transcript 1528 abundance than Col-0 (see Fig. 5). Locus codes for the network genes can be found 1529 in Methods.

1530 Figure 4. Dynamic acclimation in BBX32-OE and bbx32-1 plants. Fq'/Fm' values 1531 determined from images of $\geq 4$ mature leaves from 8 plants (24-28 dpg) over 2 1532 experiments (means \pm SE) which had first been exposed to $4 \mathrm{~h}$ HL each day for 5 1533 consecutive days (see Methods and legend of Figure 2). CF parameter values were 
bioRxiv preprint doi: https://doi.org/10.1101/2020.12.23.424212; this version posted December 26, 2020. The copyright holder for this preprint (which was not certified by peer review) is the author/funder, who has granted bioRxiv a license to display the preprint in perpetuity. It is made available under aCC-BY 4.0 International license.

1534 collected at a range of actinic PPFDs (as indicated) at the end of each daily $\mathrm{HL}$ 1535 exposure.

1536 (A) Fq'/Fm' values at day 1 (black lines) and day 5 (red lines) for mutant or OE 1537 plants (dashed line) and Col-0 (solid line) of the HL treatments for BBX32-10 and 1538 BBX32-12. Asterisks indicate difference between mutant genotype and Col-0 at day 15395 ( $P<0.01$; ANOVA and TukeyHSD).

1540 (B) Daily Fq'/Fm' values at $800 \mu \mathrm{mol} \mathrm{m} \mathrm{m}^{-2} \mathrm{~s}^{-1}$ PPFD actinic light of $b b \times 32-1$ compared 1541 with Col-0 showing differences that were significant $(P<0.01)$ only between days 2 1542 and 4.

1543 (C) Photosynthesis plotted as $\mathrm{CO}_{2}$ assimilation rate $(A)$ as a function of incident 1544 PPFD in mature leaf 7 of LL-grown BBX32-10 (green line) and BBX32-12 (red line) compared to Col-0 (blue line) plants. Data are the mean \pm SE; $n=4$ for each

1546 genotype at $49 \mathrm{dpg}$; Asterisk indicates significant differences $(P<0.02$; covariant $T$ 1547 and two-tailed $F$ tests) between Col-0 and BBX32-10 and BBX32-12 at a given 1548 PPFD. Leaf $A$, as a function of PPFD, was determined by Infra-Red Gas Analysis 1549 (see Methods).

1550 Figure 5. Partial validation of the BBX32-centric inferred gene regulatory 1551 network. The expression of 25 of the 47 TF genes in the inferred network showing 1552 the effect of $B B X 32$ over-expression. All the genes displayed significant differences 1553 ( $p<0.05$; ANOVA and Tukey HSD) in cDNA abundance in BBX32-OE plants 1554 compared with Col-0 under LL (suffix "a") and/or HL (suffix "b") conditions. Tabulated 1555 FPKM data for these genes can be found in Supplemental Data Set 7. Color codes 1556 are dark red and blue Col-0 and BBX32-OE plants in LL respectively, salmon pink 1557 and light blue are Col-0 and BBX32-OE plants in HL. The cluster number for each 1558 gene is shown on each graph.

1559 Figure 6. BBX32 over-expression in LL and HL-exposed leaves perturbs 1560 transcript level of photosynthesis-associated genes. Using RNAseq data, 1561 relative cDNA abundance of $B B X 32-O E$ compared with Col-0 of photosynthesis1562 associated genes was determined under LL and $3.5 \mathrm{~h}$ HL exposure. The transcripts 1563 encoding the above proteins all displayed a $>1.45$-fold greater or lesser abundance 1564 in fully expanded leaves of BBX32 -OE plants. The values are calculated from mean 1565 FPKM values $(n=4)$ and difference between Col-0 LL and Col-0 HL were significant 
1566 (P adj. < 0.05). In blue are the designated classifications for photosynthesis associated genes (https://www.kegg.jp/dbget-bin/www_bget?pathway+ath00195): AP, Antenna Protein; CBC, Calvin-Benson cycle enzyme; PET, photosynthetic electron transport protein; PSI and PSII, Photosystem I and II component proteins respectively. Most proteins are nuclear encoded but those marked with the suffix "C" are plastid encoded. Locus codes for the genes can be found in Methods.

1572 Figure 7. Comparisons of genes affected by BBX32 over-expression with DEGs 1573 responsive to $\mathrm{HL}$ in Col-0.

1574 (A) Venn diagram of overlapping DEGs between Col-0 and BBX32-OE plants under $\mathrm{LL}$ and $\mathrm{HL}$ conditions compared with DEGs responsive in Col-0 to 3.5h $\mathrm{HL}$ and generated by RNAseq. The relevant 3 groups of DEGs can be found in Supplemental Data Set 7.

(B) Venn diagram as in (A) except the BBX32-OE DEGs were compared with the time series HL DEGs in Supplemental Data Set 2, which were derived from microarray-based transcriptomics data (see Results and Methods). The DEGs in the overlapping segments are listed in Supplemental Data Set 10.

Figure 8. Dynamic acclimation of photoreceptor and HY5 mutants. The plots show the PSIl operating efficiencies (Fq'/Fm') determined from CF images of $\geq 4$ mature leaves from 8 plants (24-28 dpg) over 2 experiments (means $\pm S E$ ). The plants had been exposed to $4 \mathrm{~h} \mathrm{HL}$ each day for 5 consecutive days (see Methods and legend of Figure 2). CF parameter values were collected at a range of actinic PPFDs (as indicated on the X-axis) at the end of days 1 and 5 of $\mathrm{HL}$. The Fq'/Fm' values at day 1 (black lines) and day 5 (red lines) for mutant plants (dashed line) and Col-0 (solid line) of the HL treatments for (A) cry1-304, (B) cry1-M32, (C) YHB, (D) hy5-2 and (E) hy5-215. Asterisks (panels A, B, D, E) indicate significant difference between mutant compared with Col-0 at day 5 ( $P<0.01$; ANOVA and TukeyHSD).

1592 Upward arrows (panel C) indicate significant difference between YHB and Col-0 at 1593 day 1 ( $P<0.01$; ANOVA and TukeyHSD).

1594 Figure 9. Dynamic acclimation of photoreceptor signal transduction mutants.

1595 (A) Photosynthetic efficiency of the same single representative Col-0, cop1-4 and 1596 det1-1 plants after 1 and 5 days of daily $4 \mathrm{~h}$ HL exposure. The CF images are of 1597 Fq'/Fm' (PSIl operating efficiency) at a $400 \mu \mathrm{mol} \mathrm{m} \mathrm{m}^{-2} \mathrm{~s}^{-1}$ actinic PPFD. 
bioRxiv preprint doi: https://doi.org/10.1101/2020.12.23.424212; this version posted December 26, 2020. The copyright holder for this preprint (which was not certified by peer review) is the author/funder, who has granted bioRxiv a license to display the preprint in perpetuity. It is made available under aCC-BY 4.0 International license.

1598 (B - E) The plots show the PSIl operating efficiencies (Fq'/Fm') determined from CF 1599 images of from 8 plants (24-28 dpg) over 2 experiments (means \pm SE). The plants

1600 had been exposed to $4 \mathrm{~h} \mathrm{HL}$ each day for 5 consecutive days (see Methods and 1601 legend of Figure 2). Note that because of the size of the cop1-4, pifq and det1-1 1602 plants, data were collected from whole rosettes rather than from mature leaves. CF 1603 parameter values were collected at a range of actinic PPFDs (as indicated on the $\mathrm{x}$ 1604 axis) at the end of days 1 and 5 of HL. The Fq'/Fm' values at day 1 (black lines) and 1605 day 5 (red lines) for mutant plants (dashed line) and Col-0 (solid line) of the HL 1606 treatments for (B) cop1-4, (C) spa1,2,3, (D) det1-1 and (E) pifQ. Asterisks (panel E)

1607 indicate significant difference between mutant compared with Col-0 at day 5 ( $\mathrm{P}<$ 1608 0.01; ANOVA and TukeyHSD). Upward arrows (panels B, C) indicate significant 1609 difference between mutants and Col-0 at day $1(P<0.01$; ANOVA and TukeyHSD).

1610 Figure 10. Proposed regulation of dynamic acclimation by a B BX32-centric 1611 GRN. The above scheme, while was based on this study, incorporates features from 1612 schemes published on the photoreceptor-directed control of seedling 1613 photomorphogenesis (e.g. Holtan et al., 2011; Hoecker, 2017). Under LL growth 1614 conditions to which the plant is acclimated, all or a proportion of cellular CRY1 is not 1615 active and consequently COP1/SPA acts to negatively regulate GRN members 1616 including HY5 and BBX32. Upon exposure to HL, CRY1 is activated and blocks 1617 COP1/SPA, which in turn releases the GRN ultimately leading to the establishment 1618 of dynamic acclimation. However, a degree of negative regulation of dynamic 1619 acclimation is retained (dotted inverted T) under HL conditions to allow for flexibility 1620 in potential fluctuations in the light environment.

1621 Supplemental Figure 1. Examples of temporal differentially expressed clusters.

1622 These graphs are representative depictions of 6 of the 43 temporal clusters 1623 generated by SplineCluster (see Methods) from the 3844 DEGs identified from the $1624 \mathrm{HL}$ and LL time series microarray data. The graphs are program outputs, but the 1625 lettering has been enhanced for clarity.

1626 Supplemental Figure 2. A comparison of plants exposed to daily HL for 5 days 1627 with their equivalent age LL controls and induction of dynamic acclimation in 1628 older plants. 
(A) The CF parameter Fq'/Fm' and inset graphs of Fq'/Fv' and Fv'/Fm' of fully expanded leaves ( $\geq 4)$ from 4 Col-0 plants (24 - $28 \mathrm{dpg}$ ) through an incremental series of actinic PPFDs (from $200-1400 \mu \mathrm{mol} \mathrm{m} \mathrm{m}^{-2} \mathrm{~s}^{-1}$ ) as described in Methods and legend of Figure 2. The data were collected as CF images and processed digitally to collect values from expanded leaves. Prior to these measurements, the plants $(5 d$ $\mathrm{HL}$; dashed lines) were exposed to $\mathrm{HL}$ for $4 \mathrm{~h}$ per day for 5 days while control plants (5d LL; solid lines) were kept under LL conditions. CF data was collected on the fifth day after the final HL exposure. The data (means \pm SE) are combined from 5 plants from a single experiment.

(B) The CF parameters Fq'/Fm', Fq'/Fv' and Fv'/Fm' respectively of fully expanded leaves ( $\geq 4$ ) from 4 plants (44 - $48 \mathrm{dpg}$ ) through an incremental series of actinic PPFDs (from $200-1400 \mu \mathrm{mol} \mathrm{m}{ }^{-2} \mathrm{~s}^{-1}$ ) as described in Methods and legend of Figure 2. The data were collected and processed as in A. Prior to these measurements, the plants were exposed to $\mathrm{HL}$ for $4 \mathrm{~h}$ per day for 5 days, CF data being collected each day for 5 days: day 1 (blue), day 2 (red), day 3 (olive green), day 4 (purple) and day 5 (light blue). The data (means \pm SE) are combined from 6 plants from a single experiment. The differences between days 1 and 5 measurements from panels $A$ and $B$ were significant $(P<0.05$; ANOVA and TukeyHSD) for all CF parameters indicated by asterisks $\left(^{*}\right)$. A full statistical analysis is available in Supplemental Data Set 5 .

\section{Supplemental Figure 3. The HL exposure used does not produce extensive} photodamage to leaves.

(A) Fv/Fm values in leaf 7 of the plants in (A) prior to HL exposure, just after $6 \mathrm{~h}$ $\mathrm{HL}$ and $24 \mathrm{~h}$ later, having been returned to growth conditions. Plants were dark adapted for 30 min and Fv/Fm determined by CF imaging (see Methods).

(B) Relative ion leakage (conductivity) in leaf 7 of the plants in (A) after the $6 \mathrm{~h} \mathrm{HL}$ measurements compared with the LL control.

(C) Expression of $\mathrm{HL}$-responsive $\mathrm{H}_{2} \mathrm{O}_{2}$ marker genes (APX2 and FER1; Karpinski et al., 1997; 1999; Dietz et al., 2002; Ball et al 2004; Davletova et al., 2004; Mittler et al., 2004; Rossel et al., 2007; Oelze et al., 2012; Jung et al., 2013; Shao et al., 2013) and ${ }^{1} \mathrm{O}_{2}$ marker genes (AAA-ATPase and BAP1; Kim et al., 2012; Ramel et al., 2012; 2013; Shao et al., 2013). Log $_{2}$-transformed 
1662

1663

1664

1665

1666

1667

1668

1669

1670

1671

1672

1673

1674

1675

1676

1677

1678

1679

1680

1681

1682

1683

1684

1685

1686

1687

1688

1689

1690

1691

1692

1693

1694

fluorescence values (mean $\pm S E ; n=4$ ) were normalised with respect to the same values at the zero time point, are shown for the HL (dotted line) and LL (solid line) datasets, and asterisks denote statistical differences $(P<0.05$; Student's t test) at each timepoint.

\section{Supplemental Figure 4. The first draft inferred gene regulatory network and} dynamic acclimation in Ihy-21 plants.

(A) The network shown was generated from the time series expression data for HL DEGs. The networks were generated using VBSSM (threshold z-score $=2.33$; see Methods) and visualised using Cytoscape (v3.3.0; Shannon et al., 2003). The network shown is the first iteration of the modelling, which included expression data for $L H Y$. Those nodes coloured yellow highlight $L H Y, B B X 32$ and $H Y 5$.

(B) PSIl operating efficiency (Fq'/Fm') of fully expanded leaves $(\geq 4)$ from 4 Ws-0 and 4 Ihy21 plants (24 - $28 \mathrm{dpg}$ ) through an incremental series of actinic PPFDs (from $200-1400 \mu \mathrm{mol} \mathrm{m} \mathrm{m}^{-2} \mathrm{~s}^{-1}$ ) as described in Methods and legend of Figure 2. Prior to these measurements, the plants were exposed to $\mathrm{HL}$ for $4 \mathrm{~h}$ per day for a total of 5 days and the CF images were collected at day 1 (black lines) and day 5 (red lines) of the daily HL treatments for Ihy21 (dashed lines) and Col-0 (solid lines). The determination of the parameters was by CF imaging as described in the legend of Figure 2 and Methods. The data (means \pm SE) are combined from 5 plants from a are nodes of $\geq 3$ edges (connections) in the GRN shown in Figure 3 . The data are from the microarray time series transcriptomics (Fig.1A; Supplemental Data Set 1).

The numbers in parentheses is the temporal cluster to which each gene was assigned (Fig. 1; Supplemental Data Set 1). The asterisk denotes a significant difference at that time point between $L L$ and $H L$ samples $(P \leq 0.05$; ANOVA).

Supplemental Figure 6. Dynamic acclimation of phyB-9, phyA-211, cry2-1 and pif4-2 plants compared with Col-0.

The plots show the PSII operating efficiencies (Fq'/Fm') determined from CF images of $\geq 4$ mature leaves from 8 plants (24-28 dpg) from two experiments (means $\pm S E$ ) in (A-C) and a single experiment of 4 plants in (D). The plants had been exposed to 4h HL each day for 5 consecutive days (see Methods and legend of Figure 2). CF parameter values were collected at a range of actinic PPFDs (as indicated on the $x$ axis) at the end of days 1 and 5 of HL. The Fq'/Fm' values at day 1 (black lines) and day 5 (red lines) for mutant plants (dashed line) and Col-0 (solid line) of the HL 
1695

1696

1697

1698

1699

1700

1701

1702

1703

1704

1705

1706

1707

1708

1709

1710

1711

\section{2}

1713

1714

1715

1716

1717

1718

1719

1720

1721

treatments for (A) phyB-9, (B) phyA-211, (C) cry2-1 and (D) pif4-2. All CF data points comparing Col-0 and the mutants were not significantly different $(P>0.1$; ANOVA and TukeyHSD).

Supplemental Figure 7. Emission spectra for the growth lights and for the LEDisolight used to induced dynamic acclimation.

Supplemental Figure 8. Identification and characterisation of cry1-M32.

(A) Dark-adapted Fv/Fm measurements on Arabidopsis 2 weeks-old seedling taken by chlorophyll fluorescence imaging (see Methods). Plants $(n=15)$ were measured before $\mathrm{HL}$ exposure (LL), after 5 -fold $\mathrm{HL}$ exposure for 1 hour. Values are the means $\pm \mathrm{SE}$

(B) Fluence response curves of 6-d-old Col-0 and M32 mutant seedlings grown in blue light.

(C) (Effect of day length on flowering time. Chlorophylls (C) and anthocyanins.

(D) Chlorophyll content of 8 d.p.g. Col-0 and M32 mutant seedlings grown in continuous BL $\left(40 \mu \mathrm{mol} \cdot \mathrm{m}^{-2} \cdot \mathrm{s}^{-1}\right)$. Error bars represent SE.

(E) Anthocyanin content of the same seedlings as in (D).

(F) Mutation of M32 at the photolyase signature sequence of CRY1.

\section{Supplemental Figure 9. A randomized loop design employed for loading} samples onto the two-channel CATMA arrays.

A randomised loop design was employed for loading samples onto the two-channel CATMA arrays, enabling expression analysis between timepoints (measured in hours of treatment under LL or HL), both within and between treatments. (A) shows the within-treatment samples that were loaded on the same array, but differentially labelled with either Cy3 or Cy5, and (B) shows the cDNA samples from the two different treatments that were differentially labelled and loaded onto the same array. 

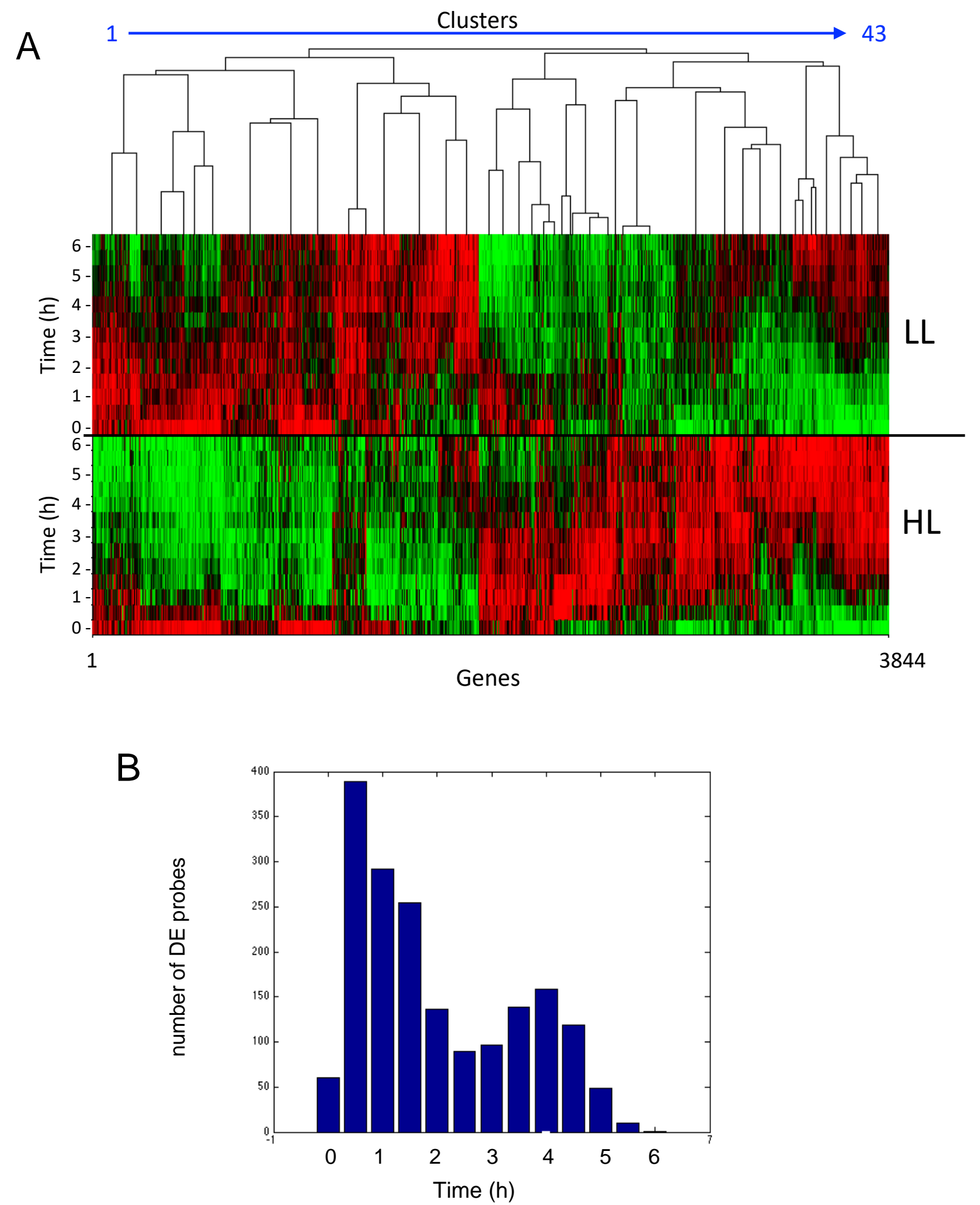

Figure 1. Temporal patterns of gene expression in LL- and HL-exposed leaf 7. A. Visual output of co-clustered expression values by SplineCluster. This was done for the 3844 genes already identified as differentially expressed in HL vs LL over the time of the experiment (see Results and Supplemental Dataset 1). The values range from $\log _{2}$ 2.5 (red) to $-\log _{2} 2.0$ (green). The 43 temporal clusters can be counted in the accompanying dendrogram. The timepoints are shown on the $y$-axes for the $\mathrm{HL}$ and $\mathrm{LL}$ gene expression.

B. The number of HL/LL differentially expressed probes first appearing at each time point. 
B
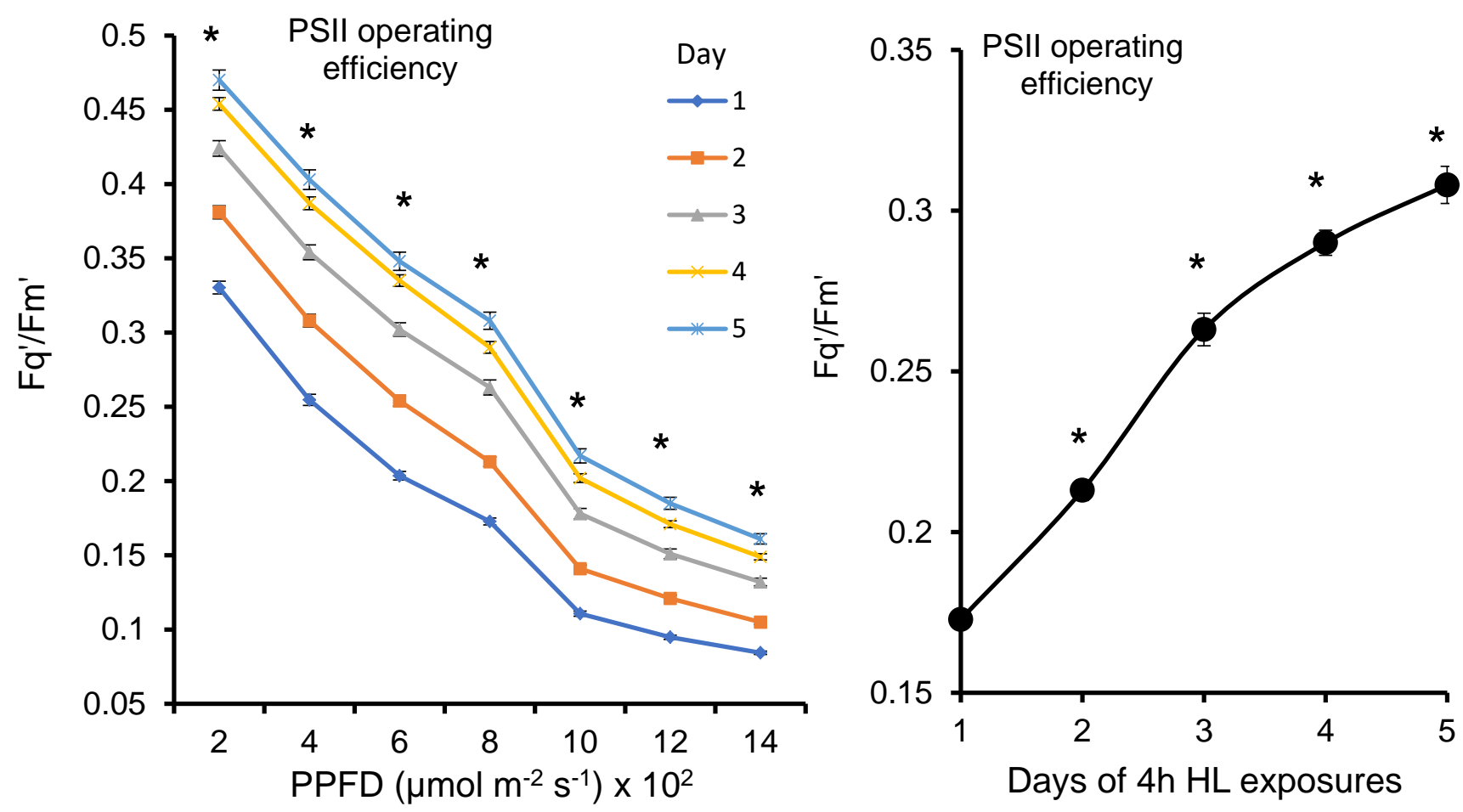

C

D
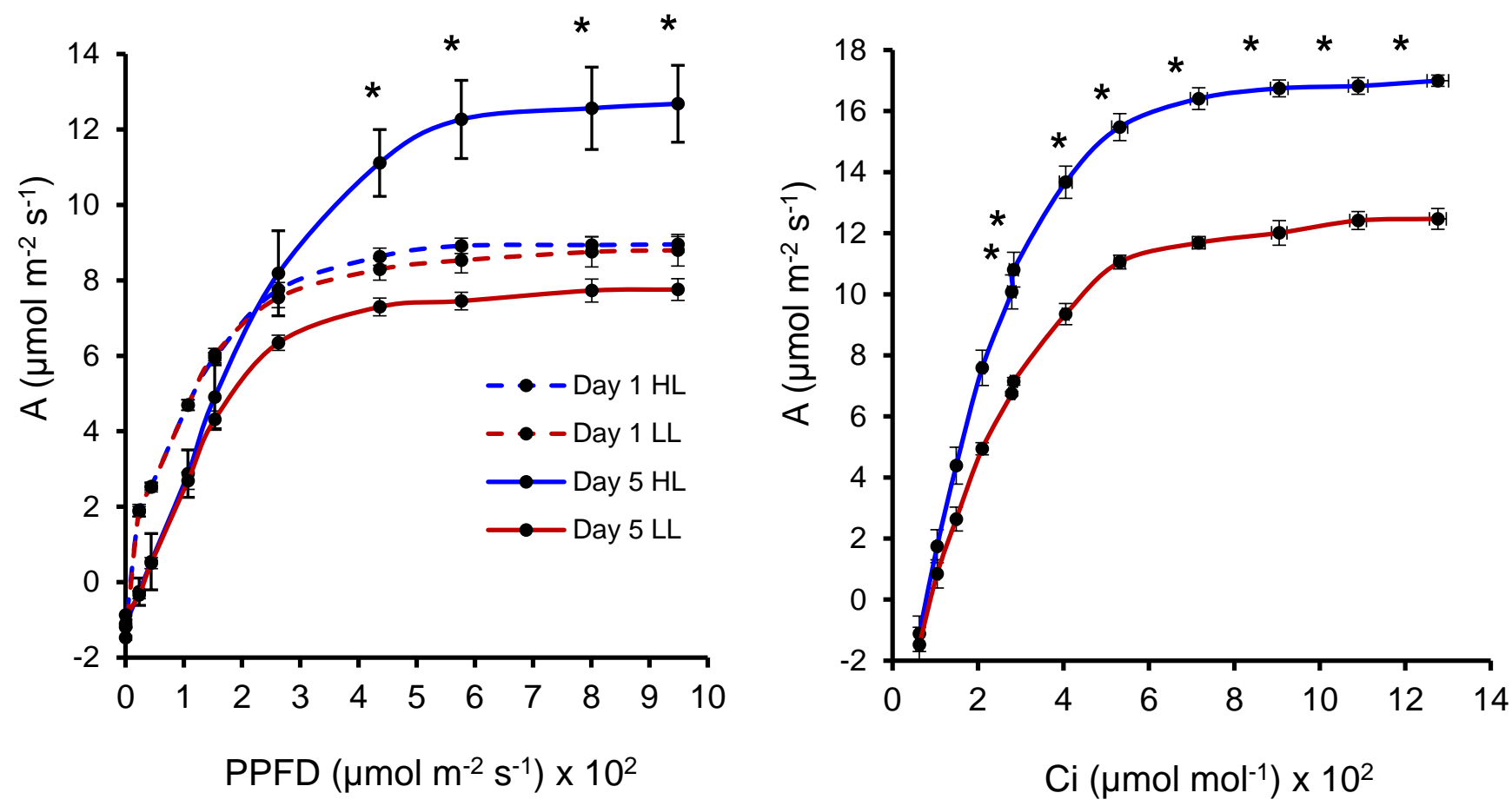

Figure 2 
Figure 2. Induction of dynamic acclimation by repeated daily exposure to HL.

(A) Plants were exposed daily to $4 \mathrm{~h} \mathrm{HL}$ and Fq'/Fm' determined for mature leaves. After the $\mathrm{HL}$, plants were dark adapted and imaged under increasing actinic PPFD from 200-to$1400 \mu \mathrm{mol} \mathrm{m}{ }^{-2} \mathrm{~s}^{-1}$ in $200 \mu \mathrm{mol} \mathrm{m}{ }^{-2} \mathrm{~s}^{-1}$ increments every $5 \mathrm{~min}$. The data were collected as CF images and processed digitally to collect values from mature leaves. The plants were treated in this way daily for 5 days: day 1 (blue), day 2 (red), day 3 (olive green), day 4 (purple) and day 5 (light blue). The data (mean \pm SE) correspond to 38 plants at $24-28$ dpg over 6 experiments and the asterisks show differences in CF parameters between days 1 and 5 were significant ( $P \leq 0.001$; ANOVA and TukeyHSD). The full statistical data comparing all days of HL exposure are provided in Supplemental Data Set 5.

(B) Daily changes in Fq'/Fm' plotted from the data in A and Supplemental Data Set 5 (right panel). Fq'/Fm' values are from the same plants over the daily $\mathrm{HL}$ exposures showing the the increase in PSII operating efficiency at $800 \mu \mathrm{mol} \mathrm{m}^{-2} \mathrm{~s}^{-1}$ PPFD actinic light over the 5 days of the experiments.

(C) Photosynthesis plotted as $\mathrm{CO}_{2}$ assimilation rate $(A)$ as a function of actinic PPFD in mature leaf 7 (mean $\pm S E ; n=8$ plants for each treatment; $49 \mathrm{dpg}$ ). Measurements were taken the day after 1 (dashed lines) and 5 days (solid lines) of daily 4h HL exposures (blue lines) along with the LL control plants (red lines) not subjected to this treatment.

(D) Photosynthesis plotted as $\mathrm{CO}_{2}$ assimilation rate $(A)$ as function of leaf internal $\mathrm{CO}_{2}$ concentration $(\mathrm{Ci})$ in mature leaf 7 (mean $\pm \mathrm{SE} ; \mathrm{n}=8$ plants for each treatment; $49 \mathrm{dpg}$ ). Measurements were taken the day after 5 days of daily $4 \mathrm{~h} \mathrm{HL}$ exposures (blue line) along with the LL control (red line). A was determined by Infra-Red Gas Analysis (see Methods). Asterisks indicate significant differences $(P<0.02$; covariant $T$ and two-tailed $F$ tests) between $\mathrm{LL}$ and $\mathrm{HL}$-exposed plants. 


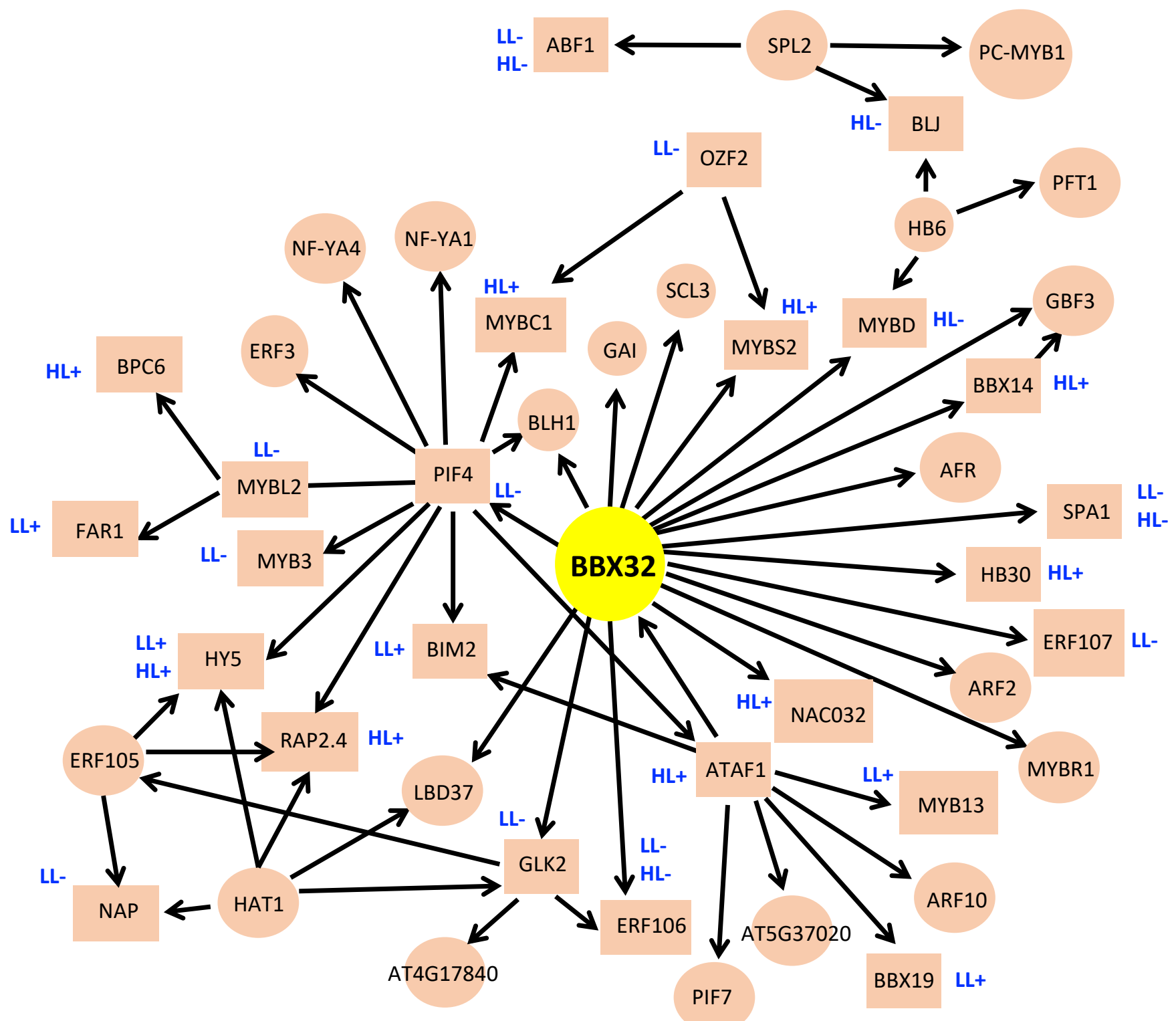

Figure 3. Inferred HL gene regulatory network centered on BBX32. The network shown was generated from the time series expression data for HL DEGs. The DEGs code for transcription (co)factors that are also light- and/or $P H Y A / P H Y B$ regulated in de-etiolating seedlings. The network was generated using VBSSM (threshold z-score = 2.33; see Methods) and initially visualised using Cytoscape (v3.3.2; Shannon et al., 2003) but re-drawn manually to improve clarity. The network shown is from the second iteration of the modelling, which omitted expression data for $L H Y$ (First iteration; Supplemental Fig. 4A). The genes depicted in rectangular nodes were responsive to $B B X 32$ over-expression in $\mathrm{HL}$ and / or LL exposed leaves by showing significantly $(\mathrm{P}<$ 0.05; Tukey HSD) higher (+) or lower (+) transcript abundance than Col-0 (see Fig. 5). Locus codes for the network genes can be found in Methods. 
A
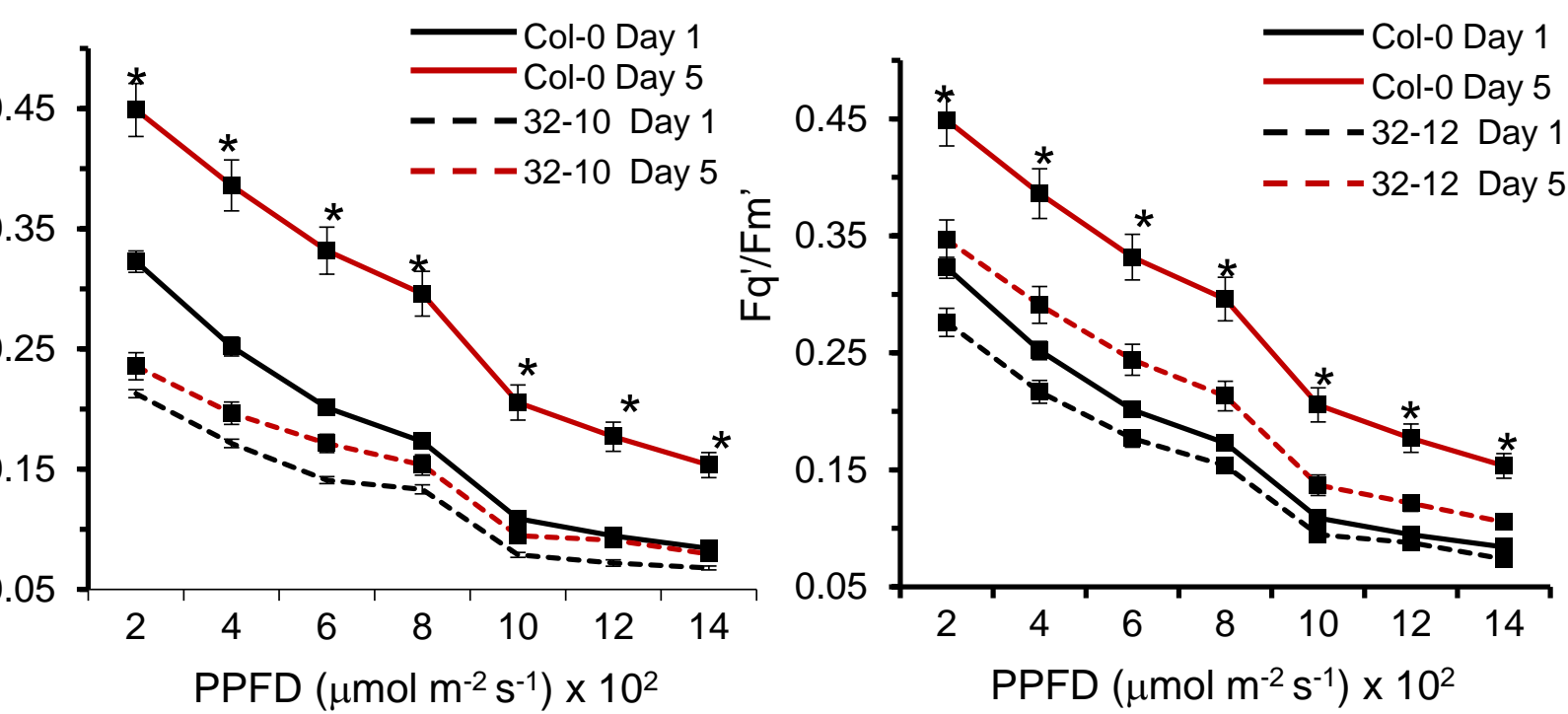

B
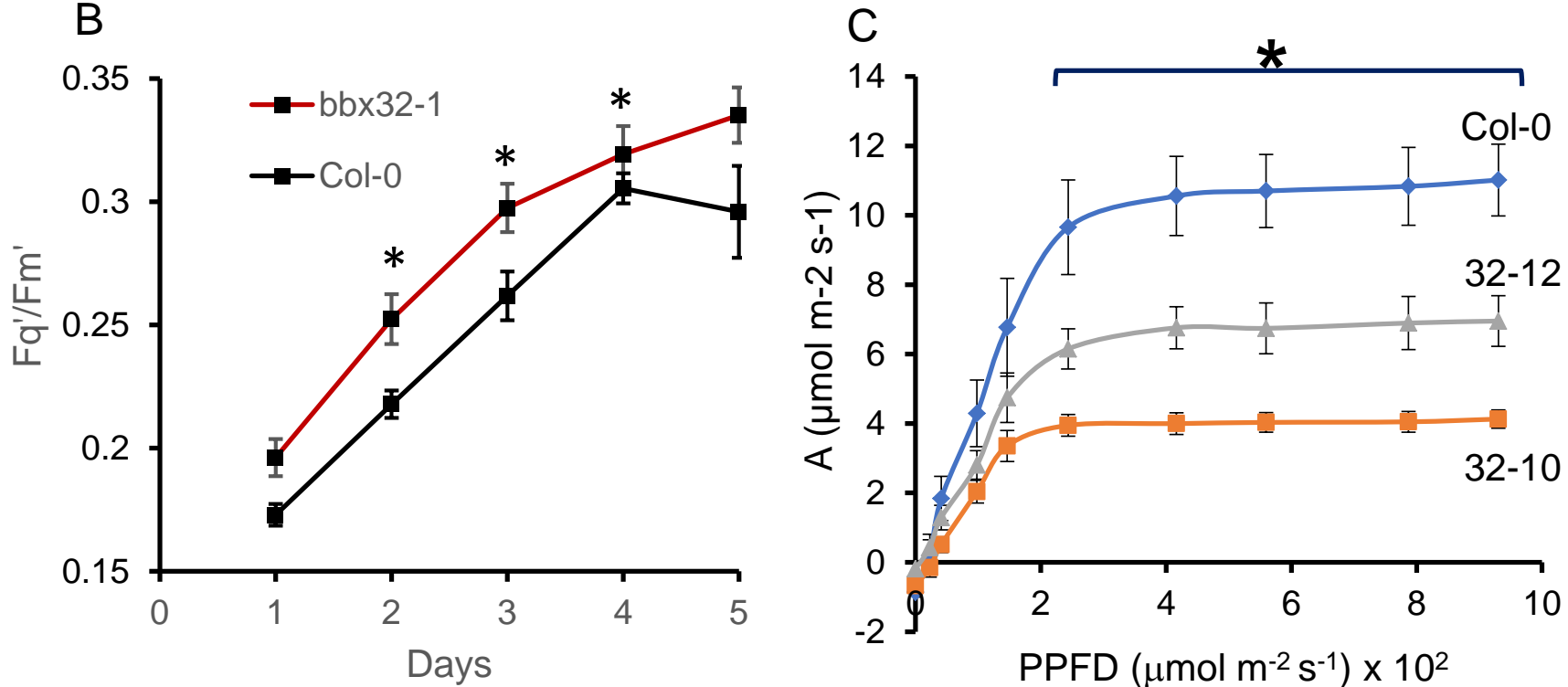

Figure 4. Dynamic acclimation in $B B X 32-\mathrm{OE}$ and $b b \times 32-1$ plants. $F q^{\prime} / F m^{\prime}$ values determined from images of $\geq 4$ mature leaves from 8 plants $(24-28 \mathrm{dpg})$ over 2 experiments (means \pm SE) which had first been exposed to $4 \mathrm{~h} \mathrm{HL}$ each day for 5 consecutive days (see Methods and legend of Figure 2). CF parameter values were collected at a range of actinic PPFDs (as indicated) at the end of each daily $\mathrm{HL}$ exposure. (A) Fq'/Fm' values at day 1 (black lines) and day 5 (red lines) for mutant or OE plants (dashed line) and Col-0 (solid line) of the HL treatments for BBX32-10 and BBX32-12. Asterisks indicate difference between mutant genotype and Col-0 at day $5(P<0.01$; ANOVA and TukeyHSD).

(B) Daily Fq'/Fm' values at $800 \mu \mathrm{mol} \mathrm{m} \mathrm{m}^{-2} \mathrm{~s}^{-1}$ PPFD actinic light of $b b \times 32-1$ compared with Col-0 showing differences that were significant $(\mathrm{P}<0.01)$ only between days 2 and 4 . (C) Photosynthesis plotted as $\mathrm{CO}_{2}$ assimilation rate $(A)$ as a function of incident PPFD in mature leaf 7 of LL-grown BBX32-10 (green line) and BBX32-12 (red line) compared to Col-0 (blue line) plants. Data are the mean \pm SE; $n=4$ for each genotype at $49 \mathrm{dpg}$; Asterisk indicates significant differences $(\mathrm{P}<0.02$; covariant $\mathrm{T}$ and two-tailed $\mathrm{F}$ tests) between Col-0 and BBX32-10 and BBX32-12 at a given PPFD. Leaf $A$, as a function of PPFD, was determined by Infra-Red Gas Analysis (see Methods). 

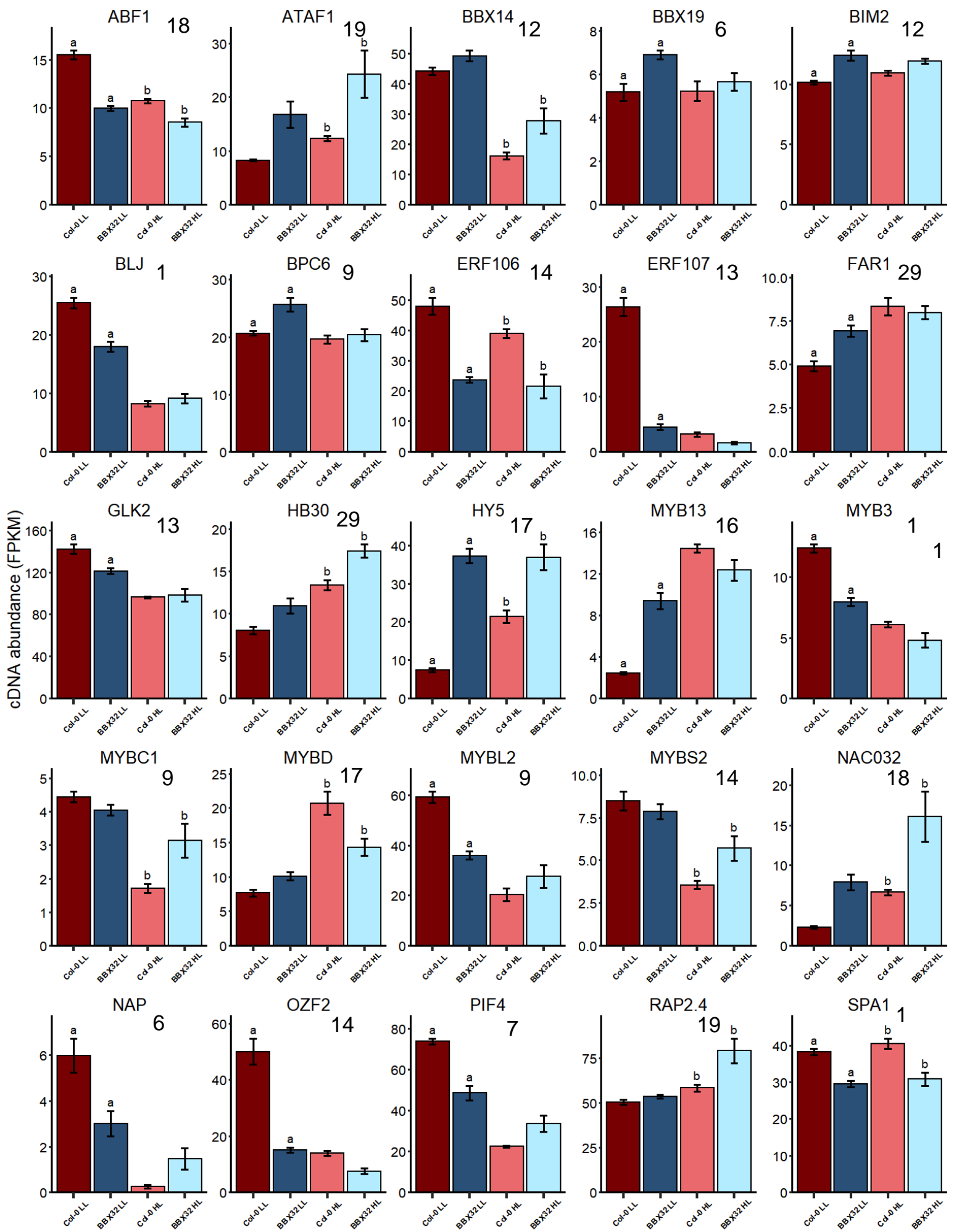

Figure 5. Partial validation of the BBX32-centric inferred gene regulatory network. The expression of 25 of the 47 TF genes in the inferred network showing the effect of $B B X 32$ overexpression. All the genes displayed significant differences ( $p<0.05$; Tukey HSD) in cDNA abundance in BBX32-OE plants compared with Col-0 under LL (suffix "a") and/or HL (suffix "b") conditions. Tabulated FPKM data for these genes can be found in Supplemental Data Set 7. Color codes are dark red and blue Col-0 and BBX32-OE plants in LL respectively, salmon pink and light blue are Col-0 and BBX32-OE plants in HL. The cluster number for each gene is shown on each graph.

Figure 5 

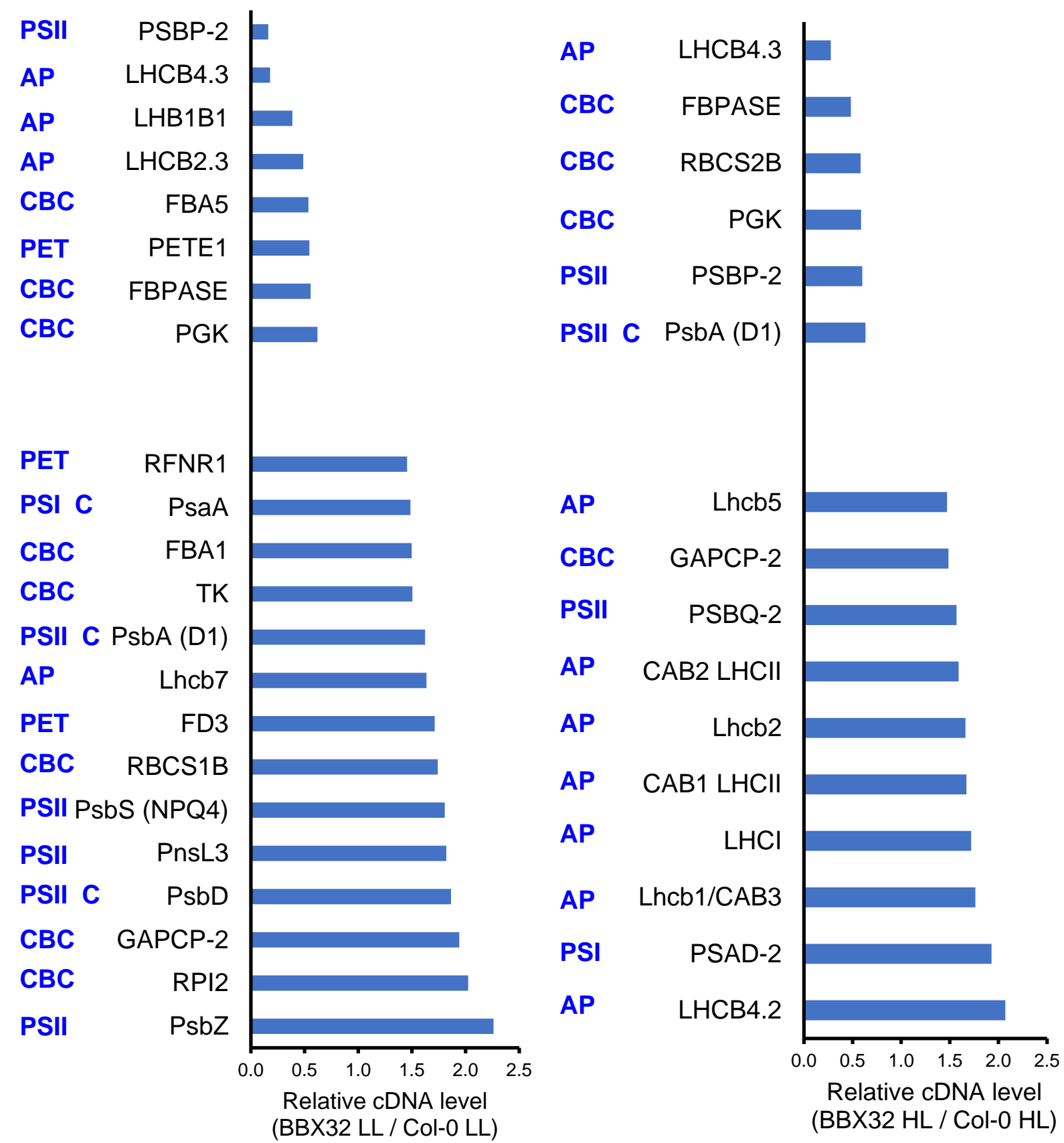

Figure 6. BBX32 over-expression in LL and HL-exposed leaves perturbs transcript level of photosynthesis-associated genes. Using RNAseq data, relative cDNA abundance of $B B X 32-O E$ compared with Col-0 of photosynthesis-associated genes was determined under $\mathrm{LL}$ and $3.5 \mathrm{~h} \mathrm{HL}$ exposure. The transcripts encoding the above proteins all displayed at $>1.45$-fold greater or lesser abundance in fully expanded leaves of BBX32 OE plants. The values are calculated from mean FPKM values $(n=4)$ and difference between Col-0 LL and Col-0 HL were significant (P adj. < 0.05). In blue are the designated classifications for photosynthesis associated genes (https://www.kegg.jp/dbgetbin/www bget?pathway+ath00195): AP, Antenna Protein; CBC, Calvin-Benson cycle enzyme; PET, photosynthetic electron transport protein; PSI and PSII, Photosystem I and II component proteins respectively. Most proteins are nuclear encoded but those marked with the suffix " $C$ " are plastid encoded. Locus codes for the genes can be found in Methods. 


\section{$P=2.25 E-308$}

HL/LL Col-0 DEGs

$P=1.25 E-107$

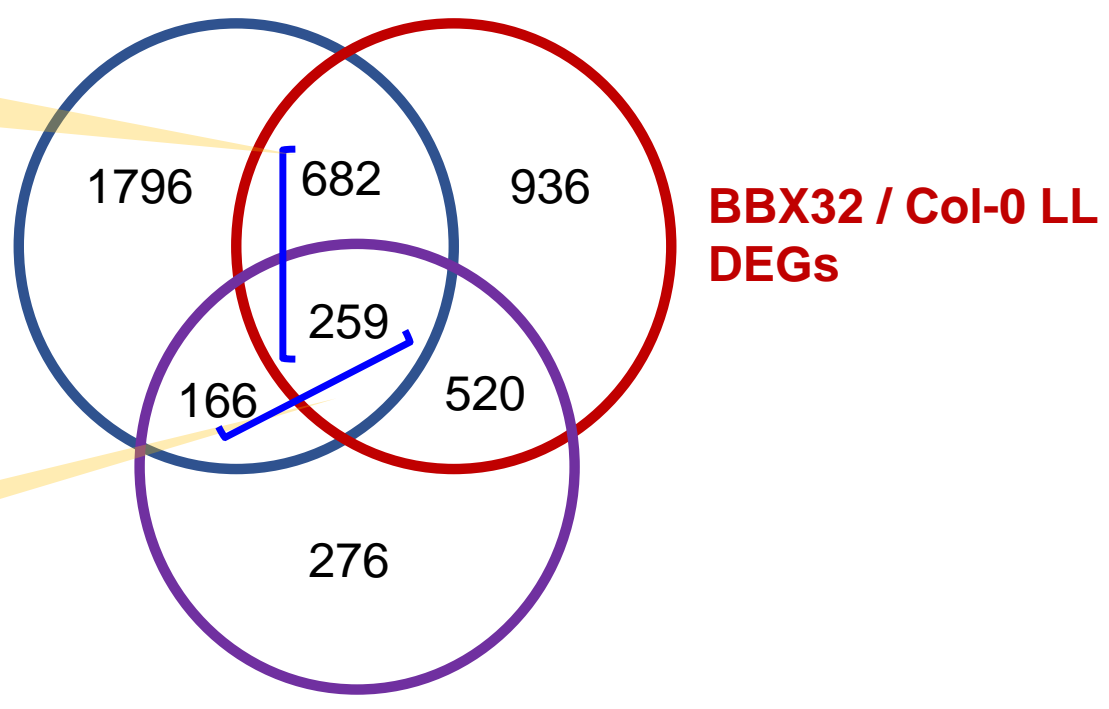

BBX32 / Col-0 HL DEGs

B

$$
P=9.3 E-03
$$

HL time series DEGs /

$$
P=3.87 E-08
$$

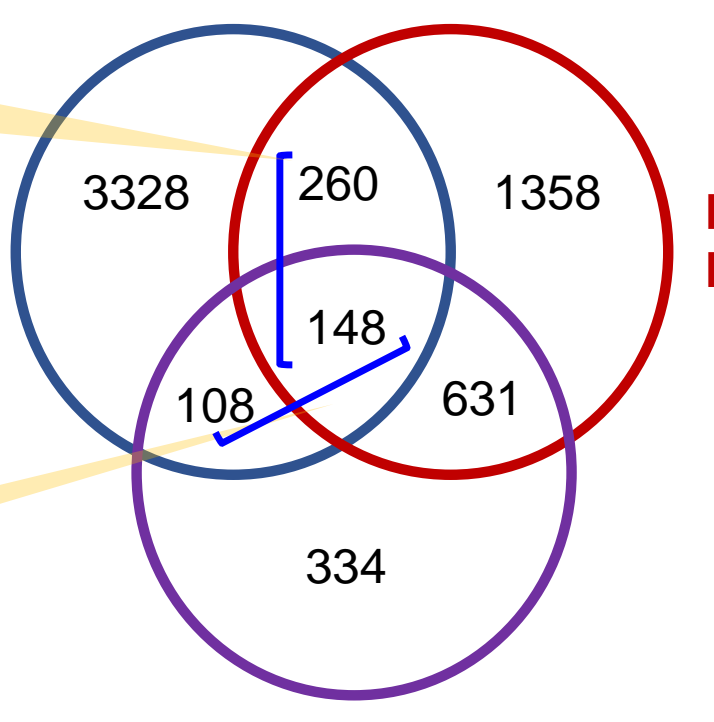

BBX32 / Col-0 LL DEGs

\section{BBX32 / Col-0 HL DEGs}

Figure 7. Comparisons of genes affected by BBX32 over-expression with DEGs responsive to $\mathrm{HL}$ in Col-0.

(A) Venn diagram of overlapping DEGs between Col-0 and BBX32-OE plants under $\mathrm{LL}$ and $\mathrm{HL}$ conditions compared with DEGs responsive in Col-0 to $3.5 \mathrm{~h} \mathrm{HL}$ and generated by RNAseq. The relevant 3 groups of DEGs can be found in Supplemental Data Set 7.

(B) Venn diagram as in (A) except the BBX32-OE DEGs were compared with the time series HL DEGs in Supplemental Data Set 1, which were derived from microarray-based transcriptomics data (see Results and Methods). The DEGs in the overlapping segments are listed in Supplemental Data Set 10. 


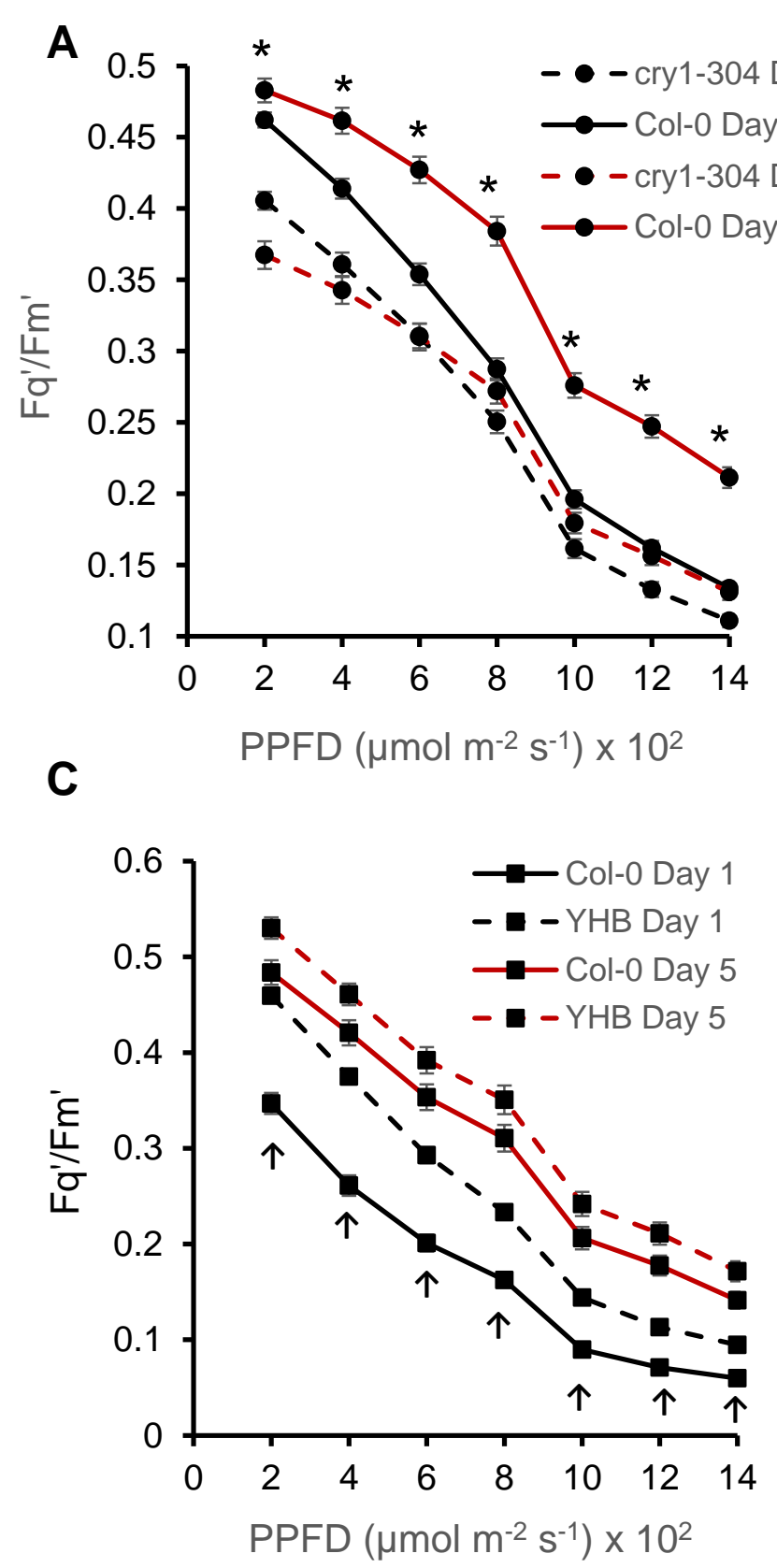

B
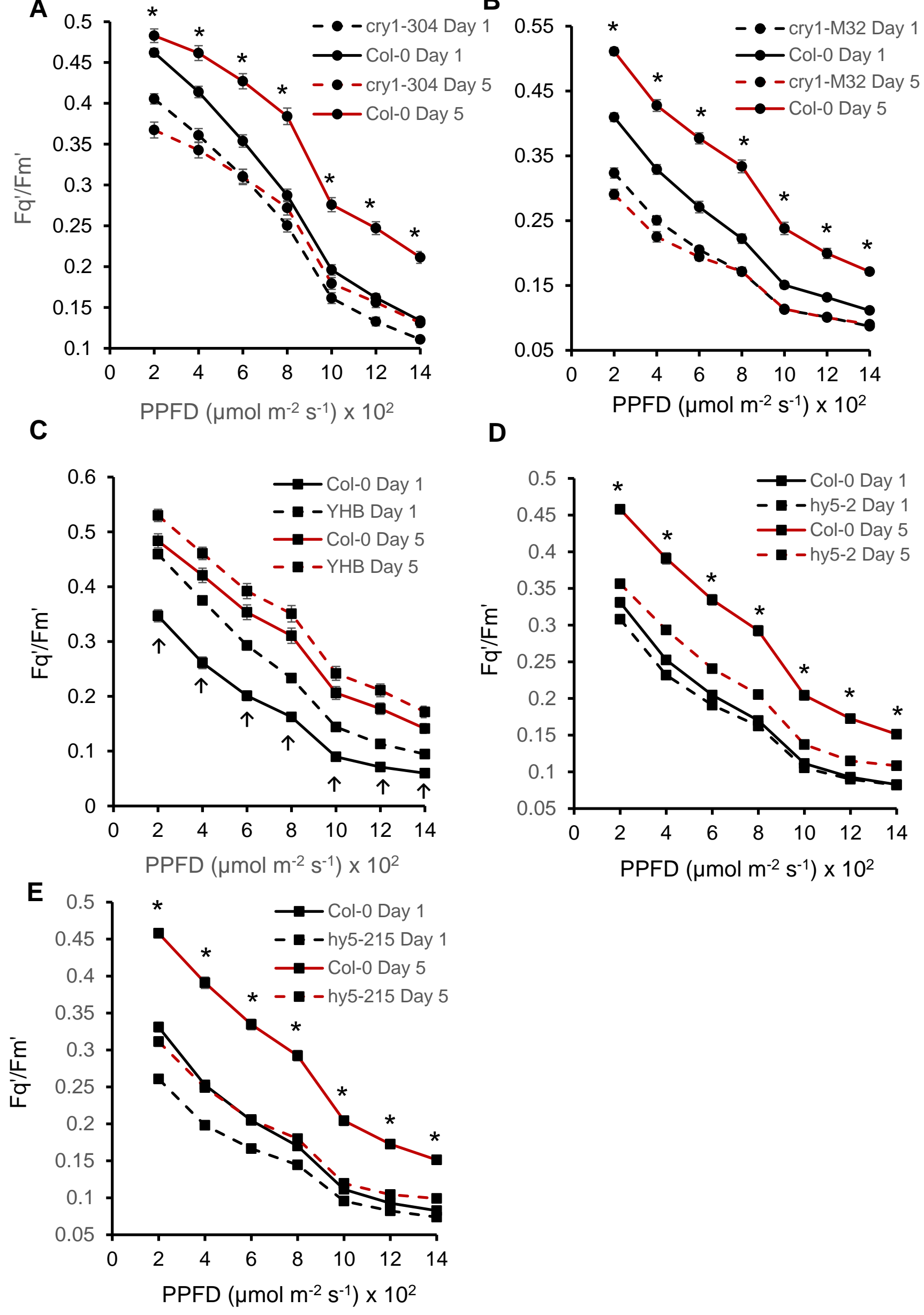

Figure 8 
Figure 8. Dynamic acclimation of photoreceptor and HY5 mutants. The plots show the PSIl operating efficiencies ( $\left.F q^{\prime} / F m^{\prime}\right)$ determined from CF images of $\geq 4$ mature leaves from 8 plants $(24-28 \mathrm{dpg}$ ) over 2 experiments (means \pm $\mathrm{SE}$ ). The plants had been exposed to $4 \mathrm{~h} \mathrm{HL}$ each day for 5 consecutive days (see Methods and legend of Figure 2). CF parameter values were collected at a range of actinic PPFDs (as indicated on the $x$-axis) at the end of days 1 and 5 of $\mathrm{HL}$. The Fq'/Fm' values at day 1 (black lines) and day 5 (red lines) for mutant plants (dashed line) and Col-0 (solid line) of the HL treatments for (A) cry1-304, (B) cry1-M32, (C) YHB, (D) hy5-2 and (E) hy5-215. Asterisks (panels A, B, D, E) indicate significant difference between mutant compared with Col-0 at day 5 ( $P<$ 0.01; ANOVA and TukeyHSD). Upward arrows (panel C) indicate significant difference between YHB and Col-0 at day 1 ( $P<0.01$; ANOVA and TukeyHSD). 

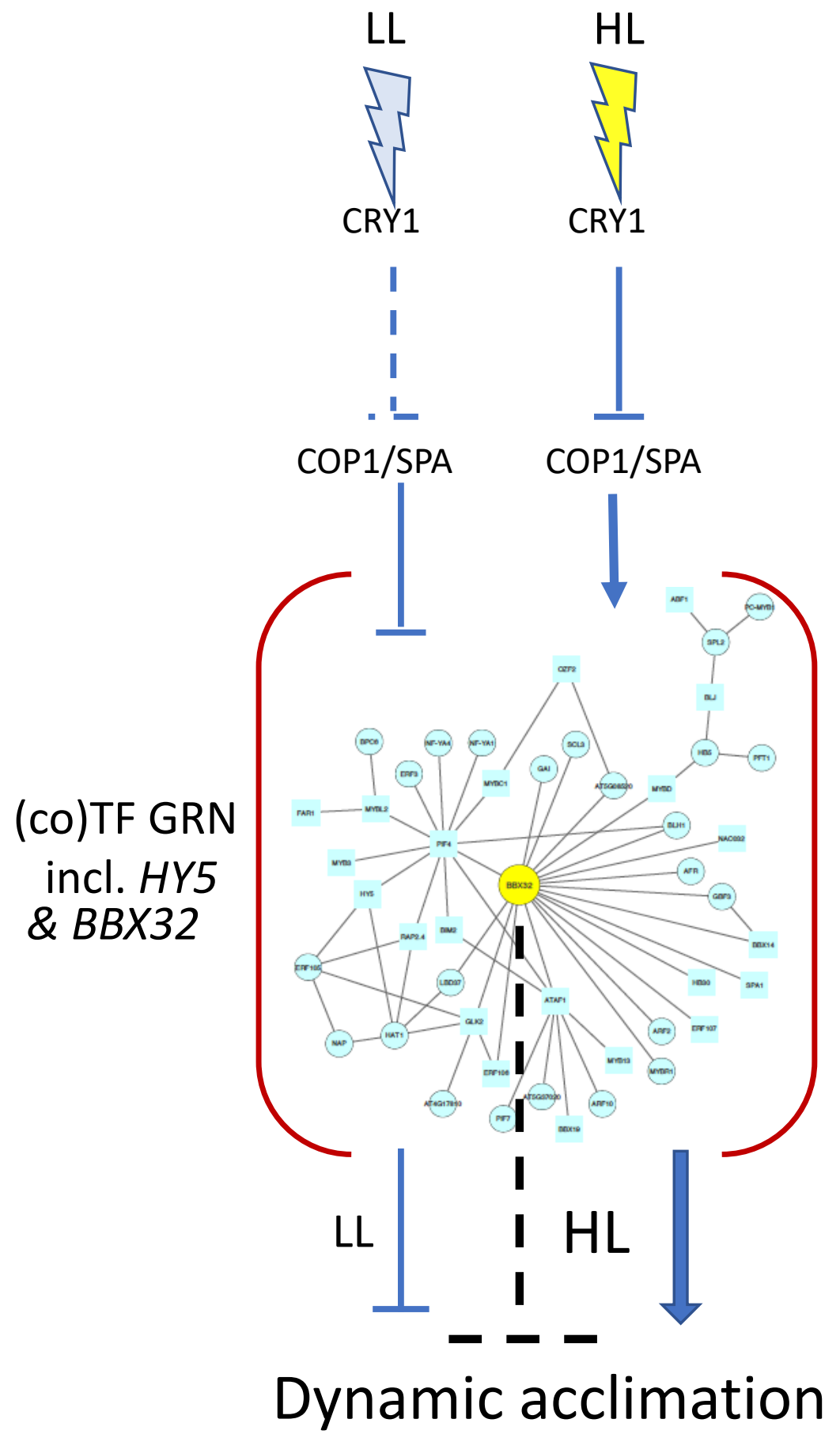

Figure 10. Proposed regulation of dynamic acclimation by a BBX32-centric GRN. The above scheme, while was based on this study, incorporates features from schemes published on the photoreceptor-directed control of seedling photomorphogenesis (e.g. Holtan et al., 2011; Hoecker, 2017). Under LL growth conditions to which the plant is acclimated, all or a proportion of cellular CRY1 is not active and consequently COP1/SPA acts to negatively regulate GRN members including HY5 and BBX32. Upon exposure to HL, CRY1 is activated and blocks COP1/SPA, which in turn releases the GRN ultimately leading to the establishment of dynamic acclimation. However, a degree of negative regulation of dynamic acclimation is retained (dotted inverted T) under HL conditions to allow for flexibility in potential fluctuations in the light environment. 


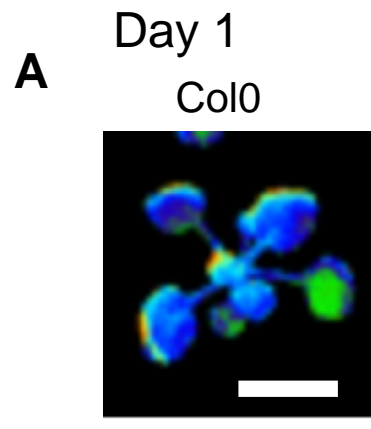

B
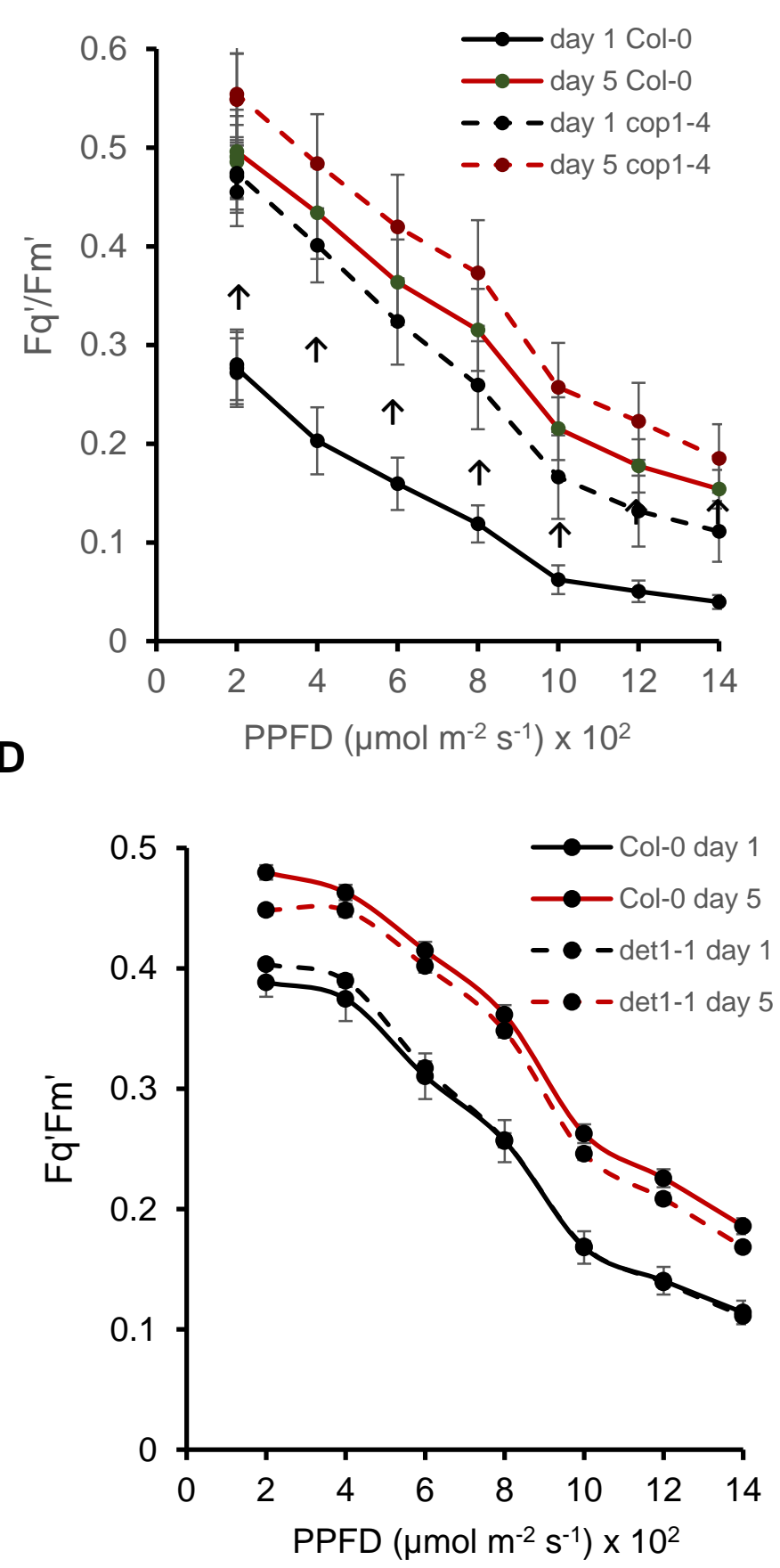

Day 5
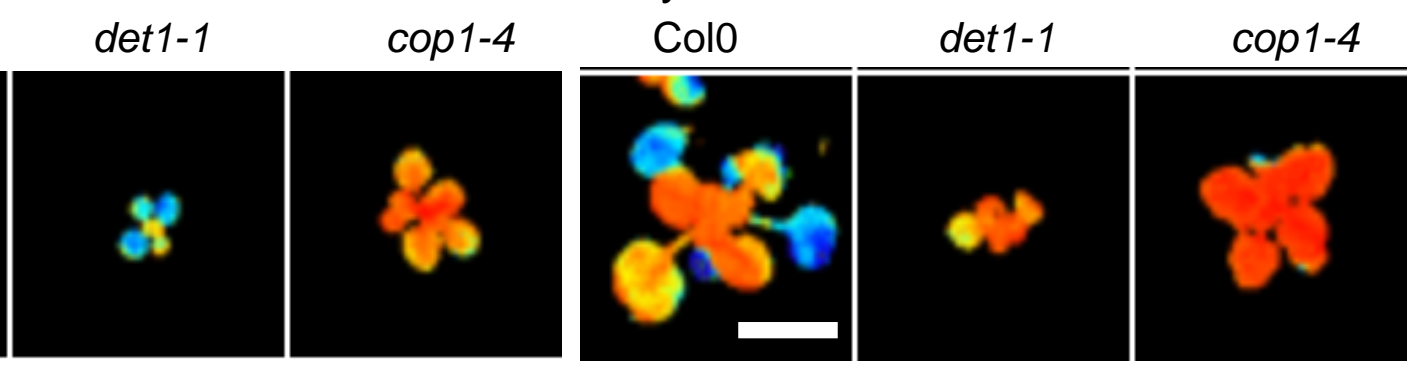

Fq'/Fm'

0.6

C
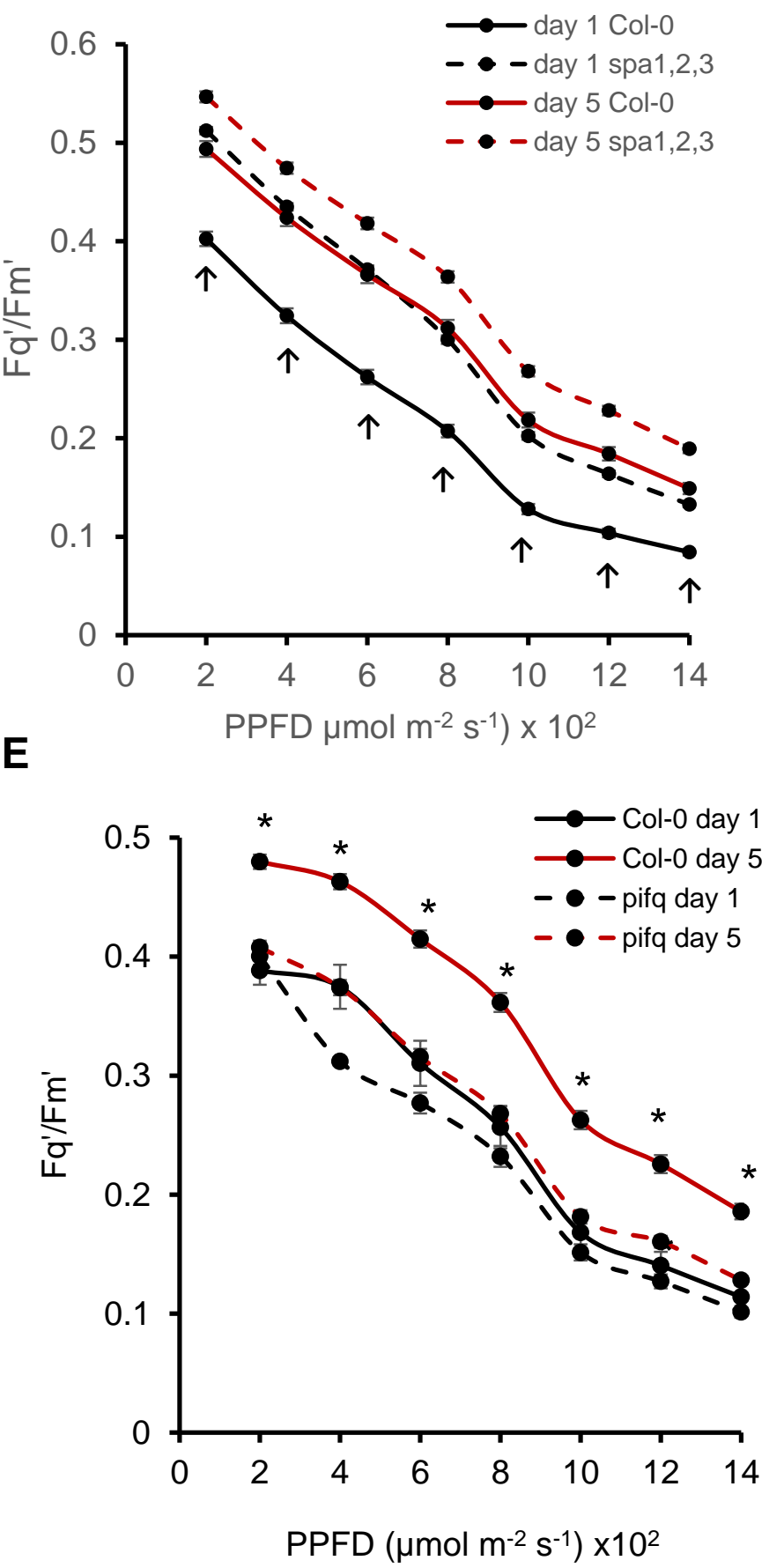


\section{Figure 9. Dynamic acclimation of photoreceptor signal transduction}

\section{mutants.}

(A) Photosynthetic efficiency of the same single representative Col-0, cop1-4 and det $1-1$ plants after 1 and 5 days of daily $4 \mathrm{~h} \mathrm{HL}$ exposure. The CF images are of $\mathrm{Fq}^{\prime} / \mathrm{Fm}$ ' (PSIl operating efficiency) at a $400 \mu \mathrm{mol} \mathrm{m}^{-2} \mathrm{~s}^{-1}$ actinic PPFD. (B - E) The plots show the PSIl operating efficiencies (Fq'/Fm') determined from CF images of from 8 plants (24-28 dpg) over 2 experiments (means \pm SE). The plants had been exposed to $4 \mathrm{~h} \mathrm{HL}$ each day for 5 consecutive days (see Methods and legend of Figure 2). Note that because of the size of the cop1-4, pifq and det1-1 plants, data were collected from whole rosettes rather than from mature leaves. CF parameter values were collected at a range of actinic PPFDs (as indicated on the x-axis) at the end of days 1 and 5 of HL. The Fq'/Fm' values at day 1 (black lines) and day 5 (red lines) for mutant plants (dashed line) and Col-0 (solid line) of the HL treatments for (B) cop1-4, (C) spa1,2,3, (D) det1-1 and (E) pifQ. Asterisks (panel E) indicate significant difference between mutant compared with Col-0 at day $5(\mathrm{P}<0.01$; ANOVA and TukeyHSD). Upward arrows (panels $B, C$ ) indicate significant difference between mutants and Col-0 at day 1 ( $P<0.01$; ANOVA and TukeyHSD). 

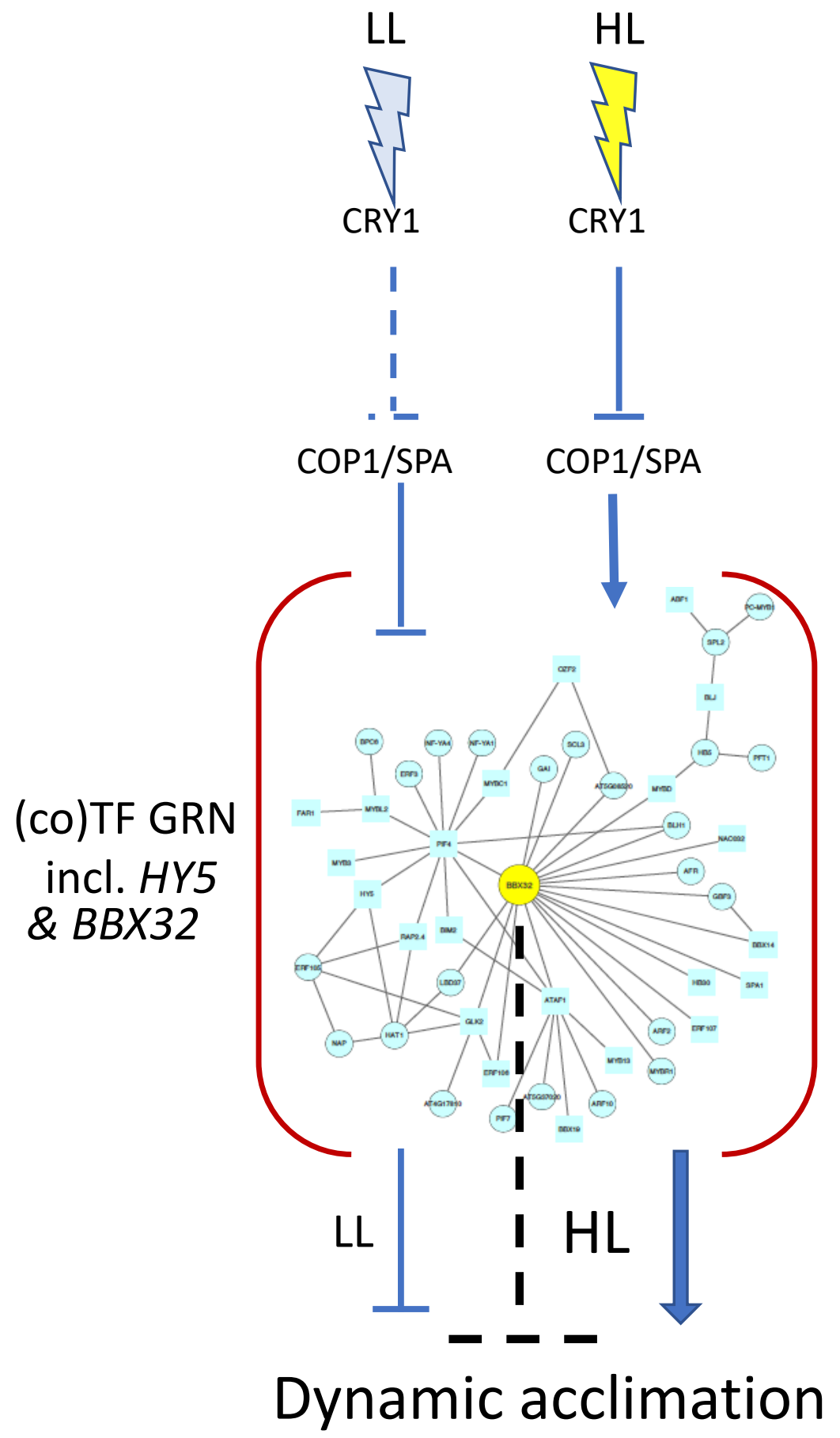

Figure 10. Proposed regulation of dynamic acclimation by a BBX32-centric GRN. The above scheme, while was based on this study, incorporates features from schemes published on the photoreceptor-directed control of seedling photomorphogenesis (e.g. Holtan et al., 2011; Hoecker, 2017). Under LL growth conditions to which the plant is acclimated, all or a proportion of cellular CRY1 is not active and consequently COP1/SPA acts to negatively regulate GRN members including HY5 and BBX32. Upon exposure to HL, CRY1 is activated and blocks COP1/SPA, which in turn releases the GRN ultimately leading to the establishment of dynamic acclimation. However, a degree of negative regulation of dynamic acclimation is retained (dotted inverted T) under HL conditions to allow for flexibility in potential fluctuations in the light environment. 


\section{Parsed Citations}

Adamiec, M., Drath, M. and Jackowski, G. (2008) Redox state of plastoquinone pool regulates expression of Arabidopsis thaliana genes in response to elevated irradiance. Acta Biochimica Polonica 55: 161-173.

Google Scholar: Author Only Title Only Author and Title

Adams III, W.W., Cohu, C.M., Amiard, V. and Demming-Adams, B (2014) Associations between the acclimation of phloem-cell wall ingrowths in minor veins and maximal photosynthesis rate. Frontiers Plant Sci. 5: article 24.

Google Scholar: Author Only Title Only Author and Title

Ahmad, M. and Cashmore, AR. (1993) HY4 gene of A thaliana encodes a protein with characteristics of a blue-light photoreceptor. Nature 366: 162-166.

Google Scholar: Author Only Title Only Author and Title

Ahmad, M., Lin, C. and Cashmore, AR. (1995) Mutations throughout an Arabidopsis blue-light photoreceptor impair blue-lightresponsive anthocyanin accumulation and inhibition of hypocotyl elongation. Plant J. 8: 653-658.

Google Scholar: Author Only Title Only Author and Title

Ahmad, M., Grancher, N., Heil, M., Black, R.M., Giovani, B., Galland, P. and Lardemer, D. (2002) Action spectrum for cryptochromedependent hypocotyl growth inhibition in Arabidopsis. Plant Physiol. 129: 774-785.

Google Scholar: Author Only Title Only Author and Title

Albanese, P., Manfedi, M., Meneghesso, A, Marengo, E., Saracco, G., Barber, J., Morosinotto, T. and Pagliano, C. (2016) Dynamic reorganization of photosystem II supercomplexes in response to variations in light intensities. Biochim Biophys. Acta 1857: $1651-1660$.

Google Scholar: Author Only Title Only Author and Title

Albihlal, W.S., Obomighie, I., Blein, T., Persad, R., Chernukhin, I., Crespi, M., Bechtold, U. and Mullineaux, P.M. (2018) Arabidopsis HEAT SHOCK TRANSCRIPTION FACTORA1b regulates multiple developmental genes under benign and stress conditions. J. Exp. Bot. 69: 2847-2862.

Google Scholar: Author Only Title Only Author and Title

Allahverdiyeva, Y., Battchikova, N., Brosché, M., Fujii, H., Kangasjärvi, S., Mulo, P., Mähönen, AP., Nieminen, K., Overmyer, K., Salojärvi, J. and Wrzaczek, M. (2015) Integration of photosynthesis, development and stress as an opportunity for plant biology. New Phytol. 208: 647-655.

Google Scholar: Author Only Title Only Author and Title

Ashburner, M., Ball, C.A, Blake, J.A, Botstein, D., Butler, H., Cherry, J.M., Davis, AP., Dolinski, K., Dwight, S.S., Eppig, J.T., Harris, M.A, Hill, D.P., Issel-Tarver, L., Kasarskis, A, Lewis, S., Matese, J.C., Richardson, J.E., Ringwald, M., Rubin, G.M. and Sherlock, G. (2000) Gene Ontology: tool for the unification of biology. Nat. Genet. 25: 25-29.

Google Scholar: Author Only Title Only Author and Title

Athanasiou, K., Dyson, E.C., Webster, R.E. and Johnson, G.N. (2010) Dynamic acclimation of photosynthesis increases plant fitness in changing environments. Plant Physiol. 152: 366-373.

Google Scholar: Author Only Title Only Author and Title

Badger, M.R., von Caemmerer, S., Ruuska, S. and Nakano, H. (2000) Electron flow to oxygen in higher plants and algae: rates and control of direct photoreduction (Mehler reaction) and rubisco oxygenase. Phil. Trans. R. Soc. Lond. B 355: 1433-1446.

Google Scholar: Author Only Title Only Author and Title

Baker, N. R. (2008) Chlorophyll fluorescence: A probe of photosynthesis in vivo. Annu. Rev. Plant Biol. 59: 89-113.

Google Scholar: Author Only Title Only Author and Title

Ball, L., Accotto, G.P., Bechtold, U., Creissen, G., Funck, D., Jimenez, A, Kular, B., Leyland, N., Mejia-Carranza, J., Reynolds, H., Karpinski, S. and Mullineaux, P.M. (2004) Evidence for a direct link between glutathione biosynthesis and stress defense gene expression in Arabidopsis. Plant Cell 16: 2448-2462.

Google Scholar: Author Only Title Only Author and Title

Barbagallo, R.P., Oxborough, K., Pallett, K.E. and Baker, N.R. (2003) Rapid, non-invasive screening for perturbations of metabolism and plant growth using chlorophyll fluorescence imaging. Plant Physiol. 132: 485-493.

Google Scholar: Author Only Title Only Author and Title

Beal, M.J., Falciani, F., Ghahramani, Z, Rangel, C. and Wild, D. L. (2005) ABayesian approach to reconstructing genetic regulatory networks with hidden factors. Bioinformatics 21: 349-356.

Google Scholar: Author Only Title Only Author and Title

Bechtold, U., Richard, O., Zamboni, A, Gapper, C., Geisler, M., Pogson, B., Karpinski, S. and Mullineaux, P.M. (2008) Impact of chloroplastic- and extracellular-sourced ROS on high light-responsive gene expression in Arabidopsis. J. Exp. Bot. 59: 121-133

Google Scholar: Author Only Title Only Author and Title

Bechtold, U., Lawson, T., Meyer, R.C., Mejia-Carranza, J., Brown, I.R., Atmann, T., Ton, J. and Mullineaux, P.M. (2010) Constitutive salicylic acid defences do not compromise seed yield, drought tolerance and water productivity in the Arabidopsis accession C24. Plant Cell Environ. 33: 1959-1973. 
Bechtold, U., Penfold, C.A, Jenkins, D.J., Legaie, R., Moore, J.D., Lawson, T., Matthews, J.S.A, Vialet-Chabrand, S.R.M., Baxter, L., Subramaniam, S., Hickman, R., Florance, H., Sambles, C., Salmon, D.L., Feil, R., Bowden, L., Hill, C., Baker, N.R., Lunn, J.E., Finkenstädt, B., Mead, A, Buchanan-Wollaston, V.,Beynon, J., Rand, D.A, Wild, D.L., Denby, K.J., Ott, S., Smirnoff, N. and Mullineaux, P.M. (2016) Time-series transcriptomics reveals that AGAMOUS-LIKE22 affects primary metabolism and developmental processes in droughtstressed Arabidopsis. Plant Cell 28: in press doi/10.1105/tpc.15.00910.

Google Scholar: Author Only Title Only Author and Title

Benjamini, Y. and Hochberg, Y. (1995) Controlling the false discovery rate: a practical and powerful approach to multiple testing. J.R. Statist. Soc. B. 57: 289-300.

Google Scholar: Author Only Title Only Author and Title

Berens, M.L., Wolinska, K.W., Spaepen, S., Zegler, J., Nobori,T., Nair, A, Krüler, V., Winkelmüller, T.M., Wang, Y., Mine, A., Becker, D., Garrido-Oter, R., Schulze-Lefert, P. and Tsuda, K. (2019) Balancing trade-offs between biotic and abiotic stress responses through leaf age-dependent variation in stress hormone cross-talk

Proc. Natl. Acad. Sci. USA 116: 2364-2373.

Google Scholar: Author Only Title Only Author and Title

Boyes, D.C., Zayed, AM., Ascenzi, R., McCaskill, AJ., Hoffman, N.E., Davis, K.R. and Görlach, J. (2001) Growth stage -based phenotypic analysis of Arabidopsis. Amodel for high throughput functional genomics in plants. Plant Cell 13: 1499-1510.

Google Scholar: Author Only Title Only Author and Title

Breeze, E., Harrison, E., McHattie, S., Hughes, L., Hickman, R., Hill, C., Kiddle, S., Kim, Y-S., Penfold, C.A, Jenkins, D., Zhang, C., Morris, K., Jenner, C., Jackson, s., Thomas, B., Tabrett, A, Legaie, R., Moore, J.D., Wild, D.L., Ott, S., Rand, D., Beynon, J., Denby, K., Mead, A and Buchanan-Wollaston, V. (2011) High-resolution temporal profiling of transcripts during Arabidopsis leaf senescence reveals a distinct chronology of processes and regulation. Plant Cell 23: 873-894.

Google Scholar: Author Only Title Only Author and Title

Chory, J. and Peto, C.A (1990) Mutations in the DET1 gene affect cell-type-specific expression of light-regulated genes and chloroplast development in Arabidopsis. Proc. Natl. Acad. Sci. USA 87: 8776-8780.

Google Scholar: Author Only Title Only Author and Title

Chen, D., Xu, G., Tang, W., Jing, Y., Ji, Q., Fei, Z and Lin, R. (2013) Antagonistic basic helix-loop-helix/bZP transcription factors for transcriptional modules that integrate light and reactive oxygen species signalling in Arabidopsis. Plant Cell 25: 1657-1673.

Google Scholar: Author Only Title Only Author and Title

Chory, J., Peto, C., Feinbaum, R., Pratt, L. and Ausubel, F. (1989) Arabidopsis thaliana mutant that develops as a light-grown plant in the absence of light. Cell 58: 991-999.

Google Scholar: Author Only Title Only Author and Title

Consentino, L., Lambert, S., Martino, C., Jourdan, N., Bouchet, P.-E., Witczak, J., Castello, P., El-Esawi, M., Corbineau, F., d'Harlingue, A and Ahmad, M. (2015) Blue-light dependent reactive oxygen species formation by Arabidopsis cryptochrome may define a novel evolutionary conserved signaling mechanism. New Phytol. 206: 1450-1462.

Google Scholar: Author Only Title Only Author and Title

Crisp, P.A, Ganguly, D.R., Smith, AB., Murray, K.D., Estavillo, G.Z, Searle, I., Ford, E., Bogdanovic, O., Lister, R., Borevitz, J.O., Eichten, S.R. and Pogson, B.J. (2017). Rapid recovery gene downregulation during excess light stress and recovery in Arabidopsis. Plant Cell 29: 1836-1863.

Google Scholar: Author Only Title Only Author and Title

Datta, S., Hettiarachchi, C., Johansson, H. and Holm, M. (2007) SALT TOLERANCE HOMOLOG2, a B-Box protein in Arabidopsis that activates transcription and positively regulates light-mediated development. Plant Cell 19: 3242-3255.

Google Scholar: Author Only Title Only Author and Title

Davletova, S., Rizhsky, L., Liang, H. J., Zhong, S. Q., Oliver, D. J., Coutu, J., Shulaev, V., Schlauch, K. and Mittler, R. (2005) Cytosolic ASCORBATE PEROXIDASE1 is a central component of the reactive oxygen gene network of Arabidopsis. Plant Cell 17: $268-281$.

Google Scholar: Author Only Title Only Author and Title

Deng, X.-W. and Quail, P.W. (1992) Genetic and phenotypic characterization of cop1 mutants of Arabidopsis thaliana. Plant J. 2: 83-95.

Google Scholar: Author Only Title Only Author and Title

Díaz, M., De Haro, V., Muñoz, R. and Quiles, M.J. (2007) Chlororespiration is involved in the adaptation of Brassica plants to heat and high light intensity. Plant Cell Environ. 30: 1578-1585.

Google Scholar: Author Only Title Only Author and Title

Dietz, K.J., Horling, F., König, J. and Baier, M. (2002) The function of the chloroplast 2-cysteine peroxiredoxin in peroxide detoxification and its regulation. J. Exp. Bot. 53: 1321-1329.

Google Scholar: Author Only Title Only Author and Title

Dietz, K.-J. (2015) Efficient high light acclimation involves rapid processes at multiple mechanistic levels. J. Exp. Bot. 66: 2401-2414.

Google Scholar: Author Only Title Only Author and Title 
Dong, J., Tang, D., Gao, Z, Yu, R., Li, K., He, H., Terzaghi, W., Deng, X.W. and Chen, H. (2014) Arabidopsis DE-ETIOLATED1 represses photomorphogenesis by positively regulating phytochrome-interacting factors in the dark. Plant Cell 26: 3630-3645.

Google Scholar: Author Only Title Only Author and Title

Driever, S. and Baker, N.R. (2010) The water-water cycle in leaves is not a major alternative electron transport sink for dissipation of excess excitation energy when $\mathrm{CO} 2$ assimilation is restricted. Plant Cell Environ. 34: 837-846.

Google Scholar: Author Only Title Only Author and Title

Drozak, A and Romanowska, E. (2006) Acclimation of mesophyll and bundle sheath chloroplasts of maize to different irradiances during growth. Biochim Biophys. Acta 1757: 1539-1546.

Google Scholar: Author Only Title Only Author and Title

Du, Z, Zhou, X., Ling, Y., Zhang, Z and Su, Z (2010) agriGO: a GO analysis toolkit for the agricultural community. Nucl. Acids Res. 38: W64-W70.

Google Scholar: Author Only Title Only Author and Title

Eberhard, S., Finazzi, G. and Wollman, F.-A (2008). The dynamics of photosynthesis. Annu. Rev. Genet. 42: $463-515$.

Google Scholar: Author Only Title Only Author and Title

Estavillo, G.M., Crisp, P.A, Pomsiriwong, W., Wirtz, M., Collinge, D., Carrie, C., Giraud, E., Whelan, J., David, P., Javot, H., Brearley, C., Hell, R., Marin, E. and Pogson, B.J. (2011) Evidence for a SAL1-PAP chloroplast retrograde pathway that functions in drought and high light signalling in Arabidopsis. Plant Cell 23: 3992-4012.

Google Scholar: Author Only Title Only Author and Title

Exposito-Rodriguez, M., Laissue, P.P., Yvon-Durocher, G., Smirnoff, N. and Mullineaux, P.M. (2017). Photosynthesis-dependent H2O2 transfer from chloroplasts to nuclei provides a high-light signalling mechanism Nature Comms. 8: art. 49.

Google Scholar: Author Only Title Only Author and Title

Gadjev, I., Vanderauwera, S., Gechev, T.S., Laloi, C., Minkov, I.N., Shulaev, V., Apel, K., Inzé, D., Mittler, R. and Van Breusegem, F. (2006) Transcriptomic footprints disclose specificity of reactive oxygen species signaling in Arabidopsis. Plant Physiol. 141 : $436-455$.

Google Scholar: Author Only Title Only Author and Title

Galvez-Valdivieso, G., Fryer, M.J., Lawson, T., Slattery, K., Truman, W., Smirnoff, N., Asami, T., Davies, W.J., Jones, AM., Baker, N.R. and Mullineaux, P.M. (2009) The high light response in Arabidopsis involves ABA signaling between vascular and bundle sheath cells. Plant Cell 21: 2143-2162.

Google Scholar: Author Only Title Only Author and Title

Gan, S. and Amasino, R.M. (1995) Inhibition of leaf senescence by autoregulated production of cytokinin. Science 270: $1986-1988$. Google Scholar: Author Only Title Only Author and Title

Gangappa, S.N. and Botto, J.F. (2014) The BBX family of plant transcription factors. Trends Plant Sci. $19: 460-470$.

Google Scholar: Author Only Title Only Author and Title

Gangappa, S.N. and Botto, J.F. (2016) The multifaceted roles of HY5 in plant growth and development. Mol. Plant 9: $1353-1365$.

Google Scholar: Author Only Title Only Author and Title

Gangappa, S.N. and Kumar, S.V. (2018) DET1 and COP1 modulate the coordination of growth and immunity in response to key seasonal signals in Arabidopsis. Cell Reports 25: 29-37.

Google Scholar: Author Only Title Only Author and Title

Ganguly, D., Crisp, P., Harter, K., Pogson, B.J. and Abrecht-Borth, V. (2015) Genetic suppression of plant development and chloroplast biogenesis via the Snowy Cotyledon 3 and Phytochrome B pathways. Func. Plant Biol. 42: 676-686.

Google Scholar: Author Only Title Only Author and Title

Garapati, P., Xue, G.-P., Munné-Bosch, S. and Balazadeh, S. Transcription factor ATAF1 in Arabidopsis promotes senescence by direct regulation of key chloroplast maintenance and senescence transcriptional cascades. (2015) Plant Physiol. $168: 1122-1139$.

Google Scholar: Author Only Title Only Author and Title

Gorecka, M., Avarez-Fernandez, R., Slattery, K., McAusland, L., Davey, P.A, Karpinski, S., Lawson, T. and Mullineaux, P. M. (2014) Abscisic acid signalling determines susceptibility of bundle sheath cells to photoinhibition in high light-exposed Arabidopsis leaves.

Phil. Trans. R. Soc. B 369: 20130234.

Google Scholar: Author Only Title Only Author and Title

Guo, H., Yang, H., Mockler, T.C. and Lin, C. Regulation of flowering time by Arabidopsis photoreceptors. Science 279: $1360-1363$.

Google Scholar: Author Only Title Only Author and Title

Guo, Z, Wang, F., Xiang, X., Ahammed, G.J., Wang, M., Onac, E., Zhou, J., Xia, X., Shi, K., Yin, X., Chen, K., Yu, J., Foyer, C.H. and Zhou, Y. (2016) Systemic induction of photosynthesis via illumination of the shoot apex is mediated sequentially by phytochrome B, auxin and hydrogen peroxide in tomato. Plant Physiol. 172: 1259-1272.

Google Scholar: Author Only Title Only Author and Title

Hardtke, C.S., Gohda, K., Osterlund, M.T., Oyama, T., Okada, K. and Deng, X.W. (2000) HY5 stability and activity in Arabidopsis is regulated by phosphorylation in its COP1 binding domain. EMBO J. 19: 4997-5006.

Google Scholar: Author Only Title Only Author and Title 
Heard, N.A, Holmes, C.C., Stephens, D.A, Hand, D.J., and Dimopoulos, G. (2005). Bayesian co-clustering of Anopheles gene expression time series: Study of immune defense response to multiple experimental challenges. Proc. Natl. Acad. Sci. USA102: 16939 16944.

Google Scholar: Author Only Title Only Author and Title

Heyno, E., Innocenti, G., Lemaire, S.D., Issakadis-Bourguet, E. and Krieger-Liszkay, A (2014) Putative role of the malate valve enzyme NADP-malate dehydrogenase in H2O2 signalling in Arabidopsis. Phil. Trans. R. Soc. B 369: 20130228.

Google Scholar: Author Only Title Only Author and Title

Hoang, N., Schleicher, E., Kacprzak, S., Bouly, J.P., Picot, M., Wu, W., Berndt, A, Wolf, E., Bittl, R. and Ahmad, M (2008) Human and Drosophila cryptochromes are light activated by flavin photoreduction in living cells. PLoS Biol. 6: e160.

Google Scholar: Author Only Title Only Author and Title

Hoecker, U. (2017) The activities of the E3 ubiquitin ligase COP1/SPA, a key repressor in light signalling. Curr. Op. Plant Biol. 37: 63-69. Google Scholar: Author Only Title Only Author and Title

Holtan, H.E., Bandong, S., Marion, C.M., Adam, L., Tiwari, S., Shen, Y., Mloof, J.N., Maszle, D.R., Ohto, M., Preuss, S., Meister, R., Petracek, M., Repetti, P.P., Reuber, L., Ratcliffe, O.J. and Khanna, R. (2011) BBX32, an Arabidopsis B-Box protein, functions in light signalling by suppressing HY5-regulated gene expression and interacting with STH2/BBX21. Plant Physiol. $156: 2109-2123$.

Google Scholar: Author Only Title Only Author and Title

Huang, D.W., Sherman, B.T. and Lempicki, R.A (2008) Systematic and integrative analysis of large gene lists using DAVD bioinformatics resources. Nature Protocols 4: 44-57.

Google Scholar: Author Only Title Only Author and Title

Huang, J., Zhao, X. and Chory J. (2019) The Arabidopsis transcriptome responds specifically and dynamically to high light stress. Cell Reports 29: 4186-4199.

Google Scholar: Author Only Title Only Author and Title

Huang, X., Ouyang, X. and Deng, X.W. (2014) Beyond repression of photomorphogenesis: role switching of COP/DET/FUS in light signalling. Curr. Op. Plant Biol. 21: 96-103.

Google Scholar: Author Only Title Only Author and Title

Inzé, A, Vanderauwera, S., Hoeberichts, F.A, Vandorpe, M., Van Gaever, T. and Van Breusegem, F. (2012) Asubcellular localization compendium of hydrogen peroxide-induced proteins. Plant Cell Environ. 35: 308-320.

Google Scholar: Author Only Title Only Author and Title

Jones M.A, Hu, W., Litthauer, S., Lagarias, J.C. and Harmer, S.L. (2015)

A constitutively active allele of phytochrome B maintains circadian robustness in the absence of light. Plant Physiol. $169: 814-825$.

Jung, H.-S., Crisp, P.A, Estavillo, G.M., Cole, B., Hong, F., Mocklere, T.C., Pogson, B.J. and Chory, J. (2013) Subset of heat-shock transcription factors required for the early response of Arabidopsis to excess light. Proc. Natl. Acad. Sci. USA110: 14474-14479.

Google Scholar: Author Only Title Only Author and Title

Kamal, N.M., Gorafi, Y.S.A, Abdelrahman, M., Abdellatef, E. and Tsujimoto, H. (2019) Stay green trait: A prospective approach for yield potential, and drought and heat stress adaptation in globally important cereals. Int. J. Mol. Sci. 20: art. 5837.

Google Scholar: Author Only Title Only Author and Title

Kangasjärvi, S., Neukermans, J., Li, S., Aro, E.-M. and Noctor, G. (2012) Photosynthesis, photorespiration, and light signalling in defence responses. J. Exp. Bot. 63: 1619-1636.

Google Scholar: Author Only Title Only Author and Title

Karpinski, S., Escobar, C., Karpinska, B., Creissen, G. and Mullineaux, P.M. (1997) Photosynthetic electron transport regulates the expression of cytosolic ascorbate peroxidase gene in Arabidopsis during excess light stress. Plant Cell 9: 627-640.

Google Scholar: Author Only Title Only Author and Title

Karpinski, S., Reynolds, H., Karpinska, B., Wingsle, G., Creissen, G. and Mullineaux, P.M. (1999) Systemic signalling and acclimation in response to excess excitation energy in Arabidopsis. Science 284: 654-657.

Google Scholar: Author Only Title Only Author and Title

Kim, C., Meskauskiene, R., Zhang, S., Lee, K.P., Ashok, M.L., Blajecka, K., Herrfurth, C., Feussner,I. and Apel K. (2012) Chloroplasts of Arabidopsis are the source and a primary target of a plant-specific programmed cell death signaling pathway. Plant Cell 24: 3026-3039.

Google Scholar: Author Only Title Only Author and Title

Kim, D., Langmead, B. and Salzberg, S.L. (2015) HISAT: a fast-spliced aligner with low memory requirements. Nature Methods 12: 357360.

Google Scholar: Author Only Title Only Author and Title

Kleine, T., Kindgren, P., Benedict, C., Hendrickson, L. and Strand Å (2007) Genome-wide gene expression analysis reveals a critical role for CRYPTOCHROME1 in the response of Arabidopsis to high irradiance. Plant Physiol. 144: $1391-1406$.

Google Scholar: Author Only Title Only Author and Title 
Koester, R.P., Skoneczka, J.A, Cary, T.R., Diers, B.W. and Ainsworth, E.A (2014) Historical gains in soybean (Glycine max Merr.) seed yield are driven by linear increases in light interception, energy conversion, and partitioning efficiencies. J. Exp. Bot. 65: $3311-3321$.

Google Scholar: Author Only Title Only Author and Title

Kromdiijk, J., Glowacka, K., Leonelli, L., Gabilly, S.T., Iwai, M., Niyogi, K.K. and Long, S.P. (2016) Improving photosynthesis and crop productivity by accelerating recovery from photoprotection. Science 354: 857-861.

Google Scholar: Author Only Title Only Author and Title

Kumar, S.V. and Wigge, P.A (2010) H2AZ-containing nucleosomes mediate the thermosensory response in Arabidopsis. Cell 140: 136147.

Google Scholar: Author Only Title Only Author and Title

Lau, K., Podolec, R., Chappuis, R., Ulm, R. and Hothorn, M. (2019) Plant photoreceptors and their signalling components compete for binding to the ubiquitin ligase COP1 using their VP-peptide motifs. EMBO J. 38: e102140.

Google Scholar: Author Only Title Only Author and Title

Lau, O.S. and Deng, X.W. (2012) The photomorphogenic repressors COP1 and DET1: 20 years later. Trends Plant Sci. 17: $584-593$.

Google Scholar: Author Only Title Only Author and Title

Laubinger, S., Fittinghoff, K. and Hoecker, U. (2004) The SPAquartet: A family of WD-repeat proteins with a central role in suppression of photomorphogenesis in Arabidopsis. Plant Cell 16: 2293-2306

Google Scholar: Author Only Title Only Author and Title

Lawson, T., Davey, P.A, Yates, S.A, Bechtold, U., Baeshen, M., Baeshen, N., Mutwaktil, M.Z, Sabir, J., Baker, N.R., Mullineaux, P.M. (2014) C3 photosynthesis in the desert plant Rhazya stricta is fully functional at high temperatures and light intensities. New Phytol. 201: 862-873.

Google Scholar: Author Only Title Only Author and Title

Lee, J., He, K., Stolc, V., Lee, H., Figueroa, P., Gao, Y., Tongprasit, W., Zhao, H., Lee, I. and Deng, X.W. (2007) Analysis of transcription factor HY5 genomic binding sites revealed its hierarchical role in light regulation of development. Plant Cell 19: $731-749$.

Google Scholar: Author Only Title Only Author and Title

Leivar, P., Monte, E., Oka, Y., Liu, T., Carle, C., Castillon, A, Huq, E. and Quail, P.H. Multiple phytochrome-interacting bHLH transcription factors repress premature seedling photomorphogenesis in darkness. Curr. Biol. 18: 1815-1823.

Google Scholar: Author Only Title Only Author and Title

LePage, E., Zampini, É. and Brisson, N. (2013) Plastid genome instability leads to reactive oxygen species production and plastid-tonucleus retrograde signalling in Arabidopsis. Plant Physiol. 163: 867-881.

Google Scholar: Author Only Title Only Author and Title

Lewis, L.L., Polanski, K., de Torres-Zabala, M., Jayaraman, S. Bowden, L., Moore, J., Penfold, C.A, Jenkins, D.J., Hill, C., Baxter, L., Kulasekaran, S., Truman, W., Littlejohn G., Prusinska, J., Mead, A, Steinbrenner,J., Hickman, R., Rand, D., Wild, D.L., Ott, S., BuchananWollaston, V., Smirnoff, N., Beynon, J., Denby, K. and Grant M. (2015) Transcriptional dynamics driving MAMP-triggered immunity and pathogen effector-mediated immunosuppression in Arabidopsis leaves following infection with Pseudomonas syringae pv tomato DC3000. Plant Cell 27: 3038-3064.

Google Scholar: Author Only Title Only Author and Title

Li, K., Gao, Z, He, H., Terzaghi, W., Fan, L.-M., Deng, X.W. and Chen, H. (2015). Arabidopsis DET1 represses photomorphogenesis in part by negatively regulating DELLA protein abundance in darkness. Mol. Plant 8: 622-630.

Google Scholar: Author Only Title Only Author and Title

Li, X., Björkman, O., Shih, C., Grossman, AR., Rosenquist, M., Jansson, S. and Niyogi, K.K. (2000). A pigment-binding protein essential for regulation of photosynthetic light harvesting. Nature 403: 391-395.

Google Scholar: Author Only Title Only Author and Title

Li, Z, Wakao, S., Fischer, B.B. and Niyogi, K.K. (2009) Sensing and responding to excess light. Ann. Rev. Plant Biol. 60: 239-260.

Google Scholar: Author Only Title Only Author and Title

Lian, H.-L., He, S.-B., Zhang, Y.-C., Zhu, D.-M., Zhang, J.Y., Jia, K.-P., Sun, S.-X., Li, L. and Yang, H.-Q. (2011) Blue-light-dependent interaction of cryptochrome 1 with SPA1 defines a dynamic signaling mechanism Genes Dev. 25:1023-1028.

Google Scholar: Author Only Title Only $\underline{\text { Author and Title }}$

Liu Q., Su T., He W., Ren H., Liu S., Chen Y., Gao L., Hu X., Lu H., Cao S., Huang Y., Wang X., Wang, Q., and Lin, C. (2020)

Photooligomerization determines photosensitivity and photoreactivity of plant cryptochromes. Mol. Plant. 13, $398-413$.

Google Scholar: Author Only Title Only Author and Title

Long, S.P., Humphries, S. and Falkowski, P.G. (1994) Photoinhibition of photosynthesis in nature. Ann. Rev. Plant Biol .45: 633-662. Google Scholar: Author Only Title Only Author and Title

Love, M.I., Huber, W. and Anders, S. (2014. Moderated estimation of fold change and dispersion for RNAseq data with DESeq2.

Genome Biol.,15: 550.

Google Scholar: Author Only Title Only Author and Title

Ma, D., Li, X., Guo, Y., Chu, J., Fang, S., Yan, C., Noel, J.P. and Liu, H. (2016) Cryptochrome 1 interacts with PIF4 to regulate high 
temperature-mediated hypocotyl ēongation in response to blue light. Proc. Nati. Acad. Sci. USA 113: 224-229.

Google Scholar: Author Only Title Only Author and Title

Mittler, R., Vanderauwera, S., Gollery, M. and Van Breusegem, F. (2004) Reactive oxygen network of plants. Trends Plant Sci. 9: 490498.

Google Scholar: Author Only Title Only Author and Title

Moriyama, E.N., Strope, P.K., Opiyo, S.O., Chen, Z and Jones, AM. (2006). Mining the Arabidopsis thaliana genome for highly-divergent seven transmembrane receptors. Genome Biol. 7: R96.

Google Scholar: Author Only Title Only Author and Title

Mullineaux, P.M., Exposito-Rodriguez, M., Laissue, P.P. and Smirnoff, N. (2018) ROS-dependent signaling pathways in plants and algae exposed to high light: Comparisons with other eukaryotes. Free Rad. Biol. Med. 122: 52-64.

Google Scholar: Author Only Title Only Author and Title

Murchie, E.H. and Horton, P. (1997) Acclimation of photosynthesis to irradiance and spectral quality in British plant species: chlorophyll content, photosynthetic capacity and habitat preference. Plant Cell Environ. 20: 438-448.

Google Scholar: Author Only Title Only Author and Title

Murchie, E.H., Hubbert, S., Peng, S. and Horton, P. (2005). Acclimation of photosynthesis to high irradiance in rice: gene expression and interactions with leaf development. J. Exp. Bot. 56: 449-460.

Google Scholar: Author Only Title Only Author and Title

Naznin, M.T., Lefsrud, M., Gravel, V. and Azad, M.O.K. (2019) Blue light added with red LEDS enhance growth characteristics, pigments content, and antioxidant capacity in lettuce, spinach, kael, Basil and sweet pepper in a controlled environment. Plants 8: art. 93.

Google Scholar: Author Only Title Only Author and Title

Oelze, M.-L., Vogel, M.O., Asharafa, K., Kahmann, U., Viehhauser, A, Maurino, V.G. and Dietz, K.-J. (2012) Efficient acclimation of the chloroplast antioxidant defence of Arabidopsis thaliana leaves in response to a 10- or 100-fold light increment and the possible involvement of retrograde signals. J. Exp. Bot. 63: 1297-1313.

Google Scholar: Author Only Title Only Author and Title

Oguchi, R., Hikosaki, K. and Hirose, T. (2003) Does the photosynthetic light-acclimation need change in leaf anatomy? Plant Cell Environ. 26: 505-512.

Google Scholar: Author Only Title Only Author and Title

Overmyer, K., Köllist, H., Tuominen, H., Betz, C., Langebartels, C., Wingsle, G., Kangasjärvi, S., Brader, G., Mullineaux, P. and Kangasjärvi, J. (2008) Complex phenotypic profiles leading to ozone sensitivity in Arabidopsis thaliana mutants. Plant Cell Environ. 31: 1237-1249.

Google Scholar: Author Only Title Only Author and Title

Oyama,T., Shimura, Y. and Okada, K. (1997) The Arabidopsis HY5 gene encodes a bZP protein that regulates stimulus-induced development of root and hypocotyl. Genes Dev. 11: 2983-2995.

Google Scholar: Author Only Title Only Author and Title

Park, H.-Y., Lee, S.-Y., Seok, H.-Y., Kim, S.-H., Sung, ZR. and Moon, Y.-H. (2011) EMF1 interacts with EIP1, EIP6 or EIP9 involved in the regulation of flowering time in Arabidopsis. Plant Cell Physiol. 52: 1376-1388.

Google Scholar: Author Only Title Only Author and Title

Pedmale, U., Huang, S.C., Zander, M., Cole, B.J., Hetzel, J., Ljung, K., Reis, P.AB., Sridevi, P., Nito, K., Nery, J.R., Ecker, J.R. and

Chory, J. (2015) Cryptochromes interact directly with PIFs to control plant growth in limiting blue light. Cell, 163: 233-245.

Google Scholar: Author Only Title Only Author and Title

Penfold, C.A and Wild, D.L (2011) How to infer gene networks from expression profiles, revisited. Interface Focus 1: 857-870.

Google Scholar: Author Only Title Only Author and Title

Penfold, C.A and Buchanan-Wollaston, V. (2014) Modelling transcriptional networks in leaf senescence. J. Exp. Bot. 65: 3859-3873.

Google Scholar: Author Only Title Only Author and Title

Pham, V.C., Xu, X. and Huq, E. (2018) Molecular bases for the constitutive photomorphogenic phenotypes in Arabidopsis. Development 145: $\operatorname{dev} 169870$.

Google Scholar: Author Only Title Only Author and Title

Piasecka, A, Jedrzejczak-Rey, N. and Bednarek, P. (2015) Secondary metabolites in plant innate immunity: conserved function of divergent chemicals. New Phytol. 206: 948-964.

Google Scholar: Author Only Title Only Author and Title

Preuss, S.B., Meister, R., Xu, Q., Urwin, C.P., Tripodi, F.A, Screen, S.E., Anil, V.S., Zhu, S., Morrell, J.A, Liu, G., Ratcliffe, O.J., Reuber, L., Khanna, R., Goldman, B.S., Bell, E., Zegler, T.E., McClerren, AL., Ruff, T.G. and Petracek, M.E. (2012). Expression of the

Arabidopsis thaliana BBX32 gene in soybean increases grain yield. PLoS ONE 7: e30717.

Google Scholar: Author Only Title Only Author and Title

Ramel, F., Birtic, S., Ginies, C., Soubigopu-Taconnat, L., Triantaphylidès, S. and Havaux, M. (2012) Carotenoid oxidation products are 
stress signals that mediate gene responses to singlet oxygen in plants. Proc. Natl. Acad. Sci. USA 109: 5535-5540.

Google Scholar: Author Only Title Only Author and Title

Ramel, F., Ksas, B., Akkari, E., Mialoundama, AS., Monnet, F., Krieger-Liszkay, A, Ravanat, J.-L., Mueller, M.J., Bouvier, F. and Havaux, M. (2013) Light-induced acclimation of the Arabidopsis chlorina1 mutant to singlet oxygen. Plant Cell, 25: 1445-1462.

Google Scholar: Author Only Title Only Author and Title

Reed, J., Nagatani, A, Elich, T., Fagan, M. and Chory, J. (1994) Phytochrome A and phytochrome B have overlapping but distinct functions in Arabidopsis development. Plant Physiol. 104: 1139-1149.

Google Scholar: Author Only Title Only Author and Title

Rossel, B., Wilson, P. B., Hussain, D., Woo, N.S., Gordon, M.J., Mewett, O.P., Howell, K.A, Whelan, J., Kazan, K. and Pogson, B.J. (2007) Systemic and intracellular responses to photooxidative stress in Arabidopsis. Plant Cell 19: 4091-4110.

Google Scholar: Author Only Title Only Author and Title

Ruban, AV. and Belgio, E. (2014) The relationship between maximum tolerated light intensity and photoprotective energy dissipation in the photosynthesis antenna: chloroplast gains and losses. Phil. Trans. R. Soc. B 369: 20130222.

Google Scholar: Author Only Title Only Author and Title

Ruckle, M.E., DeMarco, S.M. and Larkin, R.M. (2007) Plastid signals remodel light signalling networks and are essential for efficient chloroplast biogenesis in Arabidopsis. Plant Cell 19: 3944-3960.

Google Scholar: Author Only Title Only Author and Title

Schiebe, R. (2004) Malate valves to balance cellular energy supply. Physiol. Plant. 120: 21-26.

Google Scholar: Author Only Title Only Author and Title

Schiebe, R. and Dietz, K.-J. (2012) Reduction-oxidation network for flexible adjustment of cellular metabolism in photoautotrophic cells. Plant Cell Environ. 35: 202-216.

Google Scholar: Author Only Title Only Author and Title

Schottler, M.A and Toth, S.Z (2014) Photosynthetic complex stoichiometry dynamics in higher plants: environmental acclimation and photosynthetic flux control. Frontiers Plant Sci. 5: article 188.

Google Scholar: Author Only Title Only Author and Title

Sclep, G., Alemeersch, J., Liechti, R., De Meyer, B., Beynon, J., Bhalerao, R., Moreau, Y., Nietfeld, W., Renou, J-P., Reymond, P., Kuiper, M.T.R. and Hilson, P. (2007) CATMA a comprehensive genome-scale resource for silencing and transcript profiling of Arabidopsis genes. BMC Bioinformatics 8: 400.

Google Scholar: Author Only Title Only Author and Title

Shaikhali, J., Barajas-Lopéz, J.D., Ötvös, K., Kremnev, D., Garcia, AS., Srivastava, V., Wingsle, G., Bako, L. and Strand, A (2012) The CRYPTOCHROME1-dependent response to excess light is mediated through the transcriptional activators ZNC FINGER PROTEIN EXPRESSED IN INFLORESCENCE MERISTEM LIKE1 and ZML2 in Arabidopsis. Plant Cell 24: 3009-3025.

Google Scholar: Author Only Title Only Author and Title

Shannon, P., Markiel, A, Ozier, O., Baliga, N.S., Wang, J.T., Ramage, D., Amin, N., Schwikowski, B. and Ideker ,T. (2003) Cytoscape: a software environment for integrated models of biomolecular interaction networks. Genome Res. 13: 2498-2504.

Google Scholar: Author Only Title Only Author and Title

Shao, N., Duan, G.Y. and Bock, R. (2013) A mediator of singlet oxygen responses in Chlamydamonas reinhardtii and Arabidopsis identified by a luciferase-based genetic screen in algal cells. Plant Cell 25: 4209-4226.

Google Scholar: Author Only Title Only Author and Title

Shepherd, M.J., Lindsey, L.E. and Lindsey, AJ. (2018). Soybean canopy cover measured with Canopeo compared with light interception. Agric. Environ. Lett. 3: 180031.

Google Scholar: Author Only Title Only Author and Title

Shikata H., Hanada, K., Ushijima, T., Nakashima, M., Suzuki, Y. and Matsushita, T. (2014) Phytochrome controls alternative splicing to mediate light responses in Arabidopsis. Proc. Natl. Acad. Sci. USA111: 18781-18786.

Google Scholar: Author Only Title Only Author and Title

Song, Y., Jiang, Y., Kuai, B. and Li, L. (2018) CIRCADIAN CLOCK-ASSOCIATED 1 inhibits leaf senescence in Arabidopsis. Front. Plant Sci. 9: 280.

Google Scholar: Author Only Title Only Author and Title

Stegle, O., Denby, K.J., Cooke, E.J., Wild, D.L., Ghahramani, Z, and Borgwardt, K.M. (2010). A robust Bayesian two-sample test for detecting intervals of differential gene expression in microarray time series. J. Comput. Biol. 17: 355-367.

Google Scholar: Author Only Title Only Author and Title

Streb, P., Josse, E.-M., Gallouët, E., Baptist, F., Kuntz, M. and Cornic, G. (2005) Evidence for alternative electron sinks to photosynthetic carbon assimilation in the high mountain plant species Ranunculus glacialis. Plant Cell Environ. 28: 1123-1135.

Google Scholar: Author Only Title Only Author and Title

Suorsa, M., Järvi, S., Grieco, M., Nurmi, M., Pietrzykowska, M., Rantala, M., Kangasjärvi, S., Paakkarinen, V., Tikkanen, M., Jansson, S. and Aro, E.-M. (2012) PROTON GRADIENT REGULATION5 is essential for proper acclimation of Arabidopsis photosystem I to naturally 
and artificially fluctuating light conditions. Plant Cell. 24: 2934-2948.

Google Scholar: Author Only Title Only Author and Title

Terashima, I., Hanba, Y.T., Tholen, D. and Niinemets, Ü. (2011) Leaf functional anatomy in relation to photosynthesis. Plant Physiol. 155: 108-116.

Google Scholar: Author Only Title Only Author and Title

Toledo-Ortiz, G., Huq, E. and Quail, P.H. (2003) The Arabidopsis Basic/Helix-Loop-Helix transcription factor family. Plant Cell 15: 17491770.

Google Scholar: Author Only Title Only Author and Title

Toledo-Ortiz, G., Johansson, H., Lee, K.P., Bou-Torrent, J., Stewart, K., Steel, G., Rodriguez-Concepción, M. and Halliday, K.J. (2014) The HY5-PIF regulatory module coordinates light and temperature control of photosynthetic gene transcription. PLOS Genetics 10: e1004416.

Google Scholar: Author Only Title Only Author and Title

Triantaphyllidès, C., Krischke, M., Hoeberichts, F.A, Ksas, B., Gresser, G., Havaux, M., Van Breusegem, F. and Mueller, M.J. (2008)

Singlet oxygen is the major reactive oxygen species involved in photooxidative damage to plants. Plant Physiol. 148: 960-968.

Google Scholar: Author Only Title Only Author and Title

Tripathi, P., Carvallo, M., Hamilton, E.E., Preuss, S. and Kay, S.A (2017) Arabidopsis B-BOX32 interacts with CONSTANS-LIKE3 to regulate flowering. Proc. Natl. Acad. Sci. USA114: 172-177.

Google Scholar: Author Only Title Only Author and Title

Underwood, W. (2012) The plant cell wall: a dynamic barrier against pathogen invasion. Frontiers Plant Sci. 3: Article 85.

Google Scholar: Author Only Title Only Author and Title

Van Acken, O. and Whelan, J. (2012) Comparison of transcriptional changes to chloroplast and mitochondrial perturbations reveals common and specific responses in Arabidopsis. Fronters Plant Sci. 3: article 291.

Google Scholar: Author Only Title Only Author and Title

Vandenabeele, S., Vanderauwera, S., Vuylsteke, M., Rombauts, S., Langebartels, C., Seidlitz, H.K., Zabeau, M., Van Montagu, M., Inzé, D. and Van Breusegem, F. (2004) Catalase deficiency drastically affects gene expression induced by high light in Arabidopsis thaliana. Plant J. 39: 45-58.

Google Scholar: Author Only Title Only Author and Title

van Rooijen, R., Aarts, M.G.M. and Harbinson, J. (2015) Natural genetic variation for acclimation of photosynthetic light use efficiency to growth irradiance in Arabidopsis. Plant Physiol. 167: 1412-1429.

Google Scholar: Author Only Title Only Author and Title

Vermeirssen, V., De Clercq, I., Van Parys, T., Van Breusegem, F. and Van de Peer, Y. (2014) Arabidopsis ensemble reverse-engineered gene regulatory network discloses interconnected transcription factors in oxidative stress. Plant Cell 26: 4656-4679.

Google Scholar: Author Only Title Only Author and Title

Vialet-Chabrand, S., Matthews J.S.A, Simkin, AJ., Raines, C.A and Lawson, T. (2017). Importance of fluctuations in light on plant photosynthetic acclimation. Plant Physiol. 173: 2163-2179.

Google Scholar: Author Only Title Only Author and Title

Walters, R. G., Rogers, J.J.M., Shephard, F. and Horton, P. (1999) Acclimation of Arabidopsis thaliana to the light environment: the role of photoreceptors. Planta 209: 517-527.

Google Scholar: Author Only Title Only Author and Title

Waters, M.T., Wang, P., Korkaric, M., Capper, R.G., Saunders, N.J. and Langdale, J.A (2009) GLK transcription factors coordinate expression of the photosynthetic apparatus in Arabidopsis. Plant Cell 21: 1109-1128.

Google Scholar: Author Only Title Only Author and Title

Willems, P., Mhamdi, A, Stael, S., Storme, V., Kerchev, P., Noctor, G., Gevaert, K. and Van Breusegem, F. (2016) The ROS wheel: Refining transcriptional footprints. Plant Physiol. 171: 1720-1733.

Google Scholar: Author Only Title Only Author and Title

Windram, O., Madhou, P., McHattie, S., Hill, C., Hickman, R., Cooke, E., Jenkins, D. J., Penfold, C. A, Baxter, L., Breeze, E., Kiddle, S. J., Rhodes, J., Atwell, S., Kliebenstein, D. J., Kim, Y., Stegle, S., Borgwardt, K., Zhang, C., Tabrett, A, Legaie, R., Moore, J., Finkenstadt, B., Wild, D. L., Mead, A, Rand, D., Beynon, J., Ott, S., Buchanan-Wollaston, V. and Denby, K. J. (2012) Arabidopsis defense against Botrytis cinerea: Chronology and regulation deciphered by high-resolution temporal transcriptomic analysis. Plant Cell 24: $3530-3557$.

Google Scholar: Author Only Title Only Author and Title

Windram, O. and Denby, K.J. (2015) Modelling signalling networks underlying plant defence. Curr. Op. Plant Biol. 27: 165-171.

Google Scholar: Author Only Title Only Author and Title

Wingler, A, Lea, P.J., Quick, W.P. and Leegood, R.C. (2000) Photorespiration: metabolic pathways and their role in stress protection.

Phil. Trans. R. Soc. Lond. B 355: 1517-1529.

Google Scholar: Author Only Title Only Author and Title 
Wingler, A, Purdy, S.J., Edwards, S.-A, Chardon, F. and Masclaux-Daubresse, C. (2010) QTL analysis for sugar-regulated leaf senescence supports flowering-dependent and -independent senescence pathways. New Phytol. 185: 420-433.

Google Scholar: Author Only Title Only Author and Title

Wituszyńska, W., Ślesak, I., Vanderauwera, S., Szechyńska-Hebda, M., Kornaś, A, Van Der Kelen, K., Mühlenbock, P., Karpińska, B., Maćkowski, S., Van Breusegem, F. and Karpiński, Stanisław (2013) LESION SIMULATING DISEASE1, ENHANCED DISEASE

SUSCEPTIBILITY1, and PHYTOALEXIN DEFICIENT4 conditionally regulate cellular signaling homeostasis, photosynthesis, water use efficiency, and seed yield in Arabidopsis. Plant Physiol. 161: 1795-1805.

Google Scholar: Author Only Title Only Author and Title

Xu, D., Li, J., Gangappa, S.N., Hettiarachchi, C., Lin, F., Andersson, M.X., Jiang, Y., Deng, X.W. and Holm, M. (2014) Convergence of light and ABA signalling on the ABI5 promoter. PLOS Genetics 10: e1004197.

Google Scholar: Author Only Title Only Author and Title

Yoshida, Y., Sarmiento-Manus, R., Yamori, W., Ponce, M.R., Micol, J.L. and Tsukaya, H. (2018) The Arabidopsis phyB-9 mutant has a second-site mutation in the VENOSA4 gene that alters chloroplast size, photosynthetic traits, and leaf growth. Plant Physiol. $178:$ 3-6. Google Scholar: Author Only Title Only Author and Title

Yu, X., Liu, H., Klejnot, J. and Lin, C. (2010) The cryptochrome blue light receptors. The Arabidopsis Book e0135; doi: 10.1199/tab.0135. Google Scholar: Author Only Title Only Author and Title 